\title{
AERODYNAMIC DESIGN AND STRUCTURAL ANALYSIS PROCEDURE FOR SMALL HORIZONTAL-AXIS WIND TURBINE ROTOR BLADE
}

\author{
A Thesis \\ Presented to the Faculty of California Polytechnic State University, \\ San Luis Obispo
}

In Partial Fulfillment

of the Requirements for the Degree

Master of Science in Mechanical Engineering

by

Dylan Perry

April, 2015 
(C) 2015

Dylan Perry

ALL RIGHTS RESERVED 


\section{COMMITTEE MEMBERSHIP}

TITLE: $\quad$ Aerodynamic Design and Structural Analysis

Procedure for Small Horizontal-Axis Wind Turbine

Rotor Blade

AUTHOR: Dylan Perry

DATE SUBMITTED: April, 2015

COMMITTEE CHAIR: Joseph Mello, Ph.D.

Professor of Mechanical Engineering

COMMITTEE MEMBER: Patrick Lemieux, Ph.D.

Associate Professor of Mechanical Engineering

COMMITTEE MEMBER: Tom Mase, Ph.D.

Professor of Mechanical Engineering 


\title{
ABSTRACT
}

Aerodynamic Design and Structural Analysis Procedure for Small Horizontal-Axis

\author{
Wind Turbine Rotor Blade
}

\section{Dylan Perry}

This project accomplished two correlated goals of designing a new rotor blade to be used with the Cal Poly Wind Power Research Center, as well as defining the methodology required for the aerodynamic analysis of an optimized blade, the procedure required for generation of an accurate CAD model for the new blade geometry, and structural integrity verification procedure for the new blade via finite element analysis under several operating scenarios. The new rotor blades were designed to perform at peak efficiency at a much lower wind speed than the current CPWPRC rotor blades and incorporated a FEA verification process which was not performed on the earlier rotor blade design.

Since the wind characteristics relative to the location of the CPWPRC are essentially unchanging the most viable option, in regards to generating power for longer periods of time, is to redesign the HAWT rotor to capture more of the wind energy available. To achieve this, the swept area of the rotor was increased, suitable airfoils were utilized, and the new rotor blades were optimized to maximize their performance under the CPWPRC location's wind conditions.

With an increased magnitude of wind energy being captured the aerodynamic loading on the rotor blades simultaneously increased which necessitated a structural analysis step to be implemented, both with classical hand calculations and with the assistance of an adequate FEA program, to ensure the new rotor blades did not fail under normal or extreme wind conditions. With the completion of this project the new rotor blade designed and analyzed in this report may be finalized and refined in order to be incorporated into the CPWPRC system in the future or the methodology defined throughout this project may be used to design an entirely different aerodynamically optimized rotor blade, including a CAD model and FEA structural integrity verification, as well. 


\section{ACKNOWLEDGMENTS}

I would like to thank everyone who has helped guide me through these past years here at Cal Poly and who have so greatly influenced me not only as a student but as a person. Most importantly, I would like to thank my very gracious parents who have supported me in every aspect of my life and encouraged me to pursue higher education.

Although there are many fantastic professors here at Cal Poly I would like to single out Dr. Joseph Mello for being a great inspiration and mentor to me throughout my college career, especially during my post baccalaureate career.

I would also like to thank all my classmates and colleagues who have toiled alongside me all these years, everyone's education is certainly benefitted by group participation. 


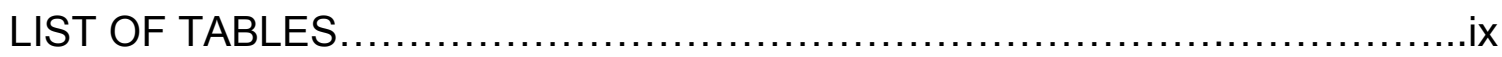

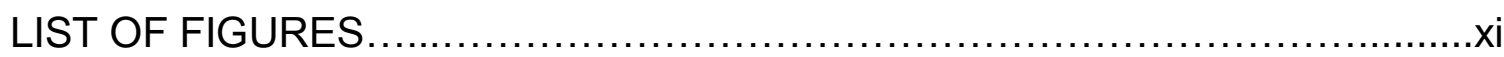

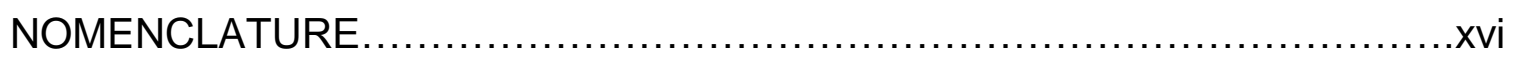

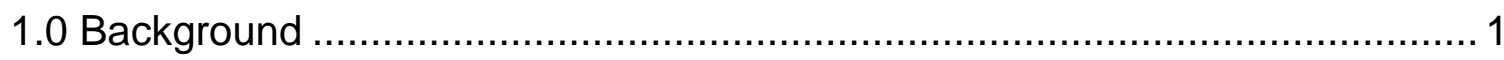

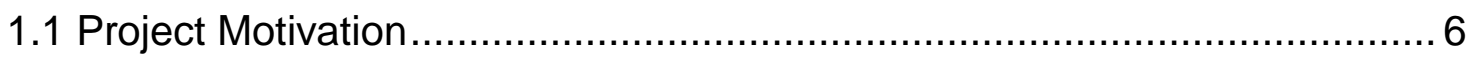

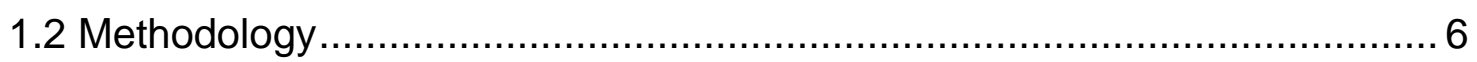

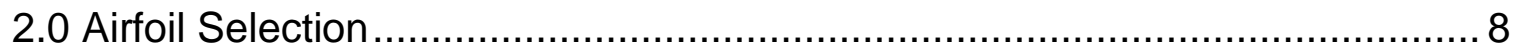

2.1 Desired Airfoil Characteristics .......................................................... 11

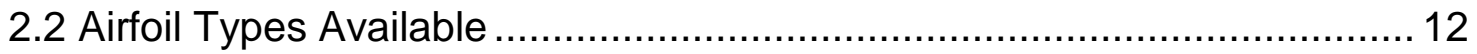

2.2.1 Previous RISO-A Airfoil Family Used .............................................. 13

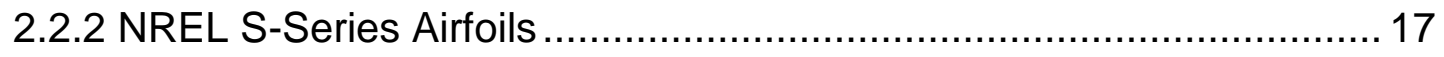

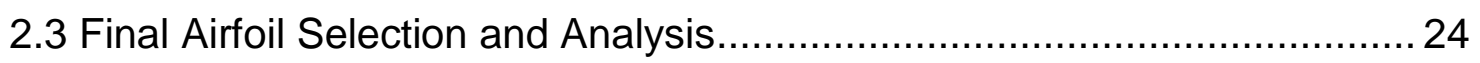

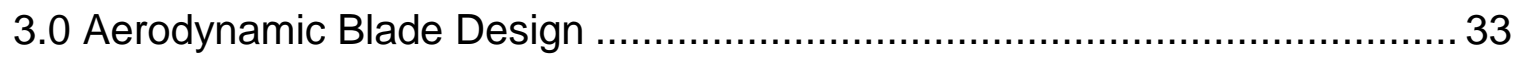

3.1 Momentum Theory and Betz Limit....................................................... 36

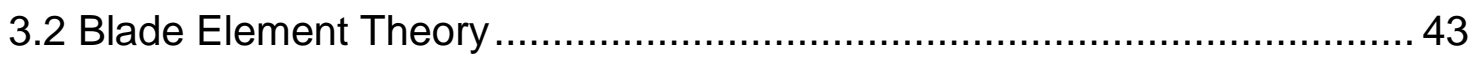

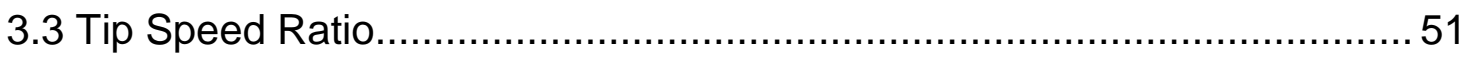

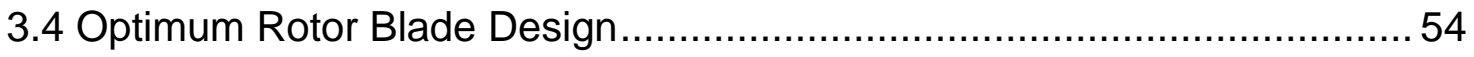

3.4.1 Blade Root and Local Blade Reference System .............................. 60

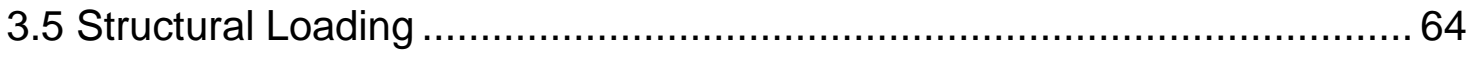

3.5.1 Types of HAWT Loading Scenarios ................................................ 67

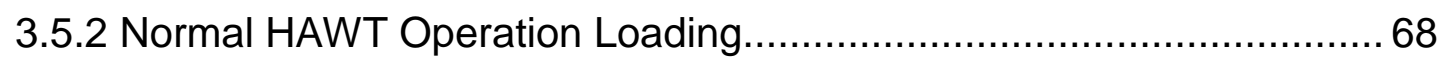

3.5.3 Parked Rotor Subject to Wind Gust Loading..................................... 73

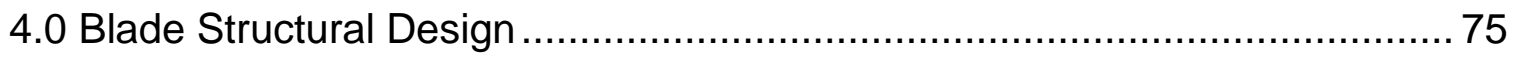


4.1 Rotor Blade Structural Requirements ................................................ 75

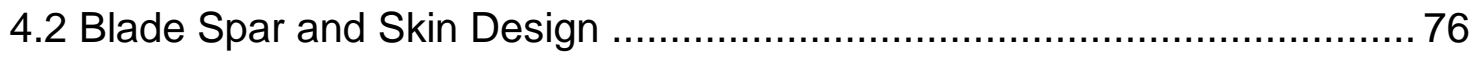

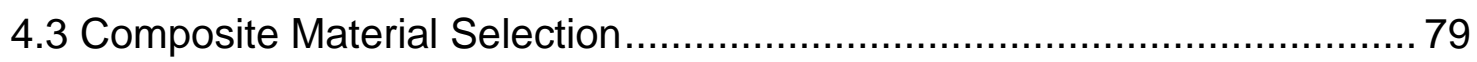

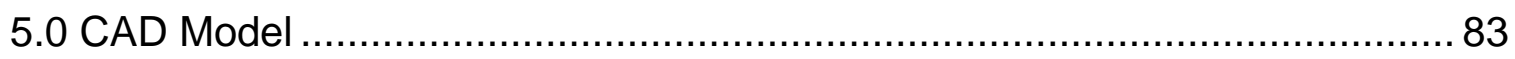

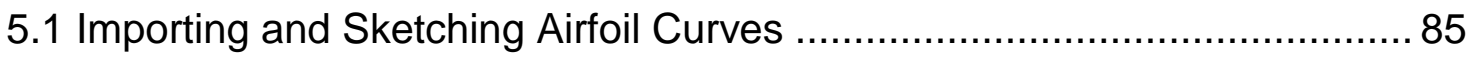

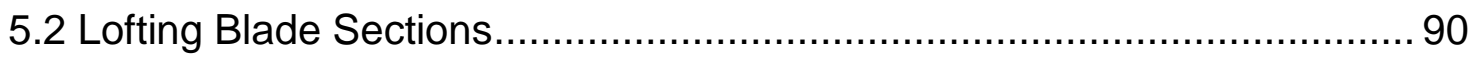

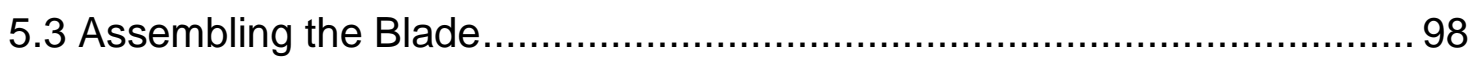

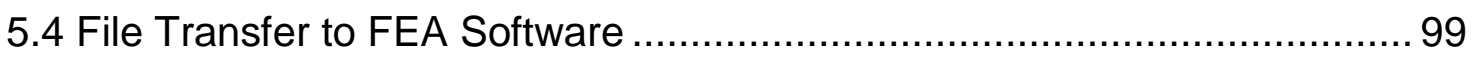

6.0 Finite Element Modeling .................................................................... 102

6.1 Importing the CAD Model ................................................................. 103

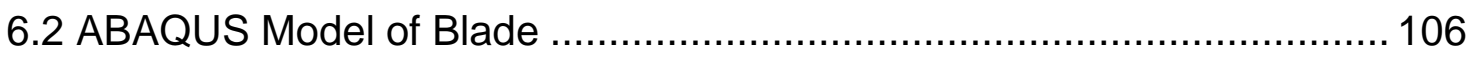

6.2.1 ABAQUS Geometry Editing and Verification................................. 107

6.2.2 Composite Lay-up Schedule ................................................... 111

6.2.3 Model Mesh Application ................................................................... 115

6.2.4 Loading Scenarios and Constraints ............................................. 122

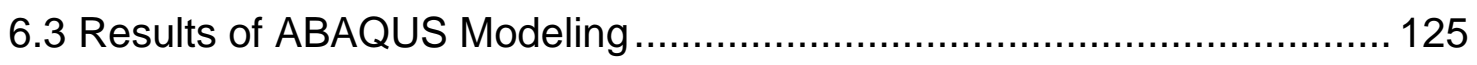

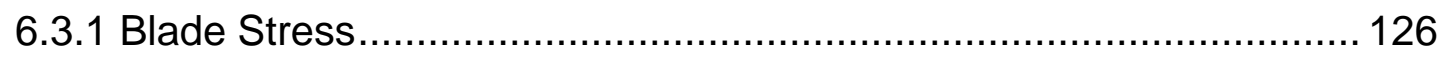

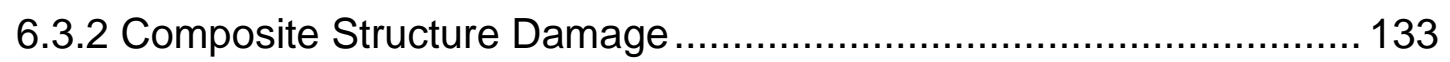

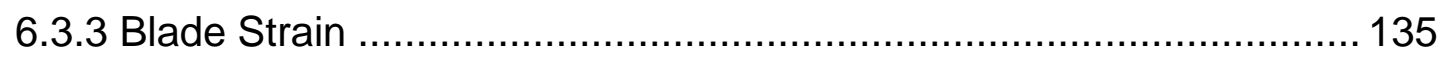

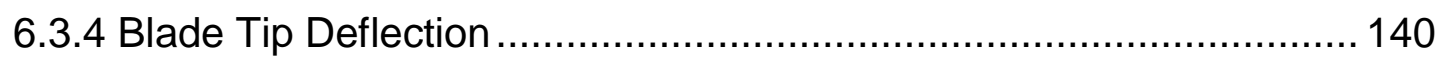

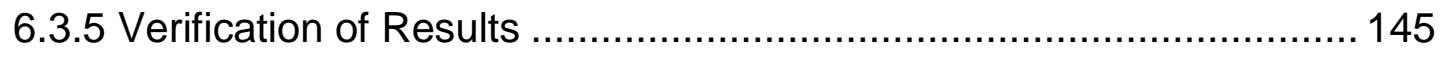

7.0 Conclusion and Future Work ............................................................. 147

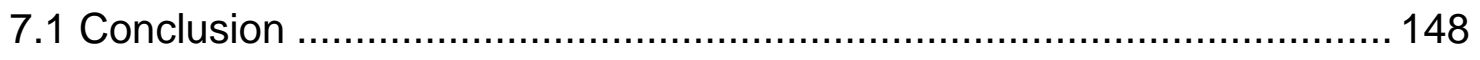

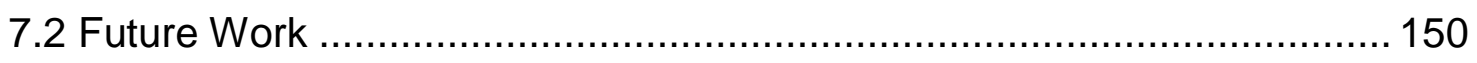

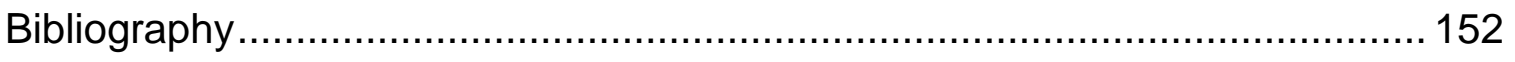




\section{Appendices}

Appendix A: Final Blade Design Parameters …....................................... 154

Appendix B: Classical Lamination Theory MATLAB Results and Hand

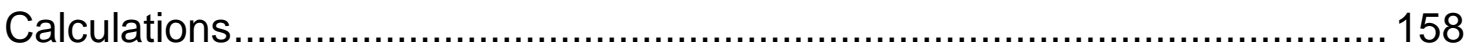




\section{LIST OF TABLES}

Table 1 NREL S-Series airfoils listed with the HAWT design parameters associated with each airfoil type. 25

Table 2 Overview of the starting HAWT rotor blade design parameters. 34

Table 3 Blade root reference system force and moment descriptions. 63

Table 4 Local blade reference system force and moment descriptions. 64 Table 5 Summary of aerodynamic loads for each loading scenario modeled. Note, loads include an IEC specified safety factor of 1.3. 66

Table 6 Summary of aerodynamic forces imparted onto a parked rotor at varying wind gust speeds.

Table 7 Composite material testing data collected by Bryan Edwards while constructing the previous rotor blades used with the CPWPRC. 80

Table 8 Material property data used for Sandia $9 \mathrm{~m}$ blade FEA model. 81

Table 9 Composite layup schedule and materials used for this project. 114 Table 10 Summary of critical ply stresses with safety factors computed with known ultimate stress values.

Table 11 Hashin failure index summary for all loading scenarios with a value of 1.0 or higher indicating damage initiation.

Table 12 Maximum strain values for critical plies during normal operating with a wind speed of $11 \mathrm{mph}$.

Table 13 Summary of tip deflection for each loading scenario modeled.

Table 14 Vibrational modes with their respective frequencies of both the blade and tower.

Table 15 Initial blade design parameters required to analyze the blade aerodynamic performance and loading. 154

Table 16 Optimized blade geometry for the entire new rotor blade model. 155 Table 17 Aerodynamic loading calculated via BET. 156

Table 18 Normalized airfoil coordinates for the NREL S822 and S823 airfoil types. 
Table 19 Classical lamination theory MATLAB strain results for the top and bottom of each ply in the spar cap during normal operation at a wind speed of $11 \mathrm{mph}$.

Table 20 Classical lamination theory MATLAB stress results for the top and bottom of each ply in the spar cap during normal operation at a wind speed of $11 \mathrm{mph}$. 


\section{LIST OF FIGURES}

Figure 1 Wind speed magnitude at an altitude of 10 meters denoted by arrow size for California, San Luis Obispo circled in red. 4

Figure 2 Contour map of average annual wind speed with San Luis Obispo circled in red in map with averages of between 5 and 4.5 meters per second. _ 5 Figure 3 Critical airfoil design parameters. __ 9

Figure 4 Aerodynamic force model for a lift driven airfoil design. 9 Figure 5 Description of the normal and tangential wind speed vectors contributing to the overall lift generated by the airfoil. 10

Figure 6 Description of the high and low pressure sides of an airfoil and the aerodynamic forces they generate. 10

Figure 7 Two dimensional airfoil coordinates normalized by chord length. 13 Figure 8 RISO-A airfoil family normalized coordinates and performance data. _ 14 Figure 9 RISO-P airfoil family normalized coordinates and performance data. _ 15 Figure 10 RISO-B airfoil family normalized coordinates and performance data. 16 Figure 11 NREL S822 and S823 airfoils with their ideal radial positions listed._19 Figure 12 University of Illinois S822 wind tunnel performance data. 20

Figure 13 University of Illinois S822 wind tunnel performance data with the inclusion of a boundary layer tripping system. 22

Figure 14 Full listing of the entire NREL S-Series of airfoils with their key performance characteristics, S822 and S823 highlighted. 23

Figure 15 S823 and S822 lift coefficient versus angle of attack data as predicted by QBlade.

Figure 16 S823 and S822 lift versus drag coefficient data as predicted by QBlade.

Figure 17 Extrapolated polar plots of lift and drag coefficients versus a full $360^{\circ}$ angle of attack spectrum.

Figure 18 Power coefficient versus tip speed ratio prediction for the new rotor system as predicted by QBlade. Power coefficient predicted without tip loss effects shown in red and with tip loss effects shown in green. 
Figure 19 Thrust coefficient versus tip speed ratio prediction by QBlade with and without tip loss effects.

Figure 20 Optimized blade aerodynamic performance and loading calculation flowchart.

Figure 21 Momentum theory stream tube and BET differential annular elements. 36

Figure 22 Thrust and power coefficient prediction limitations versus rotor axial induction factors.

Figure 23 Momentum stream tube with wake rotation effects shown.

Figure 24 Betz limit with and without wake rotation shown as a factor of both power coefficient and tip speed ratio.

Figure 25 Diagram of blade sections utilized with the BET.

Figure 26 Force diagram showing lift, drag, in-plane, and out-of rotor plane forces due to the relative wind angle.

Figure 27 Rotor power coefficients versus tip speed ratio for a number of different wind turbine designs. [2]

Figure 28 Finalized chord and twist distribution of the optimized blade design. 57 Figure 29 Blade root reference system and forces shown. The BET calculates aerodynamic forces in this reference system.

Figure 30 Visual representation and summary of several different types of possible rotor blade loading.

Figure 31 Aerodynamic forces acting on the rotor during normal operation at the design wind speed of 8 miles per hour.

Figure 32 Flapwise and flatwise rotor forces at the design wind speed of 8 miles per hour. Note the slight discrepancy between the two near the blade root where the blade twist is the most severe.

Figure 33 Flapwise and flatwise moments induced by the aerodynamic thrust forces generated during normal rotor operation at the design wind speed of 8 miles per hour. 
Figure 34 Lead-lag and edgewise forces calculated for normal rotor operation at a the design wind speed of 8 miles per hour. Negative forces caused by severe blade twisting near the rotor root.

Figure 35 The tangential, or in-plane, moment generated along the blade due to tangential aerodynamic forces at the design wind speed of 8 miles per hour. Note the small magnitude of these moments when compared to the thrust induced flapwise bending moment shown previously. 72

Figure 36 Rotor thrust forces and maximum flapwise bending moment generated due to increasing wind speeds. 73

Figure 37 CAD modeling and FEA procedure flowchart. 85

Figure 38 Imported, scaled airfoil curves to be used for CAD modeling prior to the necessary twist being applied at each blade section.

Figure 39 Individual airfoil component sketching procedure shown clockwise starting from upper left.

Figure 40 Airfoil sketches drawn on planes respective of their radial blade location along the blade with the final plane labeled as the blade tip. Imported airfoil curves are shown in blue at the plane representing the axis of rotation. _ 89 Figure 41 Twisted and fully sketched blade sections including the twisted outer airfoil curves and inner sketch lines representing the individual blade parts.

Figure 42 Spar lofting procedure completed with each individual spar blade section selected correctly and ready to be lofted.

Figure 43 Leading edge loft completed with the spar, trailing edge, and bond section sketches not yet lofted.

Figure 44 Leading edge and spar lofts completed with full airfoil sketches still shown.

Figure 45 All blade components lofted with each overall blade section airfoil shown in grey.

Figure 46 3D guided lofting lines utilized for the hub connection transitional loft from the rectangular to circular spar sections highlighted in blue. 96 Figure 47 Isometric view of hub connection blade section with internal features denoted by dashed lines. 
Figure 48 Final assembly of the aerodynamically driven blade sections and the structurally driven hub connection section.

Figure 49 Imported hub connection part with imprecise lines highlighted in red. 105

Figure 50 Trailing edge imprecise entities highlighted in red. 105

Figure 51 Removed faces for each part highlighted in red. 108

Figure 52 Tie constraint between the spar and the trailing edge highlighted in red.

Figure 53 Composite section layup orientation for the spar cap shown with the $0^{\circ}$ orientation reference shown in blue and the laminate normal direction in red.

Figure 54 Composite section layup orientation for the shear web shown with the $0^{\circ}$ orientation reference shown in blue and the laminate normal direction in red.

Figure 55 Mesh convergence study with all four of the blade components. 117 Figure 56 Mesh convergence of the trailing edge component only. 117 Figure 57 Mesh controls used for the blade hub connection. Swept mesh controls shown in yellow and structured mesh controls in green.

Figure 58 Fully meshed hub connection section with fine mesh along spar and cylindrical blade root.

Figure 59 Rotor blade with completed mesh including local seeding at blade root sections.

Figure 60 Boundary conditions shown as orange arrows at the blade to hub interface, pressure forces shown as pink arrows, rotational body forces shown in green and the gravity vector shown in yellow along the $x$ axis datum.

Figure 61 Concentrated force load application model with forces shown as yellow arrows at their respective blade sections for the parked rotor model. 124 Figure 62 Pressure loading application shown with pink arrows along the spar during normal operation. 
Figure 63 Critical ply longitudinal stresses for the overall blade model undergoing normal operation with a wind speed of $11 \mathrm{mph}$.

Figure 64 Critical ply transverse stresses for the overall blade model undergoing normal operation with a wind speed of $11 \mathrm{mph}$. 129 Figure 65 Critical ply shear stresses for the overall blade model undergoing normal operation with a wind speed of $11 \mathrm{mph}$.

Figure 66 Longitudinal fiber stress concentrations at the spar root tube and airfoil transitional sections with opposing compressive stresses shown in blue.

Figure 67 Transverse fiber stresses along the high pressure side of the spar concentrated at the airfoil transitional sections and root tube. 132

Figure 68 Fatigue coupon testing data of commercially-available composite materials from DOE/MSU database.

Figure 69 Longitudinal strain envelope plot showing higher strain values along the blade spar as viewed from an upwind position.

Figure 70 Transverse strain envelope plot showing higher strain values at the airfoil transitional blade sections and root tube, as viewed from an upwind position.

Figure 71 Shear strain envelope plot showing higher strain values along the blade spar with the highest shear strain values predicted at the airfoil transitional blade sections. 139

Figure 72 First flapwise bending mode shown at a frequency of $2.75 \mathrm{~Hz}$. 143

Figure 73 First edgewise bending moment shown at a frequency of $4.75 \mathrm{~Hz}$. 144 Figure 74 2nd flapwise bending moment shown at a frequency of $9.47 \mathrm{~Hz}$. 145 


\section{NOMENCLATURE}

CPWPRC: Cal Poly Wind Power Research Center

HAWT: Horizontal-Axis Wind Turbine

IEC: International Electrotechnical Commission

VARTM: Vacuum Assisted Resin Transfer Molding

FE: Finite Element

FEA: Finite Element Analysis

NREL: National Renewable Energy Laboratory

BEM: Blade Element Momentum

BET: Blade Element Theory

CAD: Computer Assisted Drafting

ASTM: American Society for Testing and Materials

CLT: Classical Lamination Theory 


\subsection{Background}

Since 2010 the Cal Poly Wind Power Research Center (CPWPRC) has provided students an opportunity to learn about wind turbine operation at the Escuela Ranch located approximately eight miles north of the Cal Poly Campus. The wind turbine used at the CPWPRC is a horizontal-axis type wind turbine which specifies that that the turbine axis of rotation is parallel with level ground which is the standard design of nearly all modern lift-driven wind turbines. This research based HAWT has a two-piece tower with a height of 21 meters which can be lowered about a pivot at the tower base so as to facilitate design changes to any component of the HAWT.

One of the most important components of any wind turbine are the rotor blades which generate the lift force required to spin the rotor blades about the rotor hub. A directly driven mainshaft turns a permanent magnet generator which can then produce electrical power. Currently the permanent magnet induction generator utilized by the Cal Poly Wind Power Research Center is designed for a maximum power output of 3 kilowatts with a rotor speed of approximately 200 revolutions per minute driven by a wind speed of 22 miles per hour, or 9.83 meters per second. The turbine rotor system encompasses a circular area, defined by the distance from the rotor axis of rotation to the blade tip, of 10.5 square meters and includes an aluminum hub, with a radius of 0.127 meters, and a 1.7 meter long blade, or 5 and 67 inches respectively. 
Since the rotor blades are what drives the entire turbine operation, and are the basis of all the major loading the turbine can expect to experience, they are of critical importance when designing any HAWT. The previously manufactured rotor blades are constructed of $6 \mathrm{k}$ tow AS4 carbon fiber fabric, is 0.012 inch thick, and weaved into a $2 \times 2$ twill pattern, with a fiber weight 11 ounces per square yard and is used in conjunction with a $1 \times 1$ weave, 3.7 ounces per square yard Eglass. In order to reinforce both the carbon and E-glass fibers an epoxy resin was chosen which is designed specifically for the vacuum resin infusion used to construct the blades. The chosen epoxy is produced by RevChem Plastics, named ProSet 117LV/226, and provides the high strength, durability, and toughness required of a HAWT rotor blade that will be operating in the elements for long periods of time.

The Cal Poly Wind Power Research Center has been the subject of several past theses and senior projects that have encompassed everything from the electrical subsystems to rotor balancing and the structural analysis of the turbine's unique tower. However, there has not been any structural analysis incorporating finite element analysis of the blades which is helpful for accurately predicting the stress and strain of every part of the blade.

San Luis Obispo has an average wind speed of approximately 5 meters per second, or 11 miles per hour, as seen in Figure 1 and Figure 2, therefore wind turbines in operation around the San Luis Obispo area should be designed to operate efficiently at this wind speed by capturing as much of the wind energy that is available. This may be accomplished in several ways including utilizing 
forced or shrouded induction, a contra-rotation system, increasing the swept area of the rotor, or designing the rotor blades to be more aerodynamically efficient for their applicable wind speed range. The simplest of these methods involve redesigning the rotor blades to encompass a larger swept area, thereby increasing the amount of wind energy available, and to be more aerodynamically efficient at the annual average wind speed of approximately 5 meters per second while generating lift which provides the required torque for the generator. These two options do not require major overhauling of the overall HAWT design and are more easily implementable than other options which would require significant HAWT subcomponent changes such as structural and electrical component redesigns. 


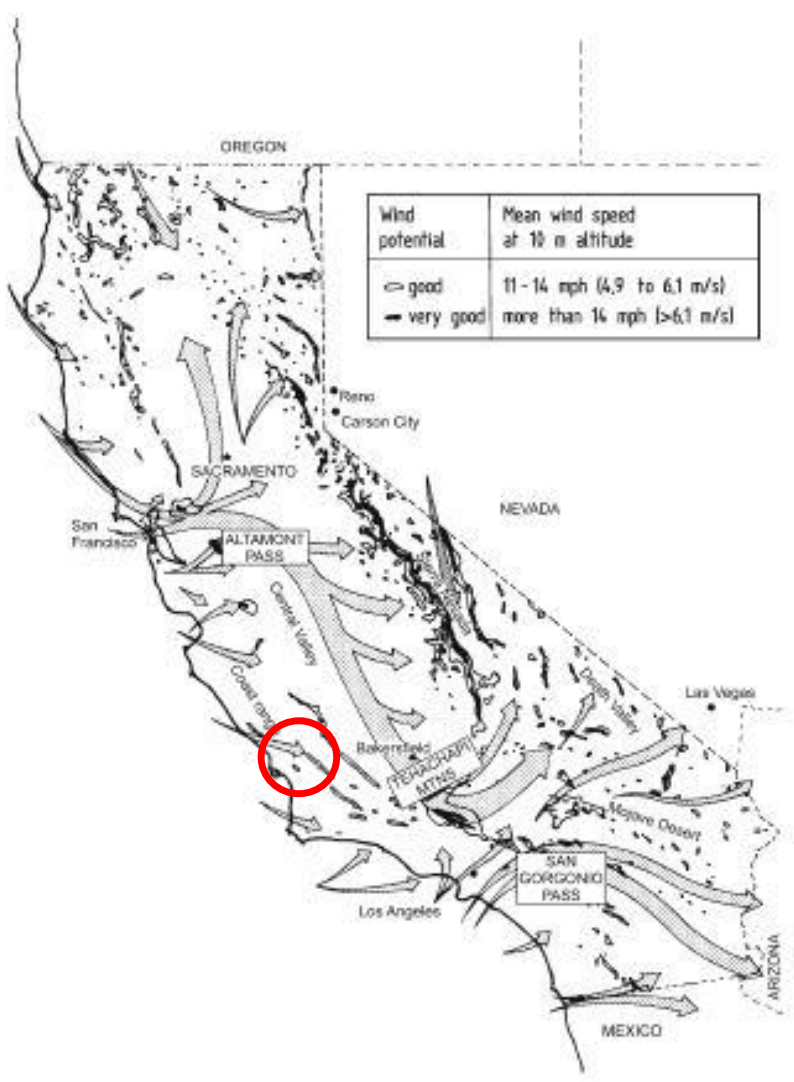

Figure 1 Wind speed magnitude at an altitude of 10 meters denoted by arrow size for California, San Luis Obispo circled in red. 


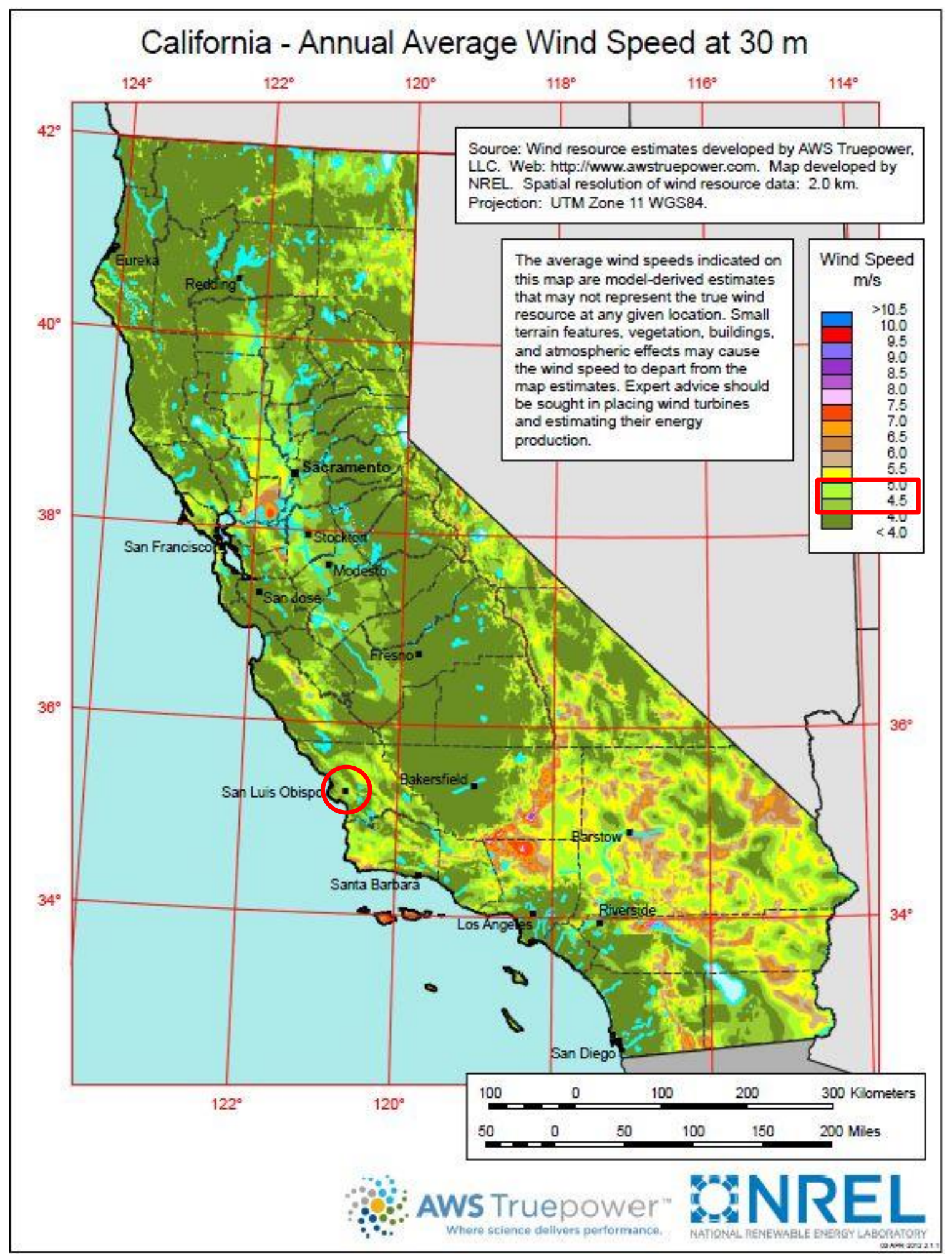

Figure 2 Contour map of average annual wind speed with San Luis Obispo circled in red in map with averages of between 5 and 4.5 meters per second. 


\subsection{Project Motivation}

This project grew from the need for a detailed aerodynamic and structural analysis process for new Cal Poly Wind Power Research Center rotor blades.

The main objective of this project was develop a procedure for the optimization of the aerodynamic performance and verification of the structural integrity regarding a new, or any, rotor blade design. The secondary objective of this project was to use the analysis process on new blades designed for the average wind speed values recorded at the turbine site, thereby lowering the HAWT cut-in speed.

The rotor blade designed for the Cal Poly Wind Power Research Center in the past focused mainly on the manufacturability of the blades and have not included a finite element structural analysis which allows for further refinement of the blade structure. Basic mechanics of materials calculations of the composite structure are a reliable method of determining structural requirements but they are able to be further optimized with the use of the finite element analysis techniques defined in this project.

\subsection{Methodology}

Designing a HAWT rotor blade entails completing several steps which each build upon each other. These steps, in order, are:

1. Selecting the design wind speed and desired power coefficient given knowledge of air properties at the wind turbine site. These parameters allow for the calculation of the required rotor swept area and therefore the rotor blade length required. 
2. Selecting appropriate airfoils to base the overall rotor blade geometry off of. The best airfoil choices will allow for a structurally sound blade root as well as an aerodynamically efficient blade towards the blade tip.

3. Calculating the aerodynamic forces generated during normal and extreme operation of the HAWT. These forces are then used to design the load bearing components of the HAWT so that the blade does not fail in operation or when parked and subject to high wind gusts.

4. Generating a CAD model of the rotor blade to be used for design verification as well as for further FE analysis to be performed on the blade structure.

5. Performing the structural analysis of the blade by importing the previously generated CAD model of the new blade geometry into a computational FEA software package. The structural components of the blade must then be defined as realistically as possible, loading scenarios applied to the blade structure, and the stress and strain throughout the blade analyzed.

Each one of these steps will be performed and thoroughly detailed throughout this report in order to both design and analyze a new HAWT rotor blade to be used at the CPWPRC, as well as to define the methodology required to facilitate future blade designs. 


\subsection{Airfoil Selection}

Airfoil design has come a long way since the early days of their inception and therefore many different airfoil types have been designed to suit a multitude of unique wind turbine blade, propeller, and aircraft wing designs. The general approach to selecting airfoils for a wind turbine rotor is to utilize at least two different airfoil types to provide for two key goals, structural and aerodynamic performance. The first goal is to have a structurally sound blade, which necessitates the use of a thicker airfoil to withstand the large bending moment caused by the aerodynamic and intrinsic gravity loads exerted on the blade during the wind turbine's operation at the root of the blade. The second goal is to be as aerodynamically efficient as possible at the outer blade sections in order to generate the required lift force with as little wind speed, and therefore available power, as possible so as to allow for power generation to occur at low wind speeds.

A basic airfoil design that might be used for an aeronautical application is shown in Figure 3 with the important airfoil design nomenclature labeled. The features labeled in Figure 3 all have a strong correlation to the aerodynamic performance of the airfoil and are constantly changing along the length of the rotor blade in order to maintain maximum performance as the direction of the relative wind, $\mathrm{U}_{\text {rel, }}$, changes. The magnitude and direction of the relative wind change along the length of the blade is due to the fact that the tangential velocity of the blade increases radially from the rotor axis of rotation which passes through the HAWT nacelle. 


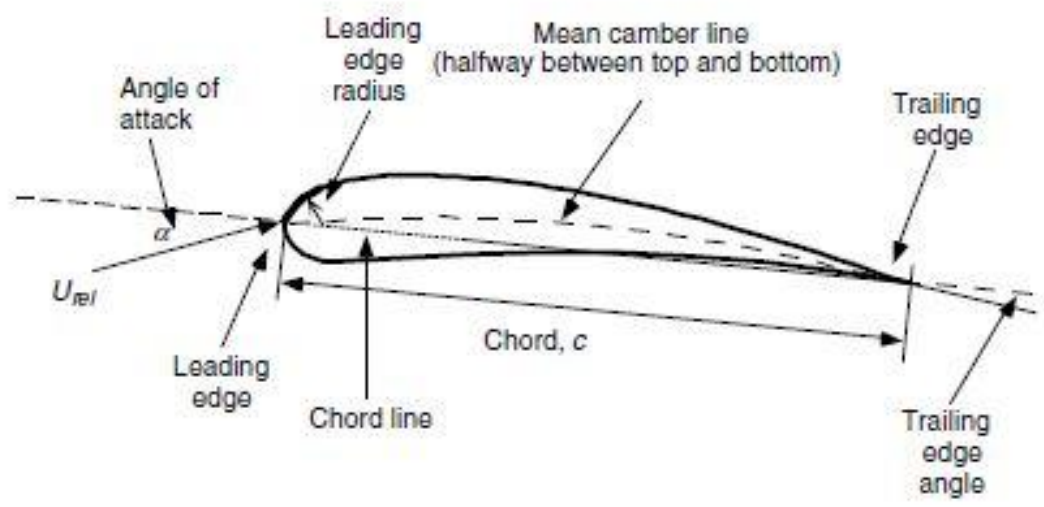

Figure 3 Critical airfoil design parameters.

As the $U_{\text {rel }}$ changes it has a direct effect on the angle of relative wind, $\varphi$, which then reverberates throughout the blade design since the aerodynamic performance of an airfoil hinges on the angle of the relative wind substantially. The aerodynamic forces and moments generated on an airfoil due to an arbitrary $\cup_{\text {rel }}$ are shown in Figure 4 which gives a general idea of how an airfoil is utilized with a modern lift-driven HAWT or airplane wing. A more detailed diagram of how the air acting as a fluid around the airfoil changes speed, and thereby pressure, around the airfoil can be seen in Figure 6.

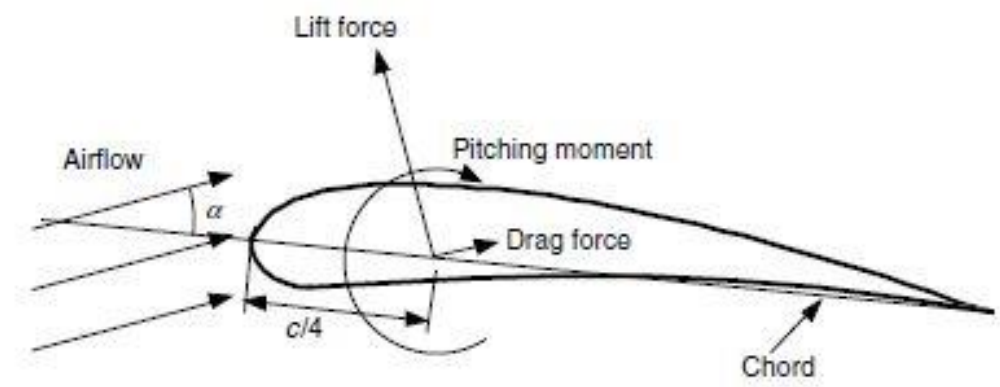

Figure 4 Aerodynamic force model for a lift driven airfoil design. 


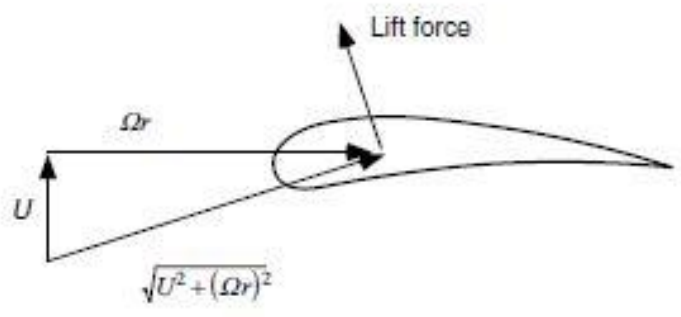

Figure 5 Description of the normal and tangential wind speed vectors contributing to the overall lift generated by the airfoil.

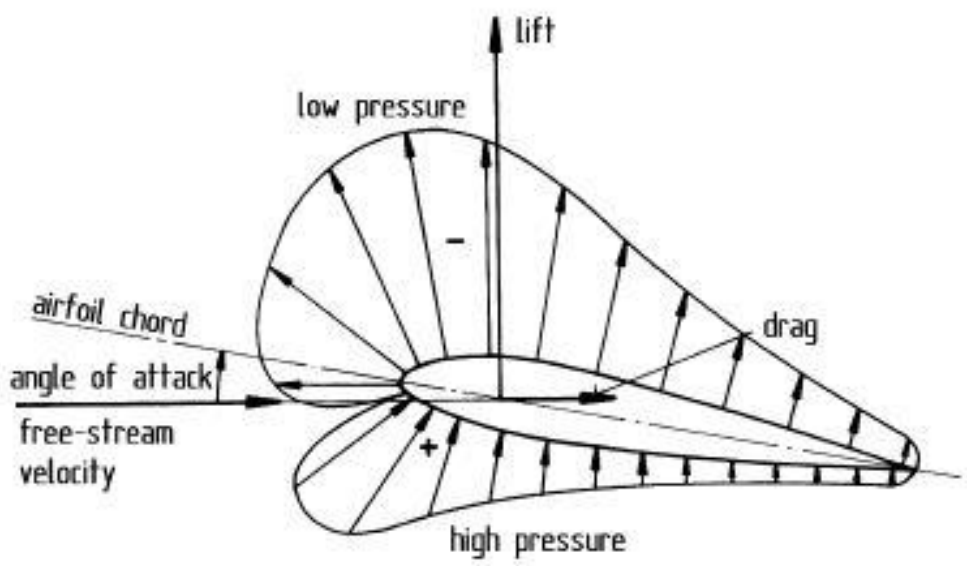

Figure 6 Description of the high and low pressure sides of an airfoil and the aerodynamic forces they generate.

Generally speaking airfoils are designed in certain "families" that have similar features but vary in aspects such as their ratio of thickness to chord length, leading edge radius, and mean camber line. One of the oldest families of airfoils are the NACA, the National Advisory Committee for Aeronautics, family of airfoils which were developed in the early $20^{\text {th }}$ century using analytical equations and defined certain parameters of the airfoil, such as their camber and thickness distribution along their length as a 4 or 5 digit number. As engineers developed new theoretical methods for calculating more aerodynamically optimized shapes a 6 digit series of airfoils was added to the NACA family of airfoils which included 
these more complicated shapes. The NACA 6-digit family of airfoils has been a trusted source of verifiably effective airfoils for a multitude of applications but recently more advanced computer models have led to the development of even more refined airfoil families utilizing a multidisciplinary design approach that includes aerodynamic, structural, maintenance, stability control, and manufacturing design concerns. All the available advanced airfoil types are researched extensively to ensure the best possible airfoil selection is made for the CPWPRC since the airfoil choices dictate the aerodynamic performance of the rotor and thereby the entire turbine's performance.

\subsection{Desired Airfoil Characteristics}

Depending on the specifics of the wind turbine application there may be multiple airfoil types which may suit that particular application with each having its own set of pros and cons. The CPWPRC is a unique wind turbine project in that it is meant for wind power generation research and has the task of testing new rotor blade designs. Therefore, the results of wind power research at the CPWPRC are meant to provide insight into the capabilities of wind power generation which may then be adopted by industry leaders.

Due to the fact that this project is more concerned with defining the procedure of designing a general, optimized rotor blade to be analyzed with FEA and not to fulfill a particular rotor blade performance issue a basic approach to airfoil selection will be performed. This basic approach entails selecting just two airfoil types, one to handle the structural requirements and another to generate the appropriate magnitude of lift force, to define the overall blade shape. The airfoil 
chosen to handle the structural requirements must be thick enough to incorporate a load bearing, rectangular spar at the base while the airfoil chosen to provide the lift force must be an aerodynamically driven design to increase lift and reduce drag.

HAWT rotor blades can vary in size considerably depending on the particular application with industrial sized turbines, which generate a megawatt or more of power, having rotor blades exceeding 45 meters in length while smaller turbines, generating several kilowatts or more, require a much smaller rotor blade. Although most airfoil designs are scalable to whichever rotor blade size is required, some are more suitable for large or small HAWT rotor blade designs which must be taken into consideration when selecting airfoil designs for the CPWPRC, which is in the small HAWT category.

\subsection{Airfoil Types Available}

There are many different airfoil designs in use in the wind energy industry and others are being developed in laboratories all over the world with each type having its benefits and weaknesses that can either help or hinder whichever wind turbine application they are employed in conjunction with. Some airfoils have been extensively tested and used in the field, such as the National Advisory Committee for Aeronautics (NACA) family of airfoils, while other airfoils are more experimental in nature and have yet to be proven in the field.

There are many airfoil databases available for perusal by designers of aeronautical components that are able to provide airfoil parameters such as data 
files that describe coordinates representing the airfoil's geometry with a twodimensional plot normalized by the airfoil's chord length, as shown in Figure 7. These databases generally also contain aerodynamic data for the airfoil such as the lift and drag coefficients generated by the airfoil under a range of Reynolds numbers describing the laminar or turbulent flow conditions around the airfoil.

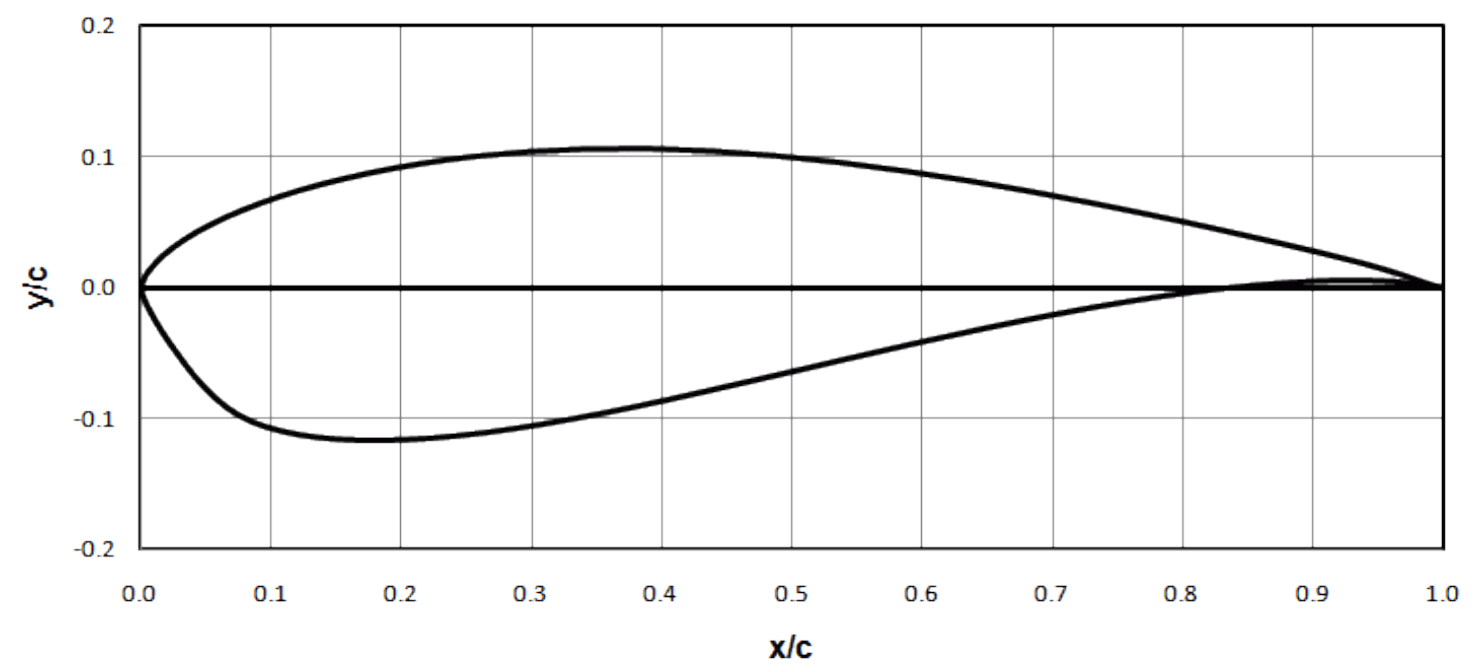

Figure 7 Two dimensional airfoil coordinates normalized by chord length.

\subsubsection{Previous RISO-A Airfoil Family Used}

Currently the Cal Poly Wind Turbine rotor blades are constructed using the RISO-A family of airfoils to develop the geometry for the 1.8-meter rotor blades, specifically the RISO-A-18 and RISO-A-27 for the outer and root portions of the blades respectively. Much analysis has been performed on the RISO airfoil families, designed by the RISO DTU National Laboratory of Denmark, including advanced computer models of the fluid dynamics and loading of the airfoils under a number of external conditions. These RISO airfoil families include the RISO-A family currently being used here at Cal Poly, the RISO-P airfoil family developed 
to replace the RISO-A airfoil family, and the RISO-B airfoil family developed for variable speed operation on HAWTs utilizing pitch control for turbines producing at least one megawatt of electricity. Each RISO airfoil family has been proven as efficient airfoils in the field and are currently installed on many wind turbines of varying rotor size and magnitude of power generation.

The RISO-A airfoil family constitutes six airfoils and was introduced in 1998 after having been optimized for wind turbines that are generating 600 kilowatts or more by utilizing high coefficient of lift values that are sensitive to surface roughness. The overall shape and design parameters of the six RISO-A airfoils can be seen in Figure 8 which are used to developed the overall rotor blade model and predict the aerodynamic forces acting on the rotor blade.

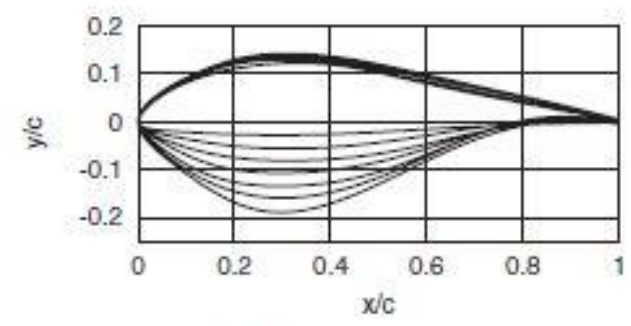

\begin{tabular}{|c|c|c|c|c|c|c|c|c|}
\hline & $x / c$ at $\max t / c$ & $y / c$ at T.E. & $\operatorname{Re} \times 10^{6}$ & $\alpha_{0}$ & $\operatorname{Max} c_{1}$ & Design $\alpha$ & Design $c_{1}$ & Max. $c_{p} / c_{d}$ \\
\hline Riso-A1-15 & 0.325 & 0.0025 & 3.0 & $-4 \cdot 0$ & 1.50 & $6 \cdot 0$ & 1.13 & 168 \\
\hline Rise-Al-18 & 0.336 & 0.0025 & 3.0 & $-3.6(-3.8)$ & $1.53(1.43)$ & $6.0(7.5)$ & $1.15(1.22)$ & $167(107)$ \\
\hline Risa-A1-21 & 0.298 & 0.005 & 3.0 & $-3 \cdot 3(-3 \cdot 3)$ & $1.45(1.38)$ & $7.0(6.3)$ & $1.15(1.10)$ & $161(96)$ \\
\hline Rise-Al-24 & 0.302 & 0.01 & 2.75 & $-3 \cdot 4(-3 \cdot 3)$ & $1.48(1.36)$ & $7.0(6.5)$ & $1.19(1.15)$ & $157(91)$ \\
\hline Riso-A1-27 & 0.303 & 0.01 & 2.75 & -3.2 & 1.44 & 7.0 & 1.15 & N/A \\
\hline Riso-A1-30 & 0.300 & $0-01$ & 2.50 & -2.7 & 1.35 & 7.0 & 1.05 & $\mathrm{~N} / \mathrm{A}$ \\
\hline Risp-A1-33 & 0.304 & 0.01 & 2.50 & -1.6 & 1.20 & 7.0 & 0.93 & N/A \\
\hline
\end{tabular}

Figure 8 RISO-A airfoil family normalized coordinates and performance data. 
The RISO-P family of airfoils were developed after the RISO-A family, in 2001, as four airfoils for use on larger, pitch controlled wind turbines that were becoming more popular due to their ability to more accurately control the angle of attack acting along the rotor blade. The RISO-P airfoil family, as shown in Figure 9 has been optimized for wind turbines that have a rated power exceeding one megawatt with testing being performed on a commercial three megawatt wind turbine.

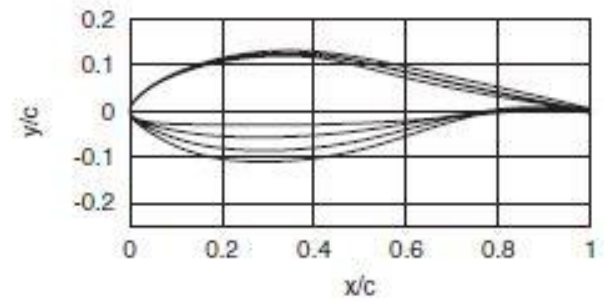

\begin{tabular}{|c|c|c|c|c|c|c|c|c|}
\hline & $x / c$ at $\max t / c$ & $\mathrm{y} / \mathrm{c}$ at T.E. & $\operatorname{Re} \times 10^{6}$ & $\alpha_{b}$ & $\operatorname{Max} c_{1}$ & Design $\alpha$ & Design $c_{1}$ & Max. $c_{\gamma} / c_{d}$ \\
\hline Riso-P-15 & 0.328 & 0.0010 & $3-0$ & -3.5 & 1.49 & 6.0 & 1.12 & 173 \\
\hline Riso-P-I8 & 0.328 & 0.0014 & $3-0$ & -3.7 & 1.50 & 6.0 & 1.15 & 170 \\
\hline Riso-P-21 & 0.323 & $0-01$ & $3-0$ & $-3 \cdot 5$ & 1.48 & 6.0 & 1.14 & 159 \\
\hline Riso-P-24 & 0.320 & 0.01 & 2.75 & $-3 \cdot 7$ & 1.48 & $6 \cdot 0$ & 1.17 & 156 \\
\hline
\end{tabular}

Figure 9 RISO-P airfoil family normalized coordinates and performance data.

The RISO-B airfoil family was designed in 2001 as a family of six separate airfoils that cover the thickness range from $15 \%$ all the way to $36 \%$ and were designed to have very high lift coefficients. These very high lift coefficients were needed in order to provide the necessary overall aerodynamic lift so that the massive rotor 
blades required to generate a megawatt or more power could be operational with relatively low wind speeds. Specifically the RISO-B airfoils, as shown in Figure 10, were designed for very large, flexible rotor blades with low solidity and a variable speed pitch control system.

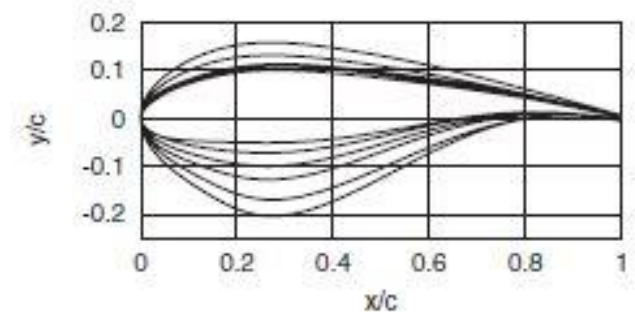

\begin{tabular}{|c|c|c|c|c|c|c|c|c|}
\hline & $x / c$ at $\max t / c$ & y/c at T.E. & $\operatorname{Re} \times 10^{6}$ & $\alpha_{\mathrm{s}}$ & $\operatorname{Max} c_{1}$ & Design $\alpha$ & Design $c_{1}$ & Max. $c_{p} / c_{d}$ \\
\hline Riso-B1-15 & 0.278 & 0.006 & $6-0$ & $-4 \cdot 1$ & 1.92 & $6-0$ & 1.21 & 157 \\
\hline Rise-B1-18 & 0.279 & 0.004 & $6-0$ & $-4.0(-3.4)$ & $1.87(1.64)$ & $6.0(6.5)$ & $1.19(1.16)$ & $166(100)$ \\
\hline Riso-B1-21 & 0.278 & 0.005 & $6-0$ & -3.6 & 1.83 & $6-0$ & 1.16 & 139 \\
\hline Rise-B1-24 & 0.270 & 0.007 & $6-0$ & $-3.1(-2.3)$ & $1.76(1.62)$ & $6.0(7.0)$ & $1.15(1.10)$ & $120(73)$ \\
\hline Rise-B1-30 & 0.270 & $0-01$ & $6-0$ & -2.1 & 1.61 & $5 \cdot 0$ & 0.90 & $\mathrm{~N} / \mathrm{A}$ \\
\hline Riso-B1-36 & 0.270 & $0-012$ & $6-0$ & $-1 \cdot 3$ & 1.15 & 5.0 & 0.90 & N/A \\
\hline
\end{tabular}

Figure 10 RISO-B airfoil family normalized coordinates and performance data.

The last two digits of the RISO-A-XX family indicate the maximum thickness of the airfoil as a percentage of the chord length. Therefore, the RISO-A-27 has a thickness of $27 \%$ of the chord, which is considerably more than the aerodynamically efficient RISO-A-18 which has a thickness of $18 \%$ of the chord length. Therefore the RISO-A-27 airfoil can be designed to handle the large maximum bending loads associated with the thrust generated maximum bending 
moment about the blade's root and the RISO-A-18 can provide the necessary higher lift-to-drag ratio.

All the RISO-A family airfoils were designed using a multidisciplinary optimization design method that took into account multiple design objectives. RISO-A airfoils with a thickness less than $24 \%$ are design to have a high lift-to-drag ratio for angles of attack ranging from 3 to 9 degrees with a maximum around an angle of attack of approximately 6 degrees. The transition point of the air passing over the airfoil from laminar to turbulent is designed to appear within $1-2 \%$ of the leading edge just before maximum lift is achieved by ensuring attached flow on the suction side until such a point to provide a well-defined stall and smooth post stall region. This is very helpful for a stall-regulated wind turbine system because it allows for the engineer to more accurately predict when and how the rotor will stall at the maximum generator efficiency point. The RISO-A-18 airfoil does have some drawbacks however. For instance, leading edge roughness which can be caused by dirt accumulating on the blade's surface or manufacturing imperfections, leads to a drop in the maximum coefficient of lift by as much as $17 \%$ while simultaneously increasing the minimum coefficient of drag.

\subsubsection{NREL S-Series Airfoils}

The National Renewable Energy Laboratory in Golden Colorado have developed seven series of aerodynamically advanced airfoil families by utilizing the Eppler Airfoil Design and Analysis Code which are suited for a multitude of HAWT types. The main design feature of all these airfoils is to maintain a restrained maximum lift coefficient that is relatively insensitive to roughness effects to be used on stall- 
regulated, variable-pitch, and variable-rpm wind turbines. Concerning their usefulness on the Cal Poly Wind Turbine project in particular, the NREL series airfoils designed for a stall-regulated rotor system have better peak-power control achieved through the design of tip airfoils that restrain the maximum lift coefficient to make use of more swept rotor area for a given generator size. The highly efficient NREL S-series airfoil design is very useful in regards to the Cal Poly Wind Turbine project due to the fact that the NREL series airfoils have been specifically designed to be used with stall-regulated rotor systems and optimized for use in several different categories of blade length and power generation capabilities matching the Cal Poly HAWT. In effect the NREL series airfoils have been tailored almost perfectly for the operational environment of the CPWPRC and have been proven to be more effective than previous airfoil designs both in the laboratory and in the field, "Annual energy improvements from the NREL airfoils are projected to be $23 \%$ to $35 \%$ for regulated turbines...The improvement for stall-regulated turbines has been verified in field tests." [14] 


\section{THICK-AIRFOIL FAMILY}

FOR SMALL BLADES

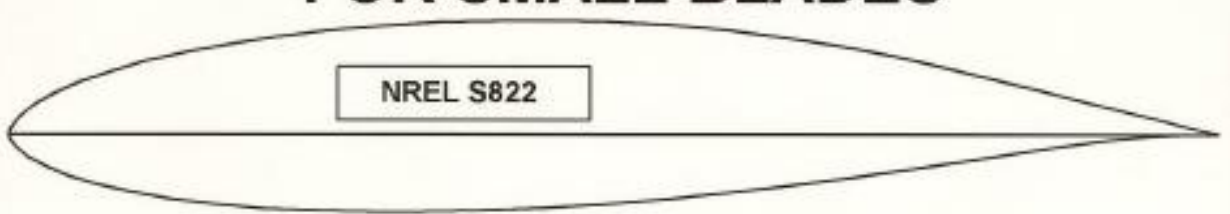

TIP-REGION AIRFOIL, 90\% RADIUS

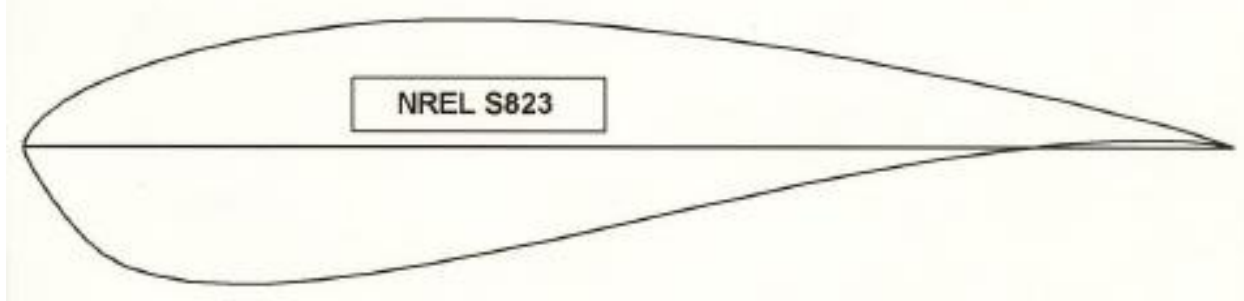

ROOT-REGION AIRFOIL, $40 \%$ RADIUS

Figure 11 NREL S822 and S823 airfoils with their ideal radial positions listed.

It is known that for stall-regulated turbines one of the main culprits of turbine power generation losses are the effects of surface roughness of the rotor blades especially leading edge contamination from both dirt and insect debris buildup. This leading edge contamination reduces the maximum coefficient of lift along the blade and worsens the ability of the stall-regulated blades to achieve their maximum coefficient of lift along the entirety of the blade's span. This roughness can amount to energy losses as much as $20 \%$ to $30 \%$ annually. In order to create an insensitiveness to leading edge roughness the transition from laminar to turbulent flow must be insured to occur very near the leading edge just prior to reaching the maximum coefficient of lift. The NREL S-series of airfoils have demonstrated their ability to do so and also demonstrate a "soft-stall" characteristic due to progressive separation from the trailing-edge which 
mitigates power and load fluctuations caused by local intermittent stall along the span of the blade.

Research on the NREL S-Series airfoils has been conducted by the University of Illinois, along with several other airfoils designed for use on small wind turbines, with a wind tunnel which is used to generate all different types of air flow conditions [7]. The NREL S822 airfoil was tested for aerodynamic performance in conjunction with a variety of flow conditions with Reynold's numbers varying from 100,000 to 500,000 as shown in Figure 12.
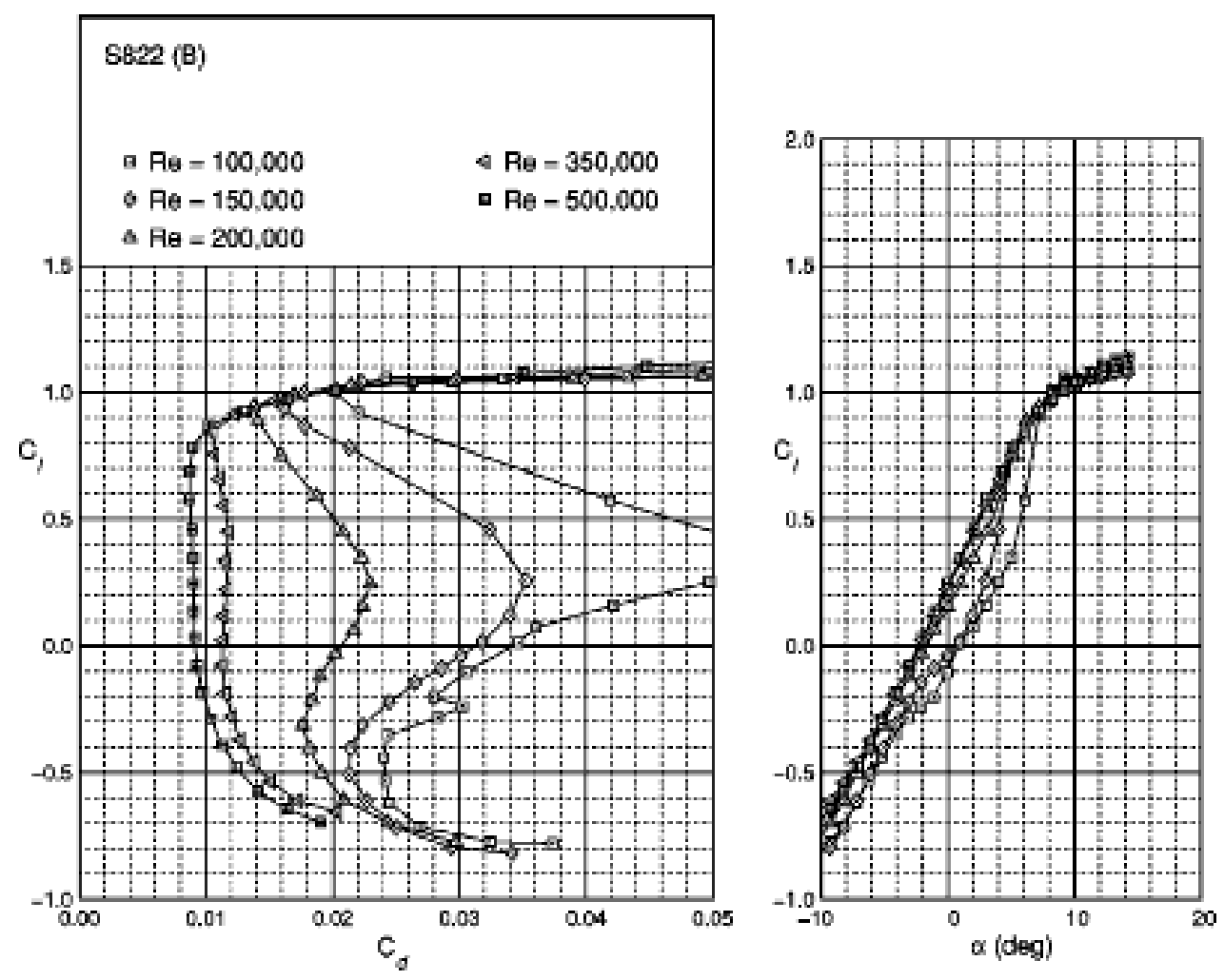

Figure 12 University of Illinois S822 wind tunnel performance data. 
The wind tunnel results showed that the $\mathbf{S} 822$ airfoil type produced a maximum lift coefficient of approximately 1.1 corresponding to an angle of attack of 12 degrees for all the Reynold's number flow conditions tested. A high drag coefficient is characteristic of the S822 airfoil at low Reynold's numbers due to the presence of a laminar separation issue which are correlated by lower lift coefficients as well but dissipate as the Reynold's number increases. This highdrag knee can be reduced by the use of zigzag boundary layer trips as shown in Figure 13. 

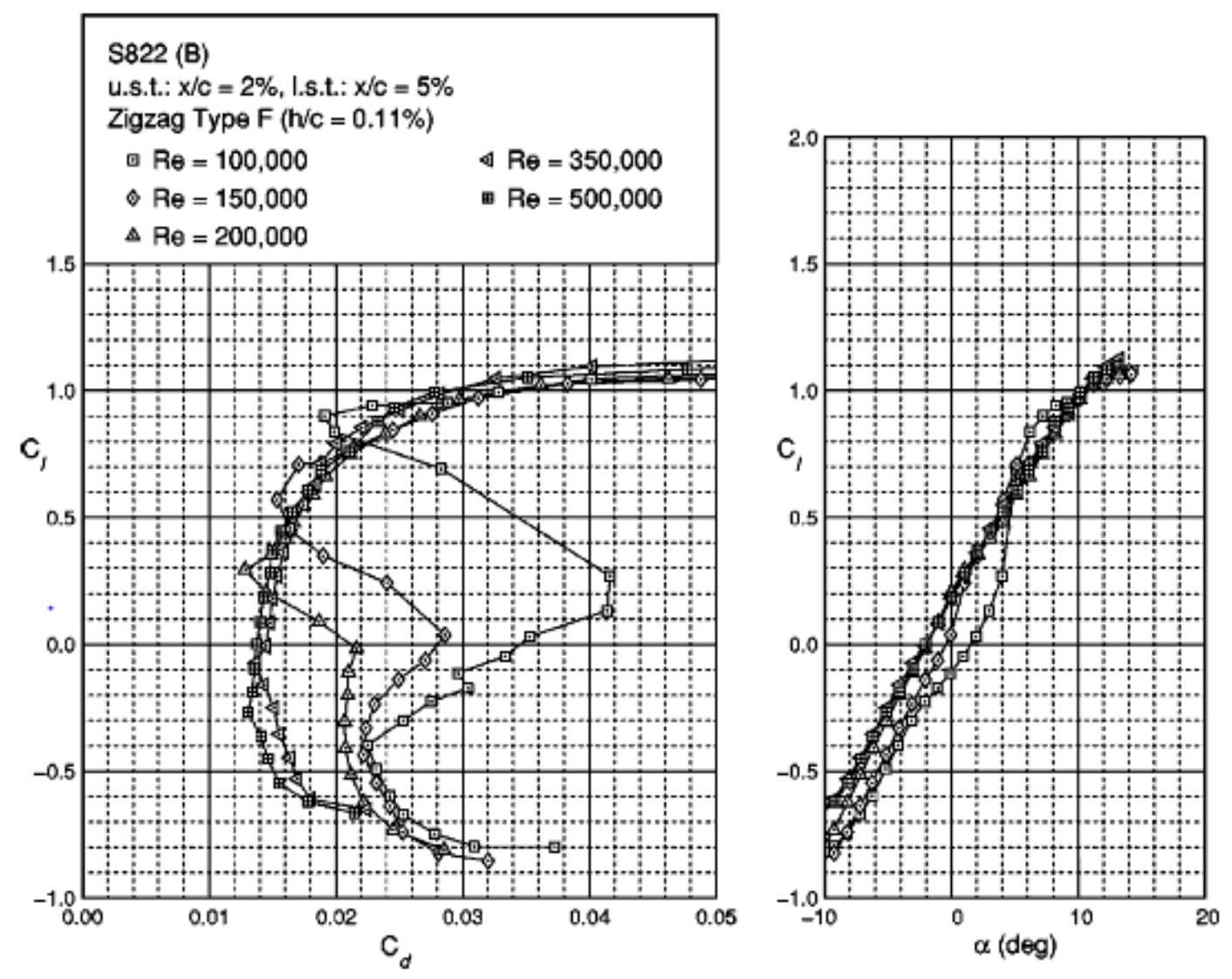

Figure 13 University of Illinois S822 wind tunnel performance data with the inclusion of a boundary layer tripping system. 
NREL's S-Series Airfoils

\begin{tabular}{|c|c|c|c|c|c|c|c|}
\hline \multirow[b]{2}{*}{ Airfoil } & \multirow[b]{2}{*}{ Location } & \multirow[b]{2}{*}{ Thickness } & \multirow[b]{2}{*}{ Rotor Diam. } & \multirow[b]{2}{*}{ Design Re } & \multicolumn{2}{|c|}{$\mathrm{Cl}, \max$} & \multirow[b]{2}{*}{ Comments } \\
\hline & & & & & Smooth & Rough & \\
\hline 5801 & primary & $13.5 \%$ & & & & & Not recommended. \\
\hline $580 z$ & $\operatorname{tip}$ & & & & & & Not recommended. \\
\hline 5803 & tip & & & & & & Not recommended. \\
\hline 5804 & root & & & & & & Not recommended. \\
\hline 5805 & primary & $13.5 \%$ & & $1.0 E 16$ & 1.18 & 1.18 & Replaced by S805A \\
\hline S805A & primary & & & & & & \\
\hline 5806 & tip & & & & & & Replaced by S806A \\
\hline S806A & tip & & & & & & \\
\hline S807 & root & & & & & & \\
\hline $\mathrm{S} 808$ & root & & & & & & \\
\hline S809 & primary & $21.0 \%$ & & $2.0 \mathrm{E}+6$ & 1.00 & & Restrained max lift coef., docile stall \\
\hline $\mathrm{S} 810$ & tip & & & & & & \\
\hline S811 & root & & & & & & \\
\hline $\mathrm{S} 812$ & primary & & & & & & \\
\hline $\mathrm{S} 813$ & tip & & & & & & \\
\hline $\mathrm{S} 814$ & root & $24.0 \%$ & $20-30 \mathrm{~m}$ & $1.5 \mathrm{E}+6$ & 1.56 & 1.51 & High max lift coef. \\
\hline $\mathrm{S} 815$ & root & $26.0 \%$ & $20-30 \mathrm{~m}$ & $1.2 \mathrm{E}+6$ & 1.46 & 1.40 & High max lift coef. \\
\hline $\mathrm{S} 816$ & primary & $21.0 \%$ & $30-50 \mathrm{~m}$ & $4.0 \mathrm{E}+6$ & 1.20 & 1.17 & Restrained max lift coef. \\
\hline $\mathrm{S} 817$ & tip & $16.0 \%$ & $30-50 \mathrm{~m}$ & $3.0 \mathrm{E}+6$ & 1.10 & 1.08 & Restrained max lift coef. \\
\hline $\mathrm{S} 818$ & root & $24.0 \%$ & $30-50 \mathrm{~m}$ & $2.5 \mathrm{E}+6$ & 1.68 & 1.61 & Restrained max lift coef. \\
\hline S819 & primary & $21.0 \%$ & $10-20 \mathrm{~m}$ & $1.0 \mathrm{E}+6$ & 1.20 & 1.16 & Restrained max lift coef. \\
\hline $\mathrm{S} 820$ & tip & $16.0 \%$ & $10-20 \mathrm{~m}$ & $1.3 \mathrm{E}+6$ & 1.10 & 1.06 & Restrained max lift coef. \\
\hline $\mathrm{S} 821$ & root & $24.0 \%$ & $10-20 \mathrm{~m}$ & $8.0 \mathrm{E}+5$ & 1.40 & 1.35 & Restrained max lift coef. \\
\hline S822 & tip & $16.0 \%$ & $2-10 \mathrm{~m}$ & $6.0 \mathrm{E}+5$ & 1.00 & 0.98 & Restrained max lift coef. \\
\hline $\mathrm{S} 823$ & root & $21.0 \%$ & $2-10 \mathrm{~m}$ & $4.0 \mathrm{E}+5$ & 1.20 & 1.16 & Restrained max lift coef. \\
\hline \multicolumn{8}{|l|}{ S824 } \\
\hline S825 & primary & $17.0 \%$ & $20-40 \mathrm{~m}$ & $2.0 \mathrm{E}+6$ & 1.44 & 1.37 & High max lift coef. \\
\hline $\mathrm{S} 826$ & tip & $14.0 \%$ & $20-40 \mathrm{~m}$ & $1.5 \mathrm{E}+6$ & 1.42 & 1.31 & High max lift coef. \\
\hline 5827 & primary & $21.0 \%$ & $40-50 \mathrm{~m}$ & $4.0 \mathrm{E}+6$ & 1.00 & 0.99 & Restrained max lift coef. \\
\hline 5828 & tip & $16.0 \%$ & $40-50 \mathrm{~m}$ & $3.0 \mathrm{E}+6$ & 0.90 & 0.89 & Restrained max lift coef. \\
\hline S829 & tip & $16.0 \%$ & $20-40 \mathrm{~m}$ & $2.0 \mathrm{E}+6$ & 0.70 & 0.68 & Restrained max lift coef. \\
\hline $\mathrm{S} 830$ & primary & $21.0 \%$ & $40-50 \mathrm{~m}$ & $4.0 \mathrm{E}+6$ & 1.60 & 1.57 & High max lift coef., quiet \\
\hline $\mathrm{S} 831$ & tip & $18.0 \%$ & $40-50 \mathrm{~m}$ & $3.5 \mathrm{E}+6$ & 1.50 & 1.48 & High max lift coef., quiet \\
\hline $\mathrm{S} 833$ & primary & $18.0 \%$ & $1-3 \mathrm{~m}$ & $4.0 \mathrm{E}+5$ & 1.10 & 1.13 & High max lift coef., quiet \\
\hline S834 & tip & $15.0 \%$ & $1-3 \mathrm{~m}$ & $4.0 \mathrm{E}+5$ & 1.00 & 1.02 & High max lift coef., quiet \\
\hline $\mathrm{S} 835$ & root & $21.0 \%$ & $1-3 \mathrm{~m}$ & $2.5 E+5$ & 1.20 & 1.03 & High max lift coef., quiet \\
\hline
\end{tabular}

Figure 14 Full listing of the entire NREL S-Series of airfoils with their key performance characteristics, S822 and S823 highlighted. 


\subsection{Final Airfoil Selection and Analysis}

Both the RISO-A family of airfoils currently being used and the NREL S-Series family of airfoils have their pros and cons. The NREL S-Series airfoils can be used on a variety of wind turbine rotor sizes and generator capabilities with certain types of the S-Series airfoils better suited to specific wind turbine applications, as seen in Table 1 NREL S-Series airfoils listed with the HAWT design parameters associated with each airfoil type., which is useful when designing rotor blades for a specific location and purpose. The RISO-A airfoil family is capable of generating very high lift coefficients and are generally scalable to fit a variety of rotor radius requirements but are known to be sensitive to surface roughness effects.

The induction generator currently equipped at the CPWPRC has a power production rating of 3 kilowatts when operating at its peak which cannot easily be changed without performing a considerably large redesign of the entire wind turbine from the tower to the nacelle. Therefore, in order to more accurately match the rated generator output, which relies heavily on the ability of the rotor blades to produce the appropriate amount of lift to spin the generator, and enhance the efficiency of the rotor blades the NREL S823 and S822 airfoils were chosen for this project due to their optimized design for smaller blade lengths and generators rated for lower power output. Although the lift-restricted design of the NREL S-Series airfoils does not produce as much lift as the RISO-A airfoil family the insensitiveness of the NREL S-Series airfoils, along with the relatively small generator power output magnitude and rotor size, makes using the NREL S- 
Series more appropriate for this project. However, the methods of determining key loading scenarios and the modeling of the stress and displacement of the wind turbine rotor blades in this project are reproducible with any other airfoil type which allows future research employing a multitude of unique airfoil designs.

Table 1 NREL S-Series airfoils listed with the HAWT design parameters associated with each airfoil type.

\begin{tabular}{|c|c|l|l|l|l|l|}
\hline $\begin{array}{c}\text { Blade Length } \\
\text { (meters) }\end{array}$ & $\begin{array}{c}\text { Generator } \\
(\mathbf{k W})\end{array}$ & $\begin{array}{c}\text { Thickness } \\
\text { Category }\end{array}$ & \multicolumn{4}{|c|}{ Airfoil Familv } \\
\hline $1-5$ & $2-20$ & thick & & S823 & & S822 \\
\hline $5-10$ & $20-150$ & thin & & S804 & S801\# & S803\# \\
\hline $5-10$ & $20-150$ & thin & S808 & S807 & S805A & S806A \\
\hline $5-10$ & $20-150$ & thick & & S821 & S819 & S820 \\
\hline $10-15$ & $150-400$ & thick & S815 & S814 & S809 & S810 \\
\hline $10-15$ & $150-400$ & thick & S815 & S814 & S812 & S813 \\
\hline $10-15$ & $150-400$ & thick & S815 & S814 & S825\# & S826\# \\
\hline $15-25$ & $400-1000$ & thick & & S818 & S816 & S817 \\
\hline $15-25$ & $400-1000$ & thick & & S818 & S827 & S828 \\
\hline
\end{tabular}

With the airfoil selection complete the necessary performance data required to perform the blade optimization procedure is required which is aided by the plethora of airfoil analysis tools available. Aeronautical engineers have developed software programs that can solve multi variable equations regarding the properties of the air flow around the airfoil as well their respective forces imparted upon the airfoil surface. One of the most widely used types of this software is called "XFOIL" which is a program developed for the design and analysis of subsonic airfoils by Mark Drela at the Massachusetts Institute of 
Technology (MIT) in 1986 with improvements constantly being made to the program's accuracy. The latest edition of XFOIL, version 6.99, was released in December of 2013 for UNIX and Windows operating systems and is widely accepted to be one of the best tools for carrying out airfoil analysis. XFOIL was released under a "General Public License" which allows the public to use it for free, therefore a variety of software programs have integrated XFOIL into their own user interfaces in order to develop a more user friendly yet useful type of an airfoil design and analysis tool. One such program is "QBlade" which is a software project developed at the Berlin Technical University Department of Experimental Fluid Mechanics led by Dr. Christian Oliver Paschereit. QBlade integrates XFOIL into a user friendly graphic user interface (GUI) and results display system that allows for easy importation of airfoil geometries, calculation of airfoil performance parameters, and to simulate a complete wind turbine rotor with BEM techniques and numerical optimization methods. Therefore, the user can import their airfoil types of choice, specify the rotor blade details such as chord length and twist angle at any number of specified radial sections, define the tip speed ratios (TSR) that the rotor blades are to be subject to, and even manually select which correction algorithms to incorporate into the analysis such as tip loss and 3-dimensional discrepancies. After the appropriate user defined data is entered into the program QBlade performs the necessary calculations, with the aid of XFOIL and numerical methods of its own, and produces a wide range of raw data and plots to subsequently be used in the final rotor blade design. This data may then be compared to what the wind turbine rotor blade 
designer calculates elsewhere using reliable momentum and blade element theories, alongside empirical data to refine the accuracy of the calculated rotor variables such as the expected power and thrust coefficients.

Some of the more important data delivered by QBlade includes the lift and drag coefficient values as shown in Figure 15 and Figure 16 which will be compared to experimental testing done on the same airfoils to determine their usefulness in further calculations.

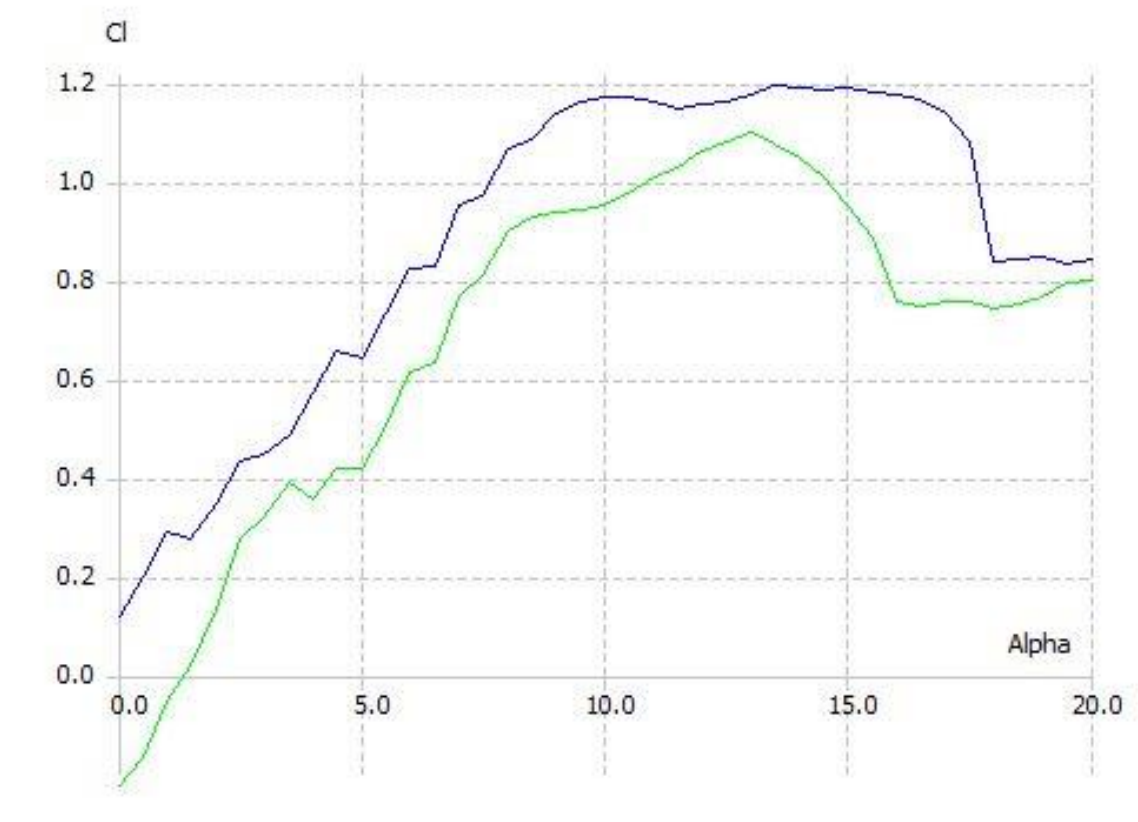

Figure 15 S823 and S822 lift coefficient versus angle of attack data as predicted by QBlade. 

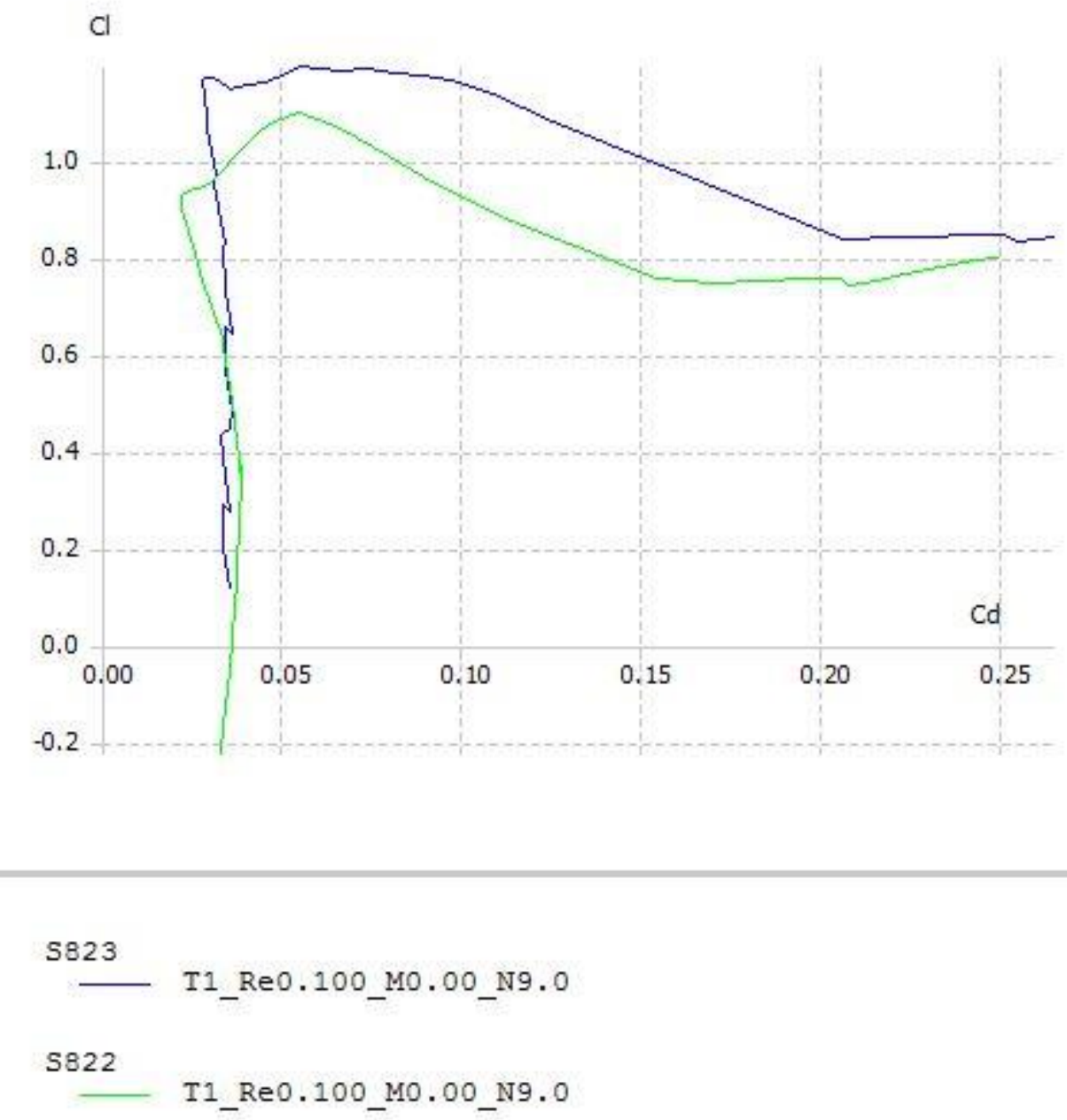

Figure 16 S823 and S822 lift versus drag coefficient data as predicted by QBlade.

The program can then take this airfoil data and create a $360^{\circ}$ polar plot of each airfoil that correlates the lift and drag coefficients to any angle of attack from $0^{\circ}$ to $360^{\circ}$ as shown in Figure 17. After some manipulation by the user this polar data are made to be as similar to the known experimental data as possible by altering certain parameters which effect the lift and drag coefficients versus the angle of attack. In this way the results of QBlade, which again is a user friendly software 
package implementing the well-known and reliable XFOIL airfoil code, are made to be as accurate as possible to be used in the forthcoming design process.
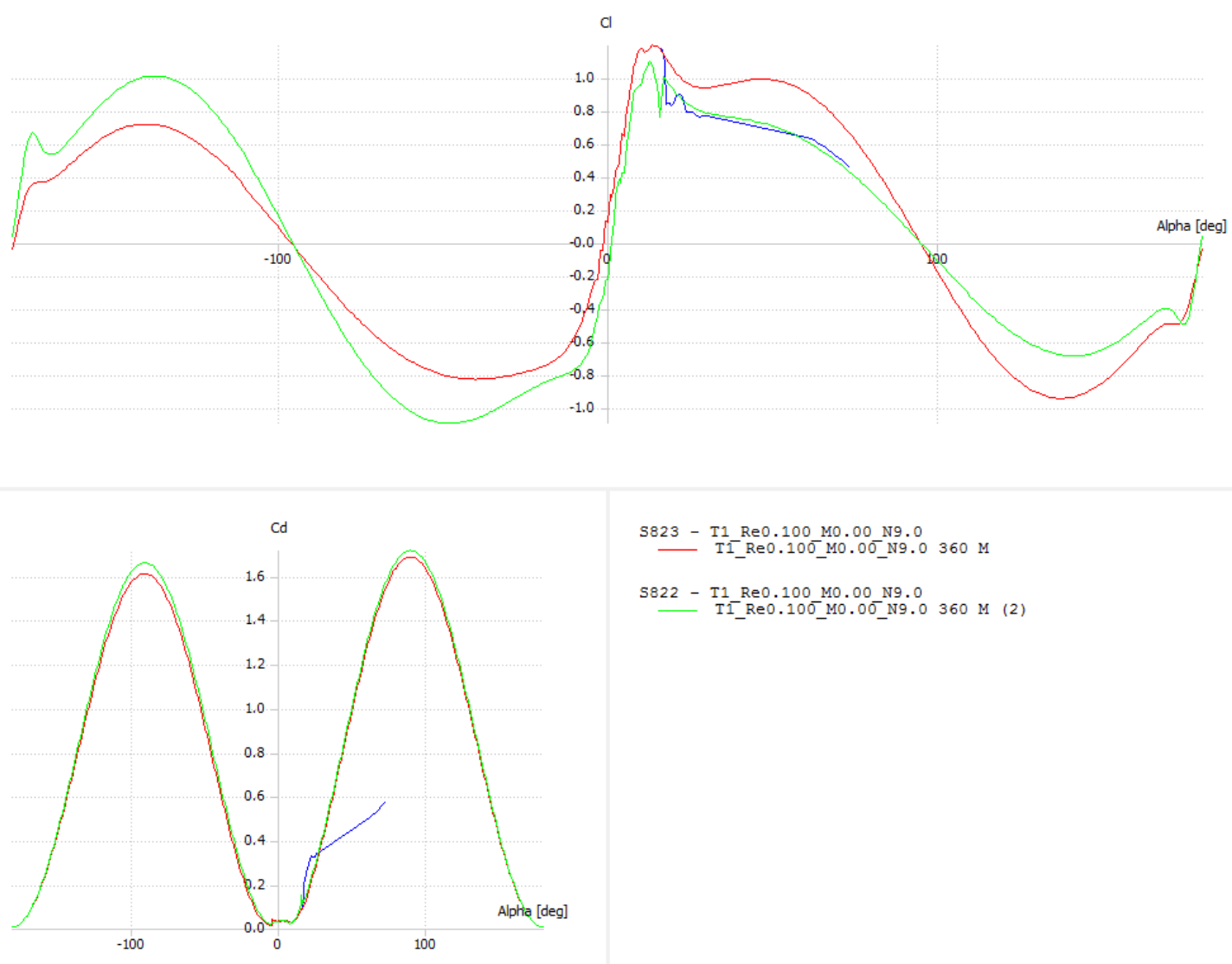

Figure 17 Extrapolated polar plots of lift and drag coefficients versus a full $360^{\circ}$ angle of attack spectrum.

After the necessary data has been calculated a full rotor simulation may be performed to determine the full wind turbine rotor characteristics such as the power and thrust coefficients versus a range of tip speed ratios. Knowing what power coefficients to expect over a range of tip speed ratios is vital information when designing a HAWT such as this project due to the wide ranging effects changing the tip speed ratio can have on the aerodynamic characteristics of the rotor blade. Corrective numerical equations may also be incorporated including 
tip and root loss corrections which are helpful in predicting the realistic rotor characteristics as shown in Figure 18.

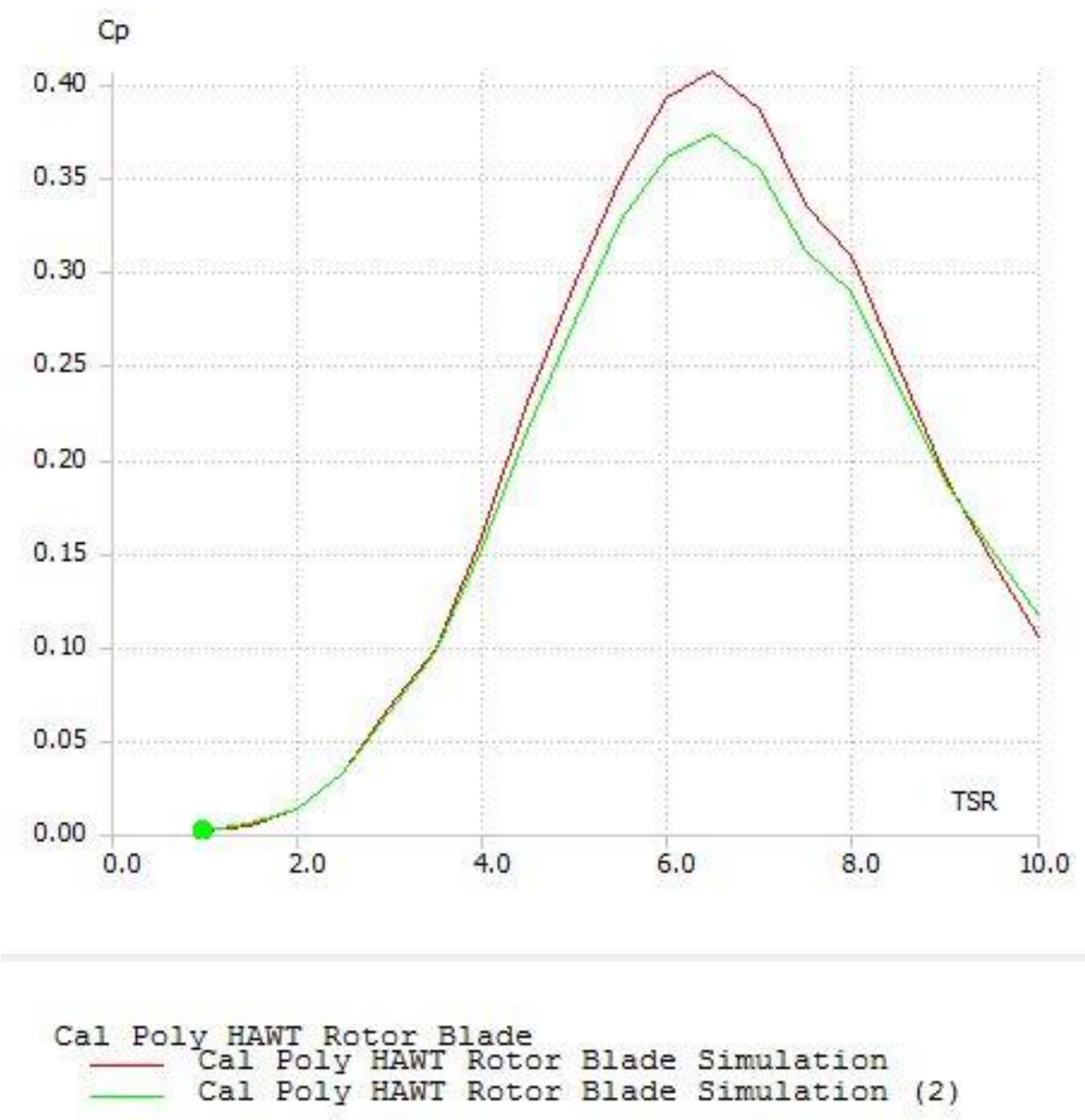

Figure 18 Power coefficient versus tip speed ratio prediction for the new rotor system as predicted by QBlade. Power coefficient predicted without tip loss effects shown in red and with tip loss effects shown in green. 


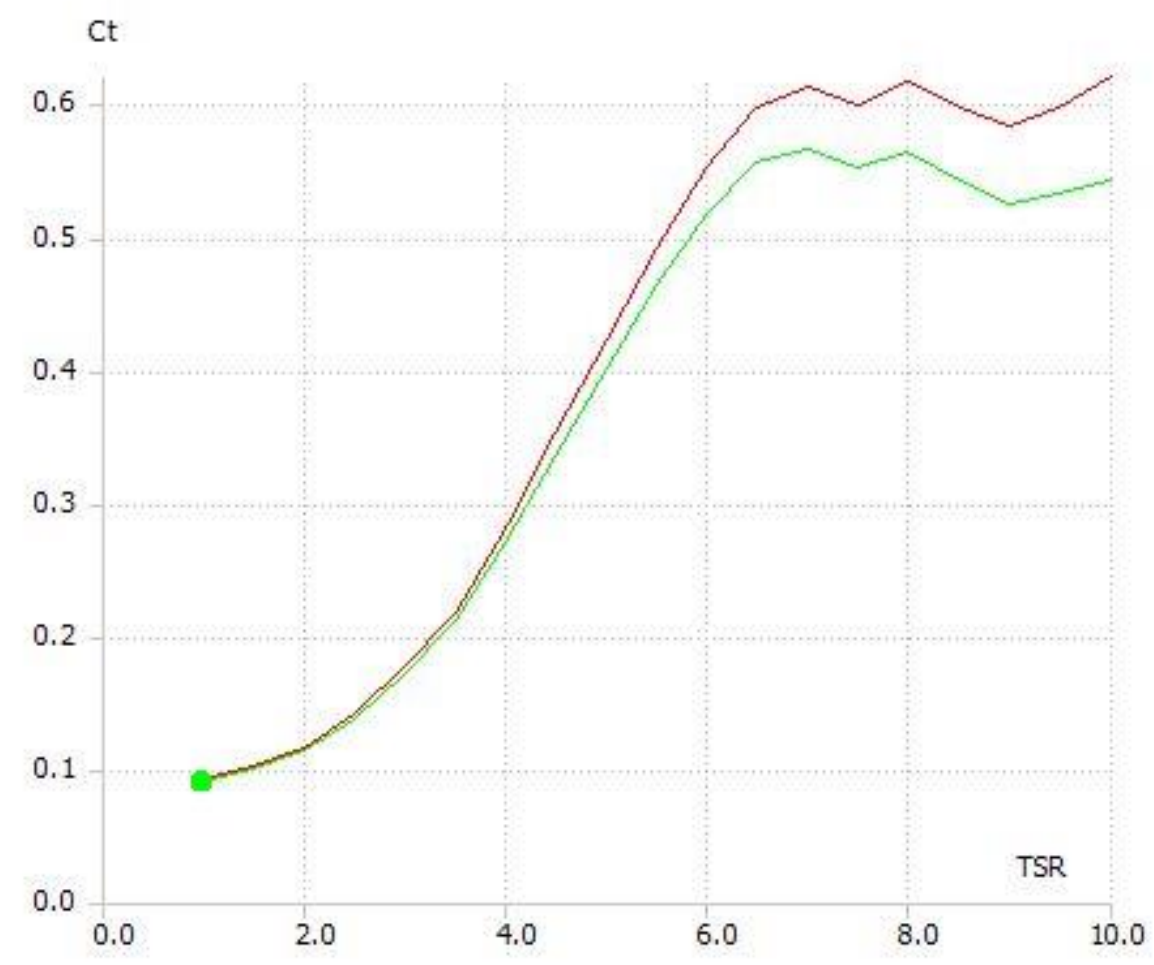

Cal Poly HAWT Rotor Blade

Cal Poly HAWT Rotor Blade Simulation

- Cal Poly HAWT Rotor Blade Simulation (2)

Figure 19 Thrust coefficient versus tip speed ratio prediction by QBlade with and without tip loss effects.

It can be seen that when comparing the aerodynamic performance results of the QBlade program and the University of Illinois wind tunnel airfoil testing that the results are very similar. The maximum lift coefficient achieved by the $\mathrm{S} 822$ airfoil during wind tunnel testing under all Reynolds number flow conditions is approximately 1.1 at an angle of attack of approximately 12 degrees, while QBlade predicts a similar lift coefficient of 1.1 at the same angle of attack. Therefore, QBlade may be utilized for any future airfoil aerodynamic performance 
analyses which may then be incorporated into the aerodynamic calculations of any future rotor blade designs. 


\subsection{Aerodynamic Blade Design}

There are a multitude of ways horizontal and vertical wind turbine blades can be designed with each technique having its usefulness or faults depending on the particular application of the wind turbine and the relative wind conditions. For this project the most reliable and established methods of designing and analyzing an optimal HAWT rotor blade will be outlined and pursued. These methods are well documented, see [1] and [2], and have been in use for many decades.

Basic physics theories define the foundations of wind energy analysis which can then be incorporated into more advanced aerodynamic theories to produce useful results regarding the optimal design of the rotor blades. In order to get the big picture idea behind wind energy capture basics, one-dimensional momentum theory is employed, in conjunction with certain assumptions, so that the magnitude of the wind energy available to be captured by an ideal wind turbine may be determined. With this information at hand, a more accurate result may be found by realizing certain physical improbabilities associated with the previous basic analysis. As more assumptions are eliminated, such as the limited number of blades and fluid rotation within the rotor plane and a more realistic representation of the rotor blade environment is realized and utilized in the rotor blade design process. With this accurate representation of the rotor operating conditions, and with known wind turbine properties, power and lift coefficients may be calculated which relate the available wind energy passing through the swept area of the rotor to the captured energy. The power coefficient is a very important blade design parameter which relates the power produced by the 
turbine to the dynamic power of the wind passing through the rotor swept area and is an important measure of the turbine performance. The basic HAWT rotor blade design parameters for this project are summarized in Table 2 including the rotor radius which is calculated in the optimum rotor blade design section of this report.

Table 2 Overview of the starting HAWT rotor blade design parameters.

\begin{tabular}{|l|c|}
\hline Number of Blades (B) & 3 \\
\hline Tip Speed Ratio, Design (-) & 7 \\
\hline Wind Speed, Design (m/s) & 3.576 \\
\hline Power, Design (Watts) & 3000 \\
\hline Number of Blade Sections (N) & 20 \\
\hline Air Density, Sea Level (kg/m $\left.{ }^{3}\right)$ & 1.225 \\
\hline Swept Rotor Area (m $\left.{ }^{2}\right)$ & 268 \\
\hline Power Coefficient, Design (-) & 0.40 \\
\hline Rotor Radius $(\mathrm{m})$ & 9.23 \\
\hline
\end{tabular}




\section{Optimized HAWT Rotor Blade Aerodynamic Design Flowchart}

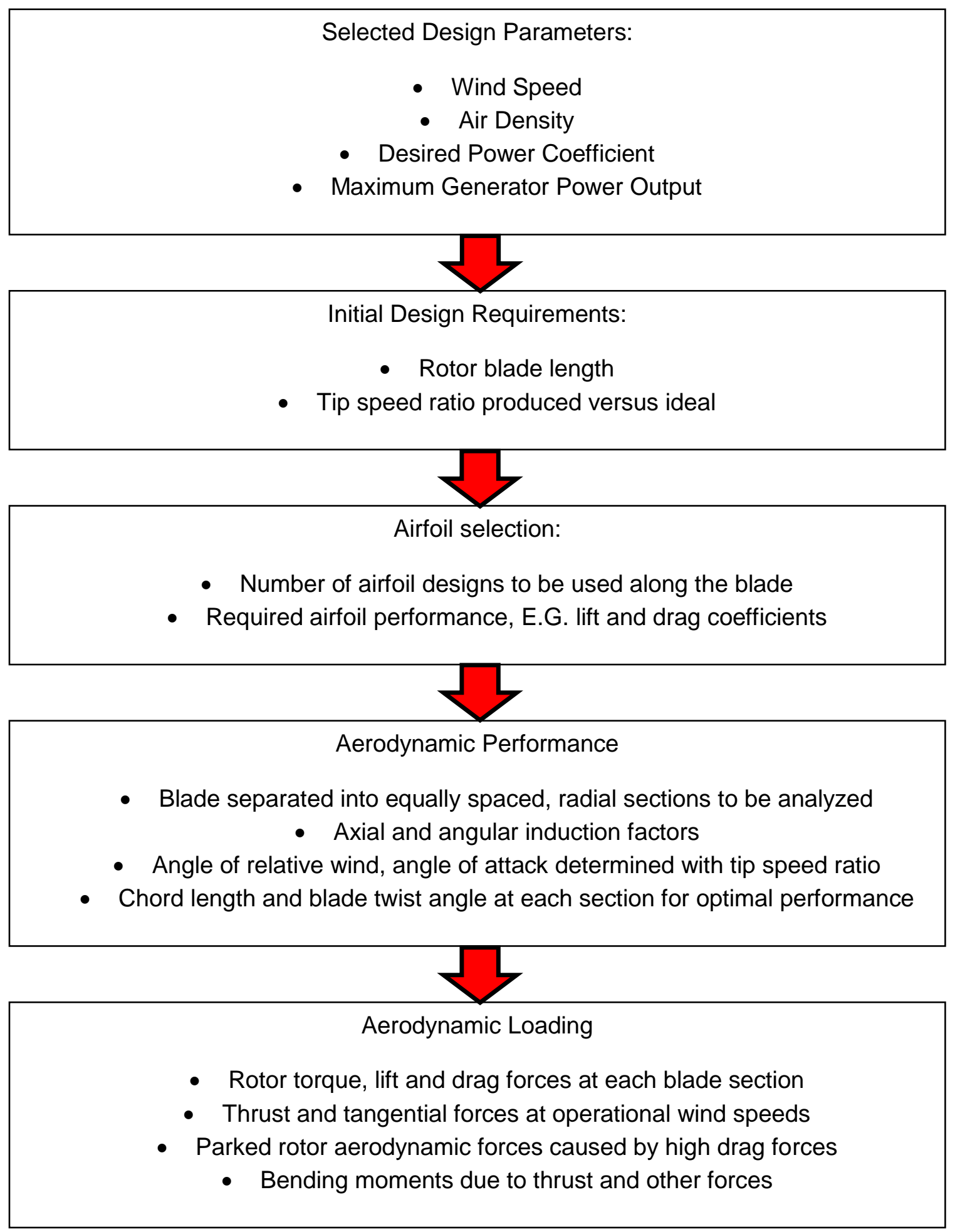

Figure 20 Optimized blade aerodynamic performance and loading calculation flowchart. 


\subsection{Momentum Theory and Betz Limit}

To analyze how much energy is available in the wind and to determine the power from an ideal wind turbine rotor system a simple one-dimensional, linear momentum theory developed by Betz in the 1930's is applied. This simple model utilizes a control volume containing a stream tube with an "actuator disk" which generates a pressure difference in the air passing through it as shown in Figure 21.

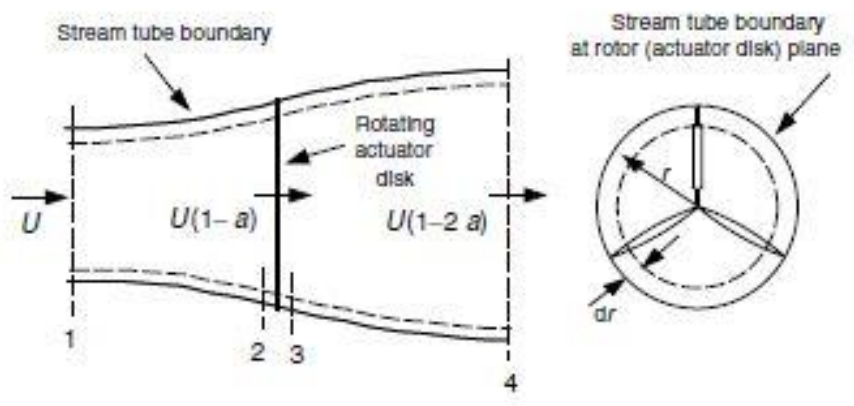

Figure 21 Momentum theory stream tube and BET differential annular elements. By applying the theories of linear momentum, mass conservation and flow rate, as well as Bernoulli's equation it can be shown that the thrust generated through the stream tube is equal to

$$
T=\frac{1}{2} \rho A_{2}\left(U_{1}^{2}-U_{4}^{2}\right)
$$

where $\rho$ is the density of air at sea level or $1.225 \mathrm{~kg} / \mathrm{m}^{3}, A$ is the swept area of the rotor, and $U_{x}$ is the wind speed at whichever location. For further simplification the mass flow rate equation is substituted into equation 1 above to define the axial induction factor as, 


$$
a=\frac{U_{1}-U_{2}}{U_{1}}
$$

which describes the fractional decrease in wind velocity through the rotor plane. The axial induction factor increase from 0 to describe the wind speed just after the air passes through the rotor plane. Therefore, it can easily be seen that a value of $a=1 / 2$ requires that the wind slow to 0 velocity behind the rotor which is unrealistic. The equation for the axial induction factor may then be used to define the wind velocity at and far downstream of the rotor plane as,

$$
U_{2}=U_{1}(1-a)
$$

and

$$
U_{4}=U_{1}(1-2 a)
$$

where the quantity " $\mathrm{U}_{1} \mathrm{a}$ " is defined as the induced velocity at the rotor plane. Knowing that the power is found by multiplying the thrust times the wind velocity at the disk and by substituting in the equations above for $U_{2}$ and $U_{4}$ the power out may be determined by,

$$
P=\frac{1}{2} \rho A U^{3} 4 a(1-a)^{2}
$$

where the control volume area denoted as " $\mathrm{A}_{2}$ " has been replaced by the rotor area as simply "A" and the free stream velocity " $U_{1}$ " is simply denoted as "U." Utilizing this equation for the power out of the rotor to define the performance of the wind turbine rotor yields, 


$$
C_{P}=\frac{P}{\frac{1}{2} \rho U^{3} A} \equiv \frac{\text { Rotor Power }}{\text { Power in the Wind }}
$$

This non-dimensional coefficient is a measure of the power available in the wind and the power extracted from the wind passing through the swept area of the rotor plane. $C_{P}$ may also be represented using the axial induction factor,

$$
C_{P}=4 a(1-a)^{2}
$$

In order to determine the maximum $\mathrm{C}_{\mathrm{P}}$ value possible one simply takes the derivative of equation 7 with respect to the axial induction factor, a, and sets the result equal to 0 which yields $a=1 / 3$ which therefore yields,

$$
C_{P}=\frac{16}{27}=0.5926
$$

In honor of the man who played a pivotal role in developing this theory, this idealized and exceptionally high coefficient of power of $59.26 \%$ is referred to as the "Betz Limit" and is strived for by wind turbine designers. This scenario requires the upstream cross-sectional area of the stream tube to be $2 / 3$ the disc area and twice the disc area downstream of the rotor plane which is a highly unpredictable parameter.

It may also be shown that the axial thrust on the disc can be described utilizing the axial induction factor by substituting the equation for axial induction into the equation for thrust derived using the one-dimensional momentum theory,

$$
T=\frac{1}{2} \rho A U^{2}[4 a(1-a)]
$$

which may also be characterized by the non-dimensional thrust coefficient as, 


$$
C_{T}=\frac{T}{\frac{1}{2} \rho U^{2} A} \equiv \frac{\text { Thrust Force }}{\text { Dynamic Force }}
$$

It may be shown that for an ideal wind turbine which extracts $100 \%$ of the energy from the wind the $C_{T}$ value would equal 1.0 when $\mathrm{a}=0.5$ and the downstream velocity of the wind is zero. However in reality, if a very high axial induction factor is generated thrust coefficients can be as high as 2.0. This idealized model of a wind turbine rotor is not a valid design tool due to the assumptions made in order to derive the equations describing the factors acting on the actuator disk in the rotor plane as described in Figure 22 but rather gives a general idea of wind turbine functioning.

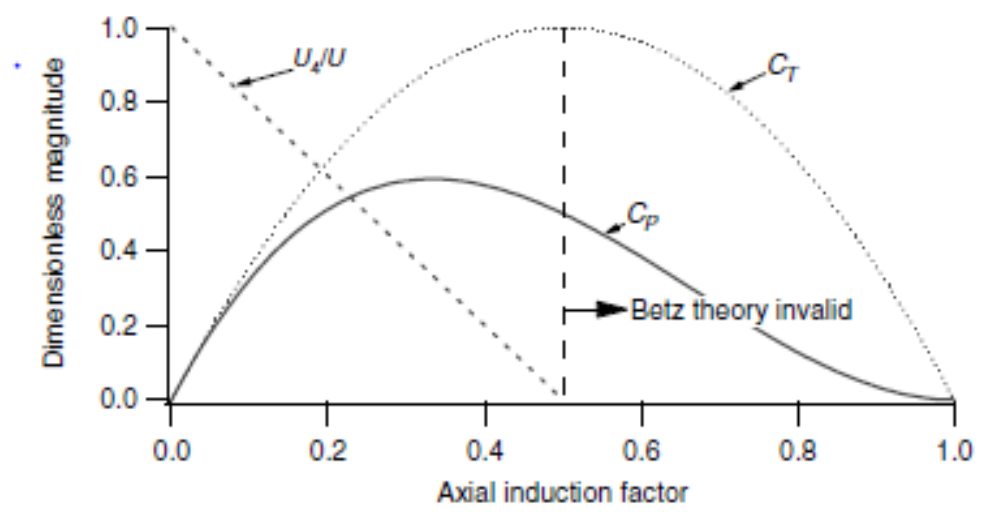

Figure 22 Thrust and power coefficient prediction limitations versus rotor axial induction factors.

In order to determine the amount of torque developed by the rotor, angular momentum is added to the linear momentum theory described previously to analyze the effect of rotation being imparted to the flow rotating in the opposite direction of the rotor rotation as shown in Figure 23. 


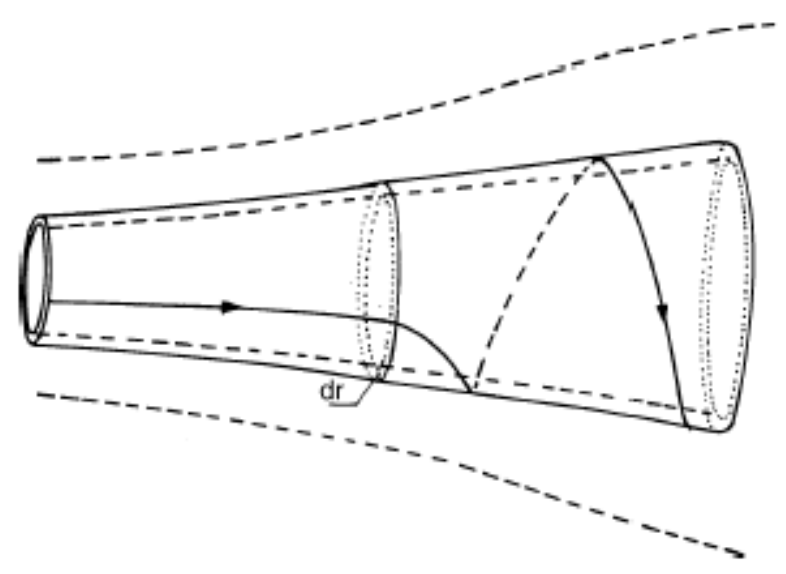

Figure 23 Momentum stream tube with wake rotation effects shown.

The rotational kinetic energy developed in the rotor wake lessens the amount of energy that may be extracted by the rotor and is effected by the rotational speed of the rotor blades. To analyze this wake rotation an additional factor is required to describe the behavior of the air as it passes through the rotor plane.

Assuming that the angular velocity imparted onto the air flow, $\omega$, is small in comparison to the angular velocity of the wind turbine itself, $\Omega$, it may be shown that the angular induction factor is defined as,

$$
a^{\prime}=\frac{\omega}{(2 \Omega)}
$$

With the inclusion of the wake rotation and angular induction factor the axial induced factor is now complimented by the induced velocity acting in the rotor plane, defined as $r \Omega \mathrm{a}^{\prime}$, which is used in the definition of the annular thrust acting on the rotor,

$$
d T=4 a^{\prime}\left(1+a^{\prime}\right) \frac{1}{2} \rho \Omega^{2} r^{2} 2 \pi r d r
$$


Note that the relations developed utilizing linear momentum analysis done previously may be used in conjunction with the axial induction factor to develop an expression for the thrust on an annular cross-section,

$$
d T=4 a(1-a) \frac{1}{2} \rho U^{2} 2 \pi r d r
$$

Therefore when the two equations for annular thrust are equated a local speed ratio, $\lambda_{r}$, may be defined as,

$$
\frac{\Omega^{2} r^{2}}{U^{2}}=\lambda_{r}^{2}
$$

where $r$ is any radial distance measured from its rotor axis of rotation. By replacing the value of any radial distance along the blade, $r$, with the maximum radial distance, $R$, one may define the tip speed ratio, $\lambda$,

$$
\lambda=\frac{\Omega R}{U}
$$

which may then be related to the local speed ratio by,

$$
\lambda_{r}=\lambda \frac{r}{R}
$$

This derivation of the local speed ratio can be related to the differential rotor torque and subsequently to the differential power at each rotor blade element such that,

$$
d P=\frac{1}{2} \rho A U^{3}\left[\frac{8}{\lambda^{2}} a^{\prime}(1-a) \lambda_{r}^{3} d \lambda_{r}\right]
$$

This derivation of the differential power demonstrates how the power from an annular section of the rotor swept area is a function of both the induction factors, 
axial and angular, as well as the local and tip speed ratio. The differential power coefficient may then be defined for each individual annular section by,

$$
d C_{P}=\frac{d P}{\frac{1}{2} \rho A U^{3}}
$$

By substituting in the axial and angular induction factors and integrating the power coefficient from 0 to the tip speed ratio and setting the result to 0 it can be shown that maximum power is produced when,

$$
a^{\prime}=\frac{1-3 a}{4 a-1}
$$

The relation between the tip speed ratio and the power coefficient, in both an idealized state and one which includes wake rotation, become evident when the two are graphed as shown in Figure 24. Given this knowledge it becomes evident that much care must be taken when deciding upon the best design tip speed ratio for a particular wind turbine design.

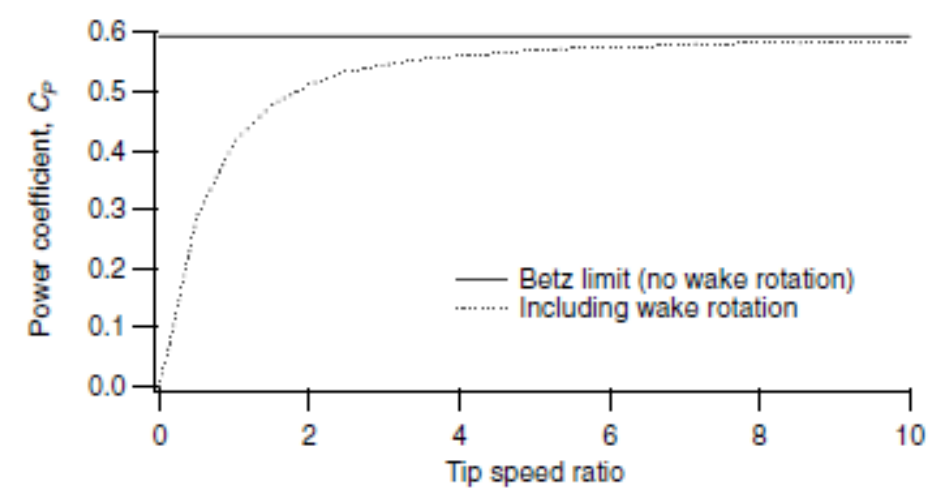

Figure 24 Betz limit with and without wake rotation shown as a factor of both power coefficient and tip speed ratio. 


\subsection{Blade Element Theory}

The momentum theory provides a basic understanding of the operation of the wind turbine rotor system but a more thorough understanding is found by utilizing the "blade element theory" which analyzes the forces at multiple blade sections, shown in Figure 25. Therefore, when the momentum and blade element theories are combined a more accurate approach to rotor blade design and modeling may be realized and is referred to as "blade element momentum (BEM)" theory or "strip theory." In this manner a detailed analysis of every section of the rotor blade may be designed to perform as optimally as possible with the assistance of the following assumptions:

- There exists no aerodynamic interaction between elements.

- The forces on the blades are determined solely by the lift and drag forces generated on the airfoil shape pertaining to individual blade sections.

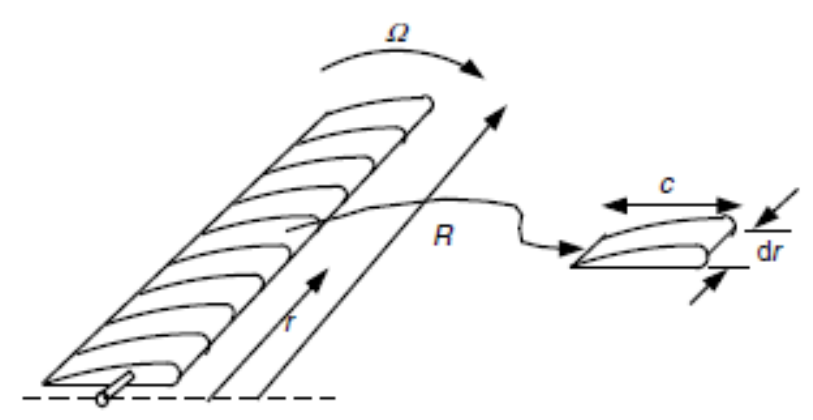

Figure 25 Diagram of blade sections utilized with the BET.

For reference the equations derived for the differential rotor thrust and torque, respectively, are reproduced below and will be combined with the equations for rotor thrust and torque derived from the blade element theory, 


$$
\begin{gathered}
d T=\rho U^{2} 4 a(1-a) \pi r d r \\
d Q=4 a^{\prime}(1-a) \rho U \pi r^{3} \Omega d r
\end{gathered}
$$

The relative wind may be determined by calculating the vector sum of the wind velocity at the rotor, described as $U(1-a)$, and the wind velocity created by the rotation of the rotor blade sections at any radial location,

$$
\Omega r+\left(\frac{\omega}{2}\right) r=\Omega r+\Omega a^{\prime} r=\Omega r\left(1+a^{\prime}\right)
$$

To describe all the components of the aerodynamic forces generated at blade sections the following definitions are required and illustrated in Figure 26:

- $\Theta_{p}$ : Section pitch angle, which describes the angle between the chord line and the rotor plane of rotation.

- $\Theta_{\mathrm{P}, 0}$ : Blade pitch angle at the tip of the blade.

- $\Theta_{\mathrm{T}}$ : Blade twist angle.

- $\alpha$ : Angle of attack I.E. the angle between the chord line and the incoming relative wind.

- $\Phi$ : Angle of the incoming relative wind.

- $\mathrm{dF}_{\mathrm{L}}$ : Incremental lift force.

- $\mathrm{dF}_{\mathrm{D}}$ : Incremental drag force.

- $\mathrm{dF}_{\mathrm{N}}$ : Incremental force normal to the plane of rotation, a major contributor to the thrust force.

- $\mathrm{dF}_{\mathrm{T}}$ : Incremental force tangential to the circle swept by the rotor.

- $\mathrm{U}_{\mathrm{rel}}$ : Magnitude of the relative wind velocity. 


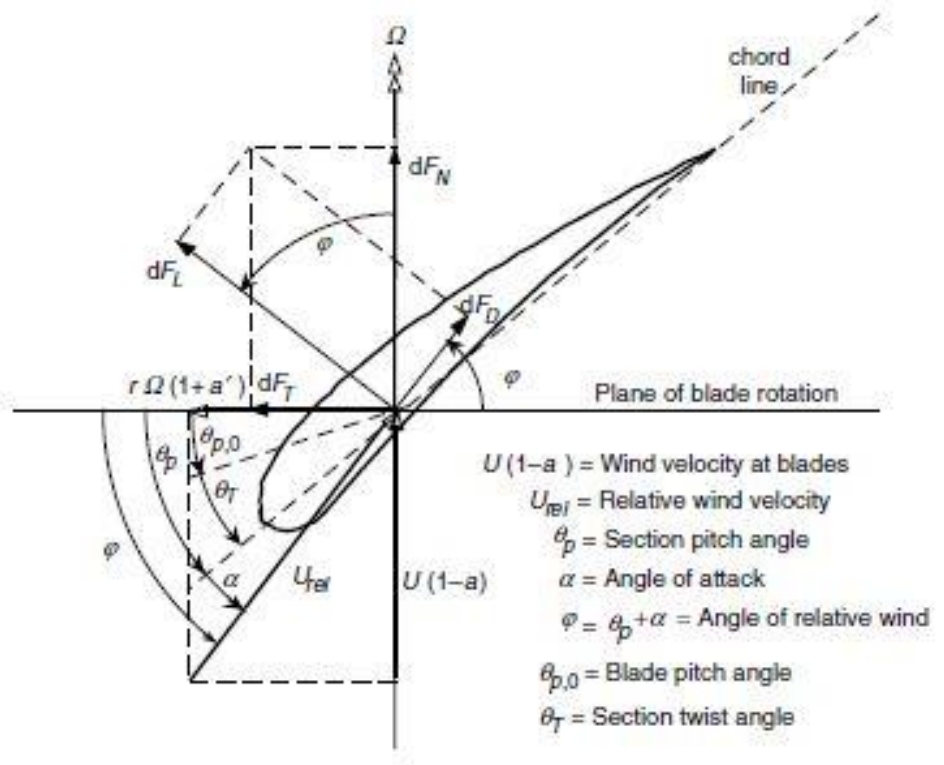

Figure 26 Force diagram showing lift, drag, in-plane, and out-of rotor plane forces due to the relative wind angle.

From Figure 26 the following relationships may be determined:

$$
\begin{gathered}
\varphi=\Theta_{P}+\alpha \\
\tan \varphi=\frac{U(1-a)}{\Omega r\left(1+a^{\prime}\right)}=\frac{1-a}{\left(1+a^{\prime}\right) \lambda_{r}} \\
U_{r e l}=U(1-a) / \sin \varphi \\
d F_{L}=C_{l} \frac{1}{2} \rho U_{r e l}^{2} c d r \\
d F_{D}=C_{d} \frac{1}{2} \rho U_{r e l}^{2} c d r \\
d F_{N}=d F_{L} c \cos \varphi+d F_{D} \sin \varphi \\
d F_{T}=d F_{L} \sin \varphi-\cos \varphi
\end{gathered}
$$

In order to account for the fact that blade element theory describes the effect of the forces on individual rotor blade sections and not an actuator disk comprised 
of an infinite number of rotor blades, as was used in the momentum theory, the actual number of rotor blades must be incorporated into the derivation of the aerodynamic forces. Therefore, if "B" refers to the number of rotor blades the normal force and torque occurring at a distance, $r$, from the axis of rotation may defined, respectively, by combining the previous equations,

$$
d F_{N}=B \frac{1}{2} \rho U_{r e l}^{2}\left(C_{l} \cos \varphi+C_{d} \sin \varphi\right) c d r
$$

and

$$
d Q=B r d F_{T}
$$

therefore,

$$
d Q=B \frac{1}{2} \rho U_{r e l}^{2}\left(C_{l} \sin \varphi-C_{d} \cos \varphi\right) c r d r
$$

With the necessary blade section geometry and force characteristics now able to be calculated the optimum blade shape may be designed. The required airfoil data, including the lift and drag coefficients, will have a significant impact on the aerodynamic forces and the rotor performance. Therefore, much care must be taken in determining those values in order to generate a rotor for optimum performance.

To complete the strip theory analysis, the aerodynamic force equations must include wake rotation, and combine the equations of forces acting on the rotor derived from the momentum and blade element theories. From the momentum theory it has been shown that due to axial momentum, 


$$
d T=\rho U^{2} 4 a(1-a) \pi r d r
$$

Also, due to angular momentum we have,

$$
d Q=4 a^{\prime}(1-a) \rho U \pi r^{3} \Omega d r
$$

From blade element theory we can equate the normal forces relative to the rotor plane and the rotor torque respectively as,

$$
\begin{aligned}
& d F_{N}=B \frac{1}{2} \rho U_{r e l}^{2}\left(C_{l} \cos \varphi+C_{d} \sin \varphi\right) c d r \\
& d Q=B \frac{1}{2} \rho U_{r e l}^{2}\left(C_{l} \sin \varphi-C_{d} \cos \varphi\right) c r d r
\end{aligned}
$$

to the differential thrust force from momentum theory while substituting in the equations derived to described the relative wind to generate the following equations,

$$
\begin{aligned}
& d F_{N}=\sigma^{\prime} \pi \rho \frac{U^{2}(1-a)^{2}}{(\sin \varphi)^{2}}\left(C_{l} \cos \varphi+C_{d} \sin \varphi\right) r d r \\
& d Q=\sigma^{\prime} \pi \rho \frac{U^{2}(1-a)^{2}}{(\sin \varphi)^{2}}\left(C_{l} \sin \varphi-C_{d} \cos \varphi\right) r^{2} d r
\end{aligned}
$$

where the local solidity, $\sigma^{\prime}$, is defined as,

$$
\sigma^{\prime}=\frac{B c}{2 \pi r}
$$

Other useful relationships result from deriving equations for the induction factors that result from setting the drag coefficient, $C_{d}$, equal to 0 since the drag coefficient is usually negligible which gives, 


$$
a^{\prime} /_{(1-a)}={ }^{\sigma^{\prime} C_{l}} /\left(4 \lambda_{r} \sin \varphi\right)
$$

Also, by combining the force equations derived from the momentum and BET it can be shown that,

$$
a /(1-a)=\sigma^{\prime} C_{l} \cos \varphi /\left[4(\sin \varphi)^{2}\right]
$$

Through additional manipulation key relationships regarding the lift coefficient, induction factors, and angle of the relative wind result in the following useful equations are derived,

$$
\begin{gathered}
C_{l}=4 \sin \varphi \frac{\left(\cos \varphi-\lambda_{r} \sin \varphi\right)}{\sigma^{\prime}\left(\sin \varphi+\lambda_{r} \cos \varphi\right)} \\
a^{\prime} /\left(1+a^{\prime}\right)=\sigma^{\prime} C_{l} /(4 \cos \varphi) \\
a=\frac{a}{a^{\prime}}=\frac{\lambda_{r}}{\tan \varphi} \\
\left.a^{\prime}=1 /\left(4 \cos \varphi /\left(\sigma^{\prime} C_{l}\right)\right)-1\right]
\end{gathered}
$$

Given these useful relationships and equations, two solution methods may now be explored to design an optimal aerodynamic blade shape. The first involves using measured airfoil characteristics and BEM to solve for the lift coefficient and axial induction factor, and the second method involves an iterative solution for 
the axial and angular induction factors. Once the necessary variables have been determined the power coefficient may be calculated from the equation,

$$
C_{P}=\left(\frac{8}{\lambda^{2}}\right) \int_{\lambda_{h}}^{\lambda} \lambda_{r}^{3} a^{\prime}(1-a)\left[1-\left(\frac{C_{d}}{C_{l}}\right) \cot \varphi\right] d \lambda_{r}
$$

in order to gauge the effectiveness of the blade shape design. While both methods are very useful and provide good results this project will make use of the second method of iteratively solving for the induction factors.

In order to improve the accuracy of the blade design procedures explained previously, factors that are not taken into account for may be included into the blade analysis with relative ease. For instance, the tip loss caused by air pressure flowing from the high pressure side of the blade to the lower pressure side over the blade tip lessens the available lift near the tip of a rotor blade and therefore lowers power production available. Due to the fact that this project entails a blade with a significant chord length at the tip, this tip loss factor has a significant impact on the aerodynamic performance of the rotor blades and must be taken into account. There are many ways to include the effect of the tip loss but the most direct method is one developed by Prandtl [1] which involves calculating a correction factor, $\mathrm{F}$, which is introduced into previously derived equations. This correction factor requires knowledge of the number of rotor blades, the angle of the relative wind and the position of the blade in the swept rotor area, 


$$
F=\left(\frac{2}{\pi}\right) \cos ^{-1}\left[-\left\{\frac{(B / 2)[1-(r / R)]}{(r / R) \sin \varphi}\right\}\right]
$$

Where $\mathrm{B}$ represents the number of rotor blades and the correction factor $\mathrm{F}$ is always between 0 , for total lift losses, and 1 , for no lift losses. This tip loss factor effects the forces and induction factors derived via BET and the momentum theory such that,

$$
\begin{gathered}
d T=F \rho U^{2} 4 a(1-a) \pi r d r \\
d Q=4 F a^{\prime}(1-a) \rho U \pi r^{3} \Omega d r \\
a^{\prime} /(1-a)=\sigma^{\prime} C_{l} /\left(4 F \lambda_{r} \sin \varphi\right) \\
a /(1-a)=\sigma^{\prime} C_{l} \cos \varphi /\left[4 F(\sin \varphi)^{2}\right] \\
C_{l}=4 F \sin \varphi \frac{\left(\cos \varphi-\lambda_{r} \sin \varphi\right)}{\sigma^{\prime}\left(\sin \varphi+\lambda_{r} \cos \varphi\right)} \\
a^{\prime} /\left(1+a^{\prime}\right)=\sigma^{\prime} C_{l} /(4 \mathrm{~F} \cos \varphi) \\
a=\frac{1}{\left[1+4 F(\sin \varphi)^{2} /\left(\sigma^{\prime} C_{l} \cos \varphi\right)\right]} \\
\left.U_{r e l}=\begin{array}{l}
U(1-a) / \sin \varphi=\frac{U}{\left(\sigma^{\prime} C_{l} / 4 F\right) \cot \varphi+\sin \varphi} \\
\left.a^{\prime}=1 /\left(4 \mathrm{~F} \cos \varphi /\left(\sigma^{\prime} C_{l}\right)\right)-1\right]
\end{array}\right]
\end{gathered}
$$


These small changes in the induction factors and relative wind calculations compound to have a significant effect on the power coefficient of the rotor which may now be calculated by,

$$
\begin{gathered}
C_{P}=\left(\frac{8}{\lambda^{2}}\right) \int_{\lambda_{h}}^{\lambda} F(\sin \varphi)^{2}\left(\cos \varphi-\lambda_{r} \sin \varphi\right)\left(\sin \varphi+\lambda_{r} \cos \varphi\right)[1 \\
\left.-\left(\frac{C_{d}}{C_{l}}\right) \cot \varphi\right] \lambda_{r}^{2} d \lambda_{r}
\end{gathered}
$$

With these theories and the helpful equations derived from them, a wind turbine rotor may not be both analyzed and designed to have the most efficient aerodynamic performance possible given appropriate airfoil characteristics.

\subsection{Tip Speed Ratio}

The tip speed ratio is of paramount importance with its effects reverberating throughout the wind turbine's design. After the power generation requirement is decided from the available wind energy and overall mechanical efficiency of the turbine's subsystems, the tip speed ratio is the next parameter to be decided upon and is involved in the calculation of nearly every other rotor design parameter including key design points such as the chord and twist distribution along the span of the blade as seen in the previous sections. Obviously the chord and twist distribution relate back to the maximum achievable lift and drag of the HAWT and thereby the effectiveness of the wind turbine in regards to capturing the available wind energy and transforming it into useable electrical power. 
As can be found in many references regarding wind energy and wind turbine operation [2], the ideal tip speed ratio of a HAWT with three blades used for power generation is between 4 and 10 depending on the design wind turbine operating conditions. When deciding on the ideal tip speed ratio for a certain set of wind turbine normal operating conditions several factors must be accounted for. For instance, the lower the tip speed ratio of the turbine the more torque the turbine can produce which is desirable for water pumping operations but lead to increased stress on rotating subsystems of the wind turbine like the rotor's mainshaft. A higher tip speed ratio lessens the amount of torque on the turbine's subsystems and is ideal for a wind turbine designed in conjunction with an electrical generator that requires a higher rotating speed in order to most efficiently generate electricity.

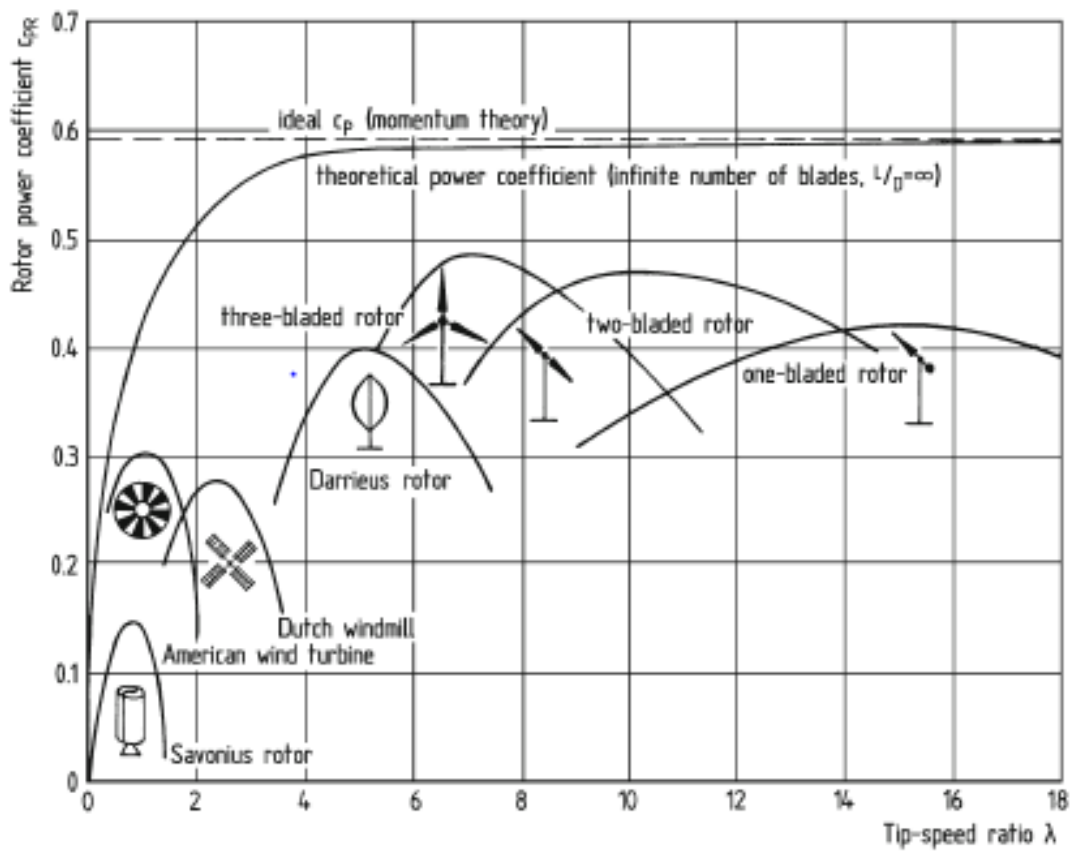

Figure 27 Rotor power coefficients versus tip speed ratio for a number of different wind turbine designs. [2] 
It can be seen in Figure 27 that the rotor power coefficient for a three bladed wind turbine rotor is highest between tip speed ratios of 5 to 11 with a peak with a tip speed ratio of 7. Currently the Cal Poly Wind Turbine's generator produces maximum power at 200 revolutions per minute. Without any gearbox implemented between the rotor and the generator this would generate a tip speed ratio of approximately 54 in accordance with the rotor radius and average wind speed at the turbine site. For consideration the 45 meter rotor radius Vestas V90 wind turbine which produces 2 megawatts of energy at a nominal operating speed of 14.5 revolutions per minute utilizes a tip speed ratio of 5.7.

Therefore this rotor system, when experiencing an average wind speed of 8 miles per hour, will be designed to produce a tip speed ratio of 7 in order to both maximize the efficiency and lessen the stresses of the turbine. However, this will make a gearbox between the rotor output shaft and the generator main-shaft necessary since the permanent magnet induction generator currently being utilized requires a rotational input speed of 200 revolutions per minute in order to produce the maximum amount of power. This gearbox will be a challenge in itself to design and much research has been done on the subject of planetary gearboxes designed specifically for wind turbine usage.

This lower tip speed ratio will then lower the normal operating condition rotor speed to 26 revolutions per minute, with an 8 mile per hour wind, thereby lowering the aerodynamic and inertial forces affecting the larger 9.23 meter blades. A quick gear ratio calculation with inversely proportional rotating speeds 
to gear teeth number suggest a gear ratio of $1: 7.7$ would be appropriate to increase the generator shaft speed to 200 revolutions per minute.

\subsection{Optimum Rotor Blade Design}

By applying the theories and equations defined in the previous sections a general rotor design procedure can now be applied to develop the design for an aerodynamically optimal wind turbine rotor system. The first step in this process is to clearly define the basic wind turbine operating parameters desired and available. For instance, the generator rated power, $\mathrm{P}$, to be generated at a particular wind velocity, $\mathrm{U}$, the density of the air present at the wind turbine site, $\rho$, the mechanical efficiency of the rotor system, $\eta$, and a desired coefficient of power can be used to then determine the necessary radius of the swept rotor area using the equation:

$$
P=C_{P} \eta\left(\frac{1}{2}\right) \rho \pi R^{2} U^{3}
$$

For this project it will be assumed that the mechanical efficiency of the wind turbine is $100 \%$, the air density shall be measured at sea level and given as 1.225 kilograms per cubic meter, the wind speed to be designed for is the average yearly wind speed at the Cal Poly Wind Turbine's location of 3.576 meters per second, and the wind turbine's generator rated power is 3000 watts. Therefore, by rearranging this equation the required rotor radius is shown to be,

$$
R=\sqrt{\frac{P}{C_{P} \eta(1 / 2) \rho \pi U^{3}}}[\mathrm{~m}]
$$

which results in a required rotor radius of 9.23 meters. 
With the tip speed ratio, number of blades, and airfoils already decided upon the empirical data for the chosen airfoils is examined very thoroughly and from a variety of reliable sources. This examination includes determining the maximum coefficients of lift and drag, the coefficient of lift and drag versus the angle of attack of the relative wind, and the ratio of the coefficient of lift to drag. These values will be used to determine the initial blade shape that will then be refined to produce an optimized blade geometry given wake rotation, tip loss effects, etc. With the needed data readily available, the blade is divided into $\mathrm{N}$ elements, the local tip speed ratio, relative wind angle, chord length, blade twist, and angle to the relative wind including a design angle of attack can now be calculated using the following equations, respectively:

$$
\begin{gathered}
\lambda_{r, i}=\lambda\left(\frac{r_{i}}{R}\right) \\
\varphi_{i}=\left(\frac{2}{3}\right) \tan ^{-1}\left(\frac{1}{\lambda_{r, i}}\right) \\
c_{i}=\frac{8 \pi r_{i}}{B C_{l, \text { design }, i}}\left(1-\cos \varphi_{i}\right) \\
\theta_{T, i}=\theta_{p, i}-\theta_{p, 0} \\
\varphi_{i}=\theta_{p, i}+\alpha_{\text {design }, i}
\end{gathered}
$$

The subscript " $\mathrm{i}$ " describes the particular blade section being examined which, for this project, totals 20 equal sections from the axis of the rotor's rotation to the blade tip. These sections are 0.462 meters in length with the first section being disregarded since the first full airfoil does not take shape until the second section at a distance of 0.923 meters from the axis of rotation, or $10 \%$ of the overall rotor 
radius. An overall rotor blade shape can now be defined with these key parameters and will be relied upon heavily for the rest of this project to determine key parameters including the aerodynamic loads on the rotor blade with complete details found in Appendix A.

An important design decision when performing these initial calculations is when to switch from the root airfoil to the outer airfoil and requires much consideration regarding how the blades will be operated and under what external conditions. The root sections of the rotor blade must be thick enough to withstand the large bending moment imposed by the thrust loading caused by the lift exerted on the outer blade sections but a balance must be struck between the number of aerodynamically and structurally driven airfoil sections. It is common practice to allow for $25 \%-30 \%$ of the rotor blade to consist of the thicker airfoil section hence this project will utilize the thicker NREL S823 airfoil design for the first $30 \%$ of the rotor blade length, or $\mathbf{2 . 7 6 9}$ meters, with a gradual transition to the S822 airfoil. The maximum chord length and twist angle is at the very first airfoil section with values of 1.276 meters and $25^{\circ}$ respectively, and a chord length of 0.301 meters with $0^{\circ}$ of twist at the blade tip. A graphical representation of the rotor blade chord and twist distribution can be seen in Figure 28 . 


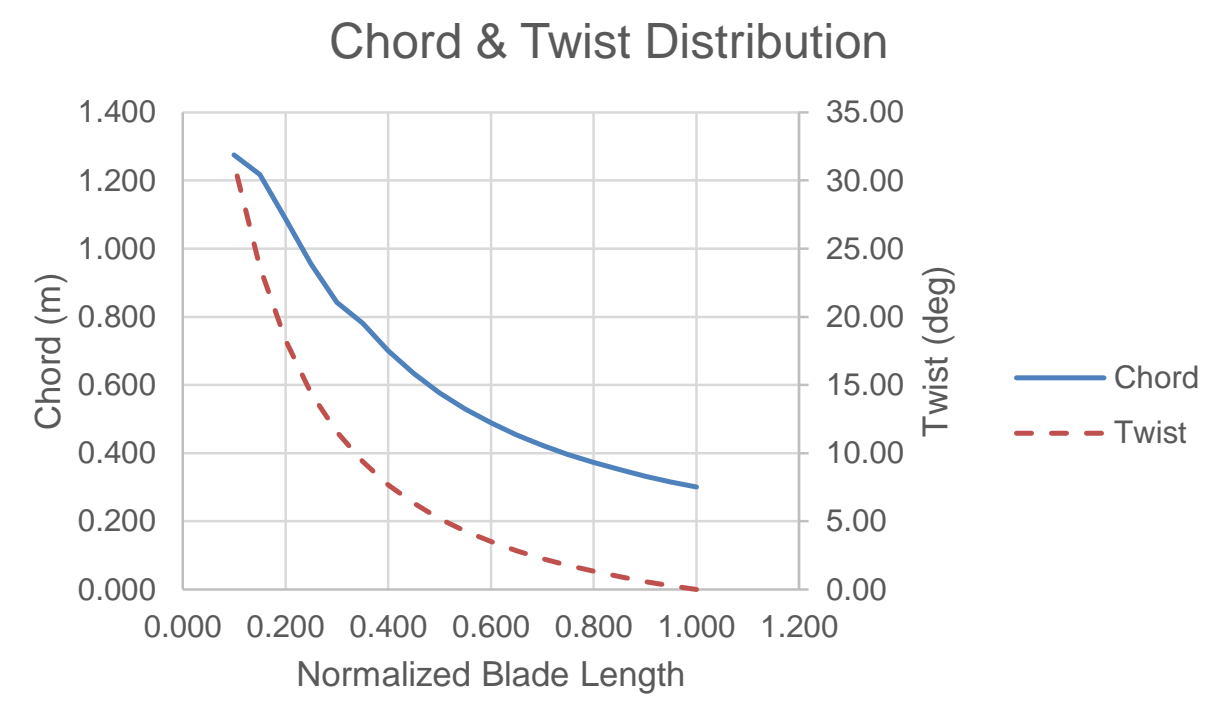

Figure 28 Finalized chord and twist distribution of the optimized blade design. At this point the chord length and blade twist distribution may be linearized to provide for a greater ease of manufacturability which is a necessary procedure for blades with large production requirements. However for this project these parameters will be unaltered from their optimized values due to the fact that the total number of blades to be manufactured per the design outlined in this project will be very limited.

During the analysis of the blade sections it is noted that towards the end of the blade the lift coefficient and induction factors calculated by the strip method varies drastically from the empirical data. Therefore, sections 14 to 20 of the blade were analyzed using the iterative method to determine the proper induction factors to yield the most accurate results. This method involves an initial guess of the induction factors which are then used to calculate a new angle of attack value which, consequently, results in a more accurate analysis of the lift coefficient, tip loss factor, and local solidity for each blade section. For the initial 
guess of the induction factor values one could use the values from an adjacent blade section, previous iterations values, or an estimate. For this project, the initial guess was placed at 0.333 for the axial induction factor with the angular induction factor being calculated with the relationship equation 19 from the momentum theory described previously. For the $j^{\text {th }}$ iterations the following equations' notations were made use of,

$$
\begin{aligned}
& \varphi_{i, j}=\left(\frac{2}{3}\right) \tan ^{-1}\left(\frac{1}{\lambda_{r, i}}\right) \\
& \left.a_{i, j}=\frac{1}{\left[1+4 F\left(\sin \varphi_{i, j}\right)^{2} /\left(\sigma_{i, \text { design }}^{\prime} C_{l, \text { design }} \cos \varphi_{i, j}\right)\right.}\right] \\
& a_{i, j}^{\prime}=\frac{1-a_{i, 1}}{\left(4 a_{i, j}\right)-1} \\
& \tan \varphi_{i, j}=\frac{U\left(1-a_{i, j}\right)}{\Omega r\left(1+a_{i, j}^{\prime}\right)}=\frac{1-a_{i, j}}{\left(1+a_{i, j}^{\prime}\right) \lambda_{r, i}} \\
& F_{i, j}=\left(\frac{2}{\pi}\right) \cos ^{-1}\left[-\left\{\frac{(B / 2)\left[1-\left(r_{i} / R\right)\right]}{\left(r_{i} / R\right) \sin \varphi_{i, j}}\right\}\right]
\end{aligned}
$$

With the induction factors, angle of relative wind, and the tip loss correction factor all calculated for whichever iteration the lift and drag coefficients, $\mathrm{C}_{\mathrm{l}, \mathrm{i}, \mathrm{j}}$ and $\mathrm{C}_{\mathrm{d}, \mathrm{i}, \mathrm{j}}$, from the given airfoil data by utilizing,

$$
\alpha_{i, j}=\varphi_{i, j}-\theta_{p, i}
$$

and for the thrust coefficient, 


$$
C_{T, i, j}=\frac{\sigma_{i}^{\prime}\left(1-a_{i, j}\right)^{2}\left(C_{l, i, j} \cos \varphi_{i, j}+C_{d, i, j} \sin \varphi_{i, j}\right)}{\left(\sin \varphi_{i, j}\right)^{2}}
$$

In order to determine whether or not the thrust value and induction factors are reasonable for that particular blade section a basic rule of if $\mathrm{C}_{\mathrm{T}, \mathrm{i}, \mathrm{j}}<0.96$ then the induction factors must be updated by,

$$
\left.a_{i, j+1}=\frac{1}{\left[1+4 F\left(\sin \varphi_{i, j}\right)^{2} /\left(\sigma_{i, \text { design }}^{\prime} C_{l, \text { design }} \cos \varphi_{i, j}\right)\right.}\right]
$$

and,

$$
a_{i, j+1}^{\prime}=\frac{1-a_{i, j+1}}{\left(4 a_{i, j+1}\right)-1}
$$

Or if $\mathrm{C}_{\mathrm{T}, \mathrm{i}, \mathrm{j}}>0.96$ :

$$
\begin{gathered}
a_{i, j}=\left(\frac{1}{F_{i, j}}\right)\left[0.143+\sqrt{0.0203-0.6427\left(0.889-C_{T, i, j}\right)}\right] \\
a_{i, j+1}^{\prime}=\frac{1}{\frac{4 F_{i, j} \cos \varphi_{i, j}}{\sigma \prime C_{l, i, j}}-1}
\end{gathered}
$$

This process is then continued until the induction factor calculations fall within an acceptable tolerance of their previous iteration which is defined as being within 0.002 of the previous axial induction factor. Finally, an estimate of the power coefficient is determined by summing the power coefficients of all the blade sections analyzed much like equation 58 , 


$$
\begin{gathered}
C_{P}=\left(\frac{8}{\lambda N}\right) \sum_{i=k}^{N} F_{i}\left(\sin \varphi_{i}\right)^{2}\left(\cos \varphi_{i}-\lambda_{r, i} \sin \varphi_{i}\right)\left(\sin \varphi_{i}+\lambda_{r, i} \cos \varphi_{i}\right)[1 \\
\left.-\left(\frac{C_{d}}{C_{l}}\right) \cot \varphi_{i}\right] \lambda_{r, i}^{2}
\end{gathered}
$$

Where "k" is an indexing operator for the first blade section comprised of a scaled airfoil, which for this project is at section 2 of the 20 blade equal blade sections. This power coefficient equation with its summation of the power coefficient for each individual blade section yields a power coefficient of $51.8 \%$ which is $11.8 \%$ higher than the power coefficient originally incorporated into the design and only $7.46 \%$ shy of the ideal Betz Limit. The calculated power coefficient generated here is significantly higher than that of a modern turbine used in industry due to the fact that it includes only the tip loss factor and utilizes the maximum values of the lift and drag coefficients. Therefore, it can be expected that this power coefficient is realistically unobtainable but is a rough approximation of the actual power coefficient under ideal operating conditions.

Although thrust coefficient values were calculated for each blade section the IEC recommends using a thrust coefficient values of 1.3 for the aerodynamic force calculations and so will be used for this project.

\subsubsection{Blade Root and Local Blade Reference System}

In order to communicate project details effectively reference systems must be imposed which correspond to important aspects of HAWT rotor systems. A typical HAWT requires many reference systems, in regards to subsystems and 
their respective functions such as a rotating or not rotating reference system for the nacelle and rotor, however this project will only need two.

The blade root reference system, see Figure 29, rotates with the turbine and has its origin at the blade root center, the x-axis is in the downwind direction, the $y$ axis is in the tangential direction defined from the leading to trailing edge assuming no blade twist angle, and the z-axis is in the radial direction directed towards the blade tip. The $y-z$ plane of the blade root reference systems is generally referred to as the rotor plane, with zero rotor cone angle, and is referred to in the blade element and momentum theory as the plane in which the aerodynamic forces are calculated.

The second reference system required for this project is the local blade reference system which has its origin at the leading edge of whichever blade section is being investigated, the $x$-axis is perpendicular to the chord line and positive in the downwind direction with zero blade twist, the $y$-axis follows the chord line from the leading to the trailing edge, and the z-axis is directed along the rotor blade axis towards the blade tip. It should be noted that the origin and orientation of the local blade reference system can move due to blade bending or torsion. This reference system is very useful when performing structural spar design calculations because the local blade reference system is coincident with the primary axes used to define the shear web and spar cap.

The aerodynamic forces calculated previously, which are defined in the blade root reference system, must be transformed with a two-dimensional 
transformation matrix to the local blade reference system and then used to determine how much composite material is required which may then be modeled with FEA later in the project. Therefore, Table 3 and Table 4 describe the three forces and moments acting on the blade root and local reference system and their descriptions which will be referenced throughout this report. Further, information regarding the terminology and reference systems used in the wind energy industry may be found in the bibliography [3].

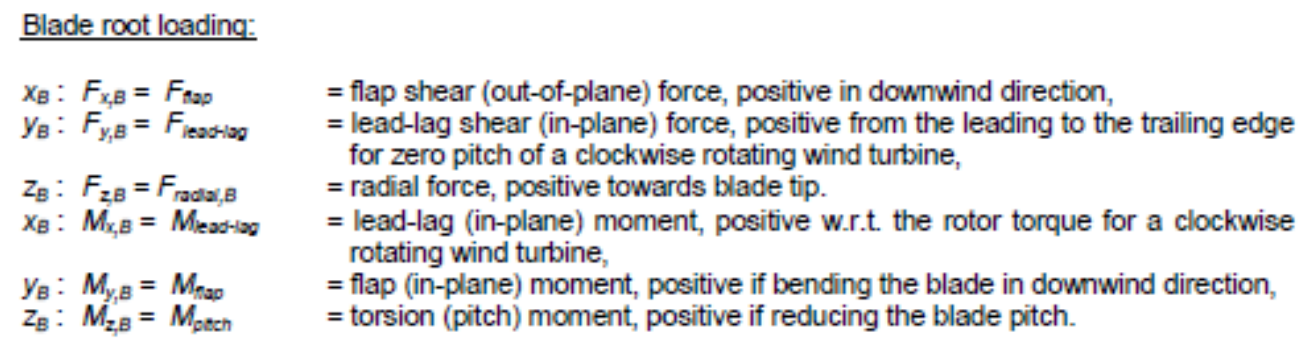

= flap shear (out-of-plane) force, positive in downwind direction,

= lead-lag shear (in-plane) force, positive from the leading to the trailing edge for zero pitch of a clockwise rotating wind turbine,

$=$ radial force, positive towards blade tip.

= lead-lag (in-plane) moment, positive w.r.t. the rotor torque for a clockwise rotating wind turbine,

= flap (in-plane) moment, positive if bending the blade in downwind direction,

$=$ torsion (pitch) moment, positive if reducing the blade pitch.

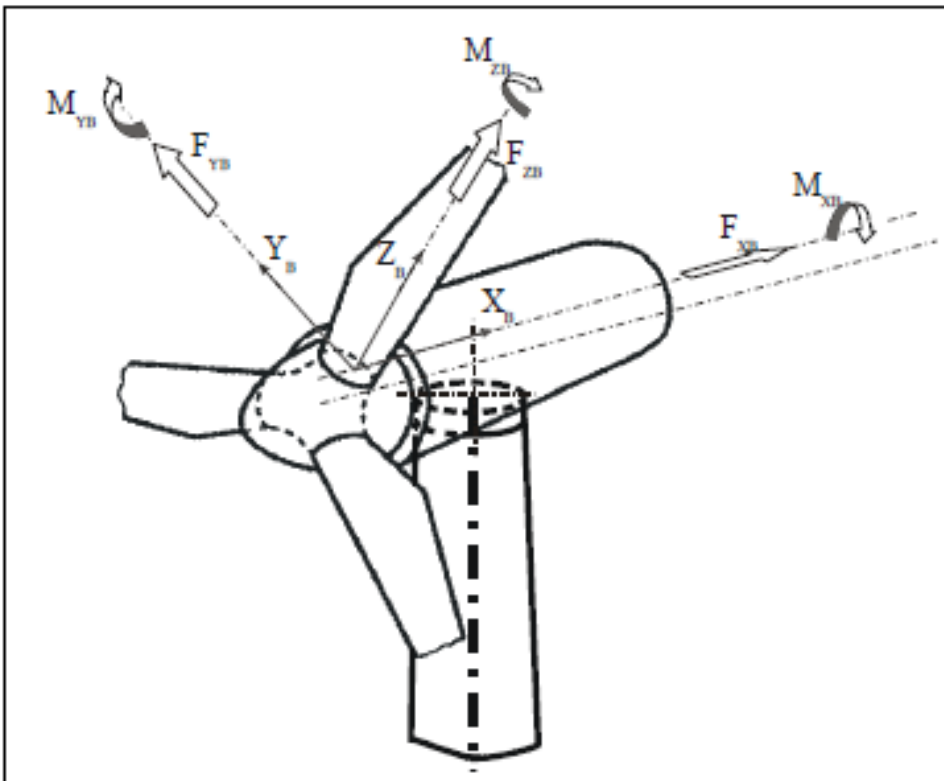

Figure 18: Blade root reference system [4].

Figure 29 Blade root reference system and forces shown. The BET calculates aerodynamic forces in this reference system. 
Table 3 Blade root reference system force and moment descriptions.

\begin{tabular}{|c|c|c|}
\hline \multicolumn{3}{|r|}{ Blade Root Reference System } \\
\hline $\mathrm{X}_{\mathrm{B}}$ & $F_{x, B}=F_{\text {flap }}$ & $\begin{array}{c}=\text { flap shear force, I.E. out-of-plane force, positive in } \\
\text { the downwind direction }\end{array}$ \\
\hline $\mathrm{y}_{\mathrm{B}}$ & $\mathrm{F}_{Y, \mathrm{~B}}=\mathrm{F}_{\text {lead-lag }}$ & $\begin{array}{l}\text { = lead-lag shear, I.E. in-plane force, positive from the } \\
\text { leading edge to the trailing edge for zero blade twist }\end{array}$ \\
\hline $\mathrm{Z}_{\mathrm{B}}$ & $\mathrm{F}_{\mathrm{z}, \mathrm{B}}=\mathrm{F}_{\text {radial }, \mathrm{B}}$ & $=$ radial force, positive towards blade tip \\
\hline $\mathrm{X}_{\mathrm{B}}$ & $\mathrm{M}_{\mathrm{x}, \mathrm{B}}=\mathrm{M}_{\text {lead-lag }}$ & $\begin{array}{c}\text { = lead-lag, I.E. in-plane moment, positive with regards } \\
\text { to rotor torque for a wind turbine system operating } \\
\text { clockwise }\end{array}$ \\
\hline $\mathrm{y}_{\mathrm{B}}$ & $\mathrm{M}_{\mathrm{y}, \mathrm{B}}=\mathrm{M}_{\mathrm{flap}}$ & $\begin{array}{l}=\text { flap, I.E. in-plane moment, positive if the blades bend } \\
\text { in the downwind direction }\end{array}$ \\
\hline$z_{B}$ & $\mathrm{M}_{\mathrm{z}, \mathrm{B}}=\mathrm{M}_{\text {pitch }}$ & $\begin{array}{c}=\text { torsion, I.E. pitch moment, positive if the torsion } \\
\text { twists the blade to reduce the blade's pitch }\end{array}$ \\
\hline
\end{tabular}


Table 4 Local blade reference system force and moment descriptions.

\begin{tabular}{|c|c|c|}
\hline \multicolumn{3}{|r|}{ Local Blade Reference System } \\
\hline $\mathrm{X}_{\text {rot }}$ & $F_{x, \text { rot }}=F_{\text {flat }}$ & $\begin{array}{c}=\text { flat shear force positive in the downwind direction with no } \\
\qquad \text { blade twist }\end{array}$ \\
\hline $\mathrm{Y}_{\text {rot }}$ & $F_{Y, \text { rot }}=F_{\text {edge }}$ & $=$ edge shear force, positive towards the trailing edge \\
\hline$Z_{\text {rot }}$ & $\mathrm{F}_{\mathrm{z}, \mathrm{rot}}=\mathrm{F}_{\text {radial, rot }}$ & $=$ radial force, positive towards blade tip \\
\hline $\mathrm{X}_{\text {rot }}$ & $\mathrm{M}_{\mathrm{x}, \mathrm{rot}}=\mathrm{M}_{\mathrm{edge}}$ & $=$ edge moment, positive in the rotor torque direction \\
\hline $\mathrm{Y}_{\text {rot }}$ & $M_{y, \text { rot }}=M_{\text {flat }}$ & $=$ flat moment, positive if blade is being bent downwind $\left(x_{B}\right)$ \\
\hline$Z_{\text {rot }}$ & $M_{z, \text { rot }}=M_{\text {pitch, rot }}$ & $\begin{array}{l}=\text { torsional pitch moment, positive if reducing the blade's } \\
\qquad \text { pitch }\end{array}$ \\
\hline
\end{tabular}

\subsection{Structural Loading}

There are many types of loading that any HAWT will experience which include aerodynamic loads caused by the lift-driven nature of the turbine as well as large wind gust forces acting on the parked rotor, operational forces such as the gyroscopic forces produced as the rotor is yawed into the wind, inertial loading such as the centrifugal forces caused by the rotor accelerating or decelerating 
quickly, gravity forces caused by the intrinsic weight of the blades, and many others, some of which are shown in Figure 30.

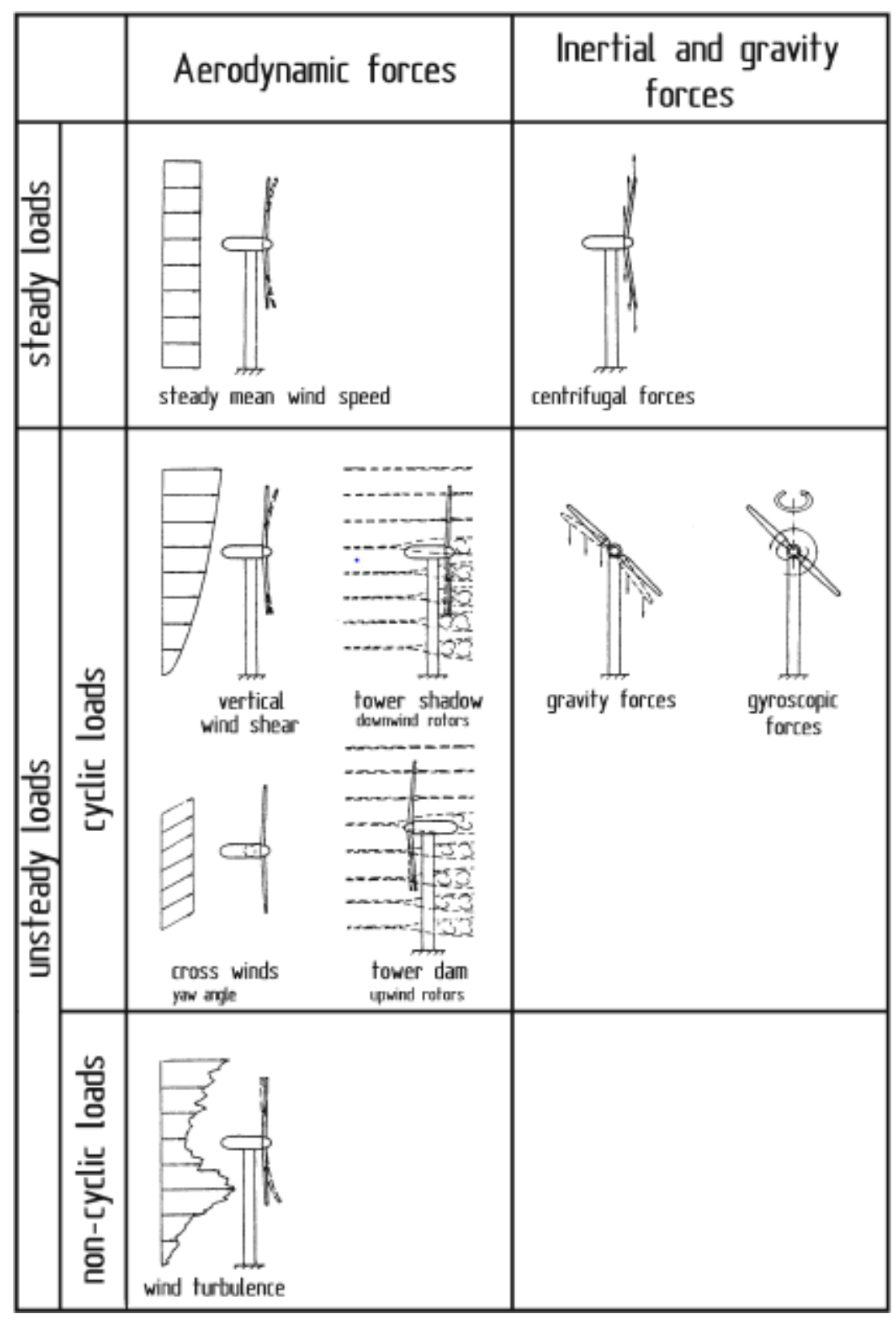

Figure 30 Visual representation and summary of several different types of possible rotor blade loading. 
Three different loading scenarios were modeled including a normal operational model operating with 8 mile per hour wind speeds, a normal operational model operating with 11 mile per hour wind speeds, and a parked rotor subjected to a wind gust of 33.5 mile per hour wind speeds. A summary of the major loads for each scenario is presented in Table 5.

Table 5 Summary of aerodynamic loads for each loading scenario modeled. Note, loads include an IEC specified safety factor of 1.3.

\begin{tabular}{|c|c|c|c|c|c|}
\hline $\begin{array}{l}\text { Loading } \\
\text { Scenario }\end{array}$ & $\begin{array}{l}\text { Total Thrust } \\
\text { Loading } \\
\text { (N) }\end{array}$ & $\begin{array}{c}\text { Total } \\
\text { Tangential } \\
\text { Loading } \\
\text { (N) }\end{array}$ & $\begin{array}{c}\text { Maximum } \\
\text { Flapwise } \\
\text { Bending } \\
\text { Moment } \\
\left(N^{*} \mathrm{~m}\right)\end{array}$ & $\begin{array}{c}\text { Maximum } \\
\text { Edgewise } \\
\text { Moment } \\
\quad\left(N^{*} m\right)\end{array}$ & $\begin{array}{l}\text { Rotor } \\
\text { Torque } \\
\left(\mathrm{N}^{*} \mathrm{~m}\right)\end{array}$ \\
\hline $\begin{array}{l}\text { Normal } \\
\text { Operation } \\
\text { at } 8 \mathrm{mph}\end{array}$ & 4718 & 562 & 25662 & 2427 & 536 \\
\hline $\begin{array}{l}\text { Normal } \\
\text { Operation } \\
\text { at } 11 \mathrm{mph}\end{array}$ & 9220 & 1100 & 50149 & 4742 & 1046 \\
\hline $\begin{array}{l}\text { Parked } \\
\text { Rotor at } \\
33.5 \mathrm{mph}\end{array}$ & 1250 & $\mathrm{~N} / \mathrm{A}$ & 5770 & $\mathrm{~N} / \mathrm{A}$ & 0 \\
\hline
\end{tabular}




\subsubsection{Types of HAWT Loading Scenarios}

This project will focus mainly on the aerodynamic forces generated during normal and gust wind conditions, however gravity will also be included with regards to a static loading of the blade. Aerodynamic forces acting on the rotor are one of the most important loading aspects to investigate in HAWT design and have a large dependence on the blade shape and operating speed of said HAWT which are also calculated in this project. Investigating and quantifying the many loading scenarios encountered during the lifespan of a typical HAWT has been the focus of many engineers for many years but the scope of this project does not allow for any further investigation other than a basic loading analysis.

Gravity loading is the main culprit of fatigue failure in HAWT's due to the rotation of the rotor blades causing an alternating loading effect depending on the position of the rotor blade in the rotor revolution cycle. For instance, if an individual blade is examined as it completes one full rotation cycle, starting at the three o'clock position which is horizontal with the ground, it can be seen that the direction of the gravity load vector is reversed once the blade reaches the six o'clock position. This alternating loading causes fatigue stress issues that must be addressed in a HAWT is to not fail prematurely, with most HAWT's designed to operate for the IEC specified minimum of 20 years.

The inertial forces generated are generally only of major concern when the rotor is either rotating very quickly or the rotor swept area has a radius of 10 meters or greater [15]. Although the rotor blades designed for this project are neither large enough nor rotating fast enough for the centrifugal forces to be of much concern, 
these forces will nonetheless be added in the FEA model due to the simplicity of including them.

Eccentric loading scenarios will also be neglected for the purposes of this project due to the unpredictable nature of these types of loading scenarios. Anything from incoming transverse wind gusts causing large yawing accelerations or the magnitude of the mechanical braking loads are certainly required information to ensure no physical injury to bystanders or any type of HAWT failure occurs but will be excluded from this project. Previously in this chapter equations were derived which represent the normal and tangential forces acting at the aerodynamic center of blade sections with respect to the blade root reference system. These forces are calculated assuming ideal conditions and a rotor which is perfectly yawed into the wind which may then be transformed into the local blade reference system to assist the spar design calculations, for full aerodynamic loading results see appendix $A$. These loads will be the most significant loads applied in the FEA modeling portion of this project which will then be used to gauge the magnitude and location of stresses and strains caused in the blade structure.

\subsubsection{Normal HAWT Operation Loading}

The thrust loads generated while the turbine is in operation are by far the largest aerodynamic load, shown in Figure 31, with the highest thrust loads occurring at the outer most blade sections. Tangential loads are significantly less than the thrust loading and are consistent along the length of the rotor blade and taper off to zero towards the blade tip due to tip loss effects. 


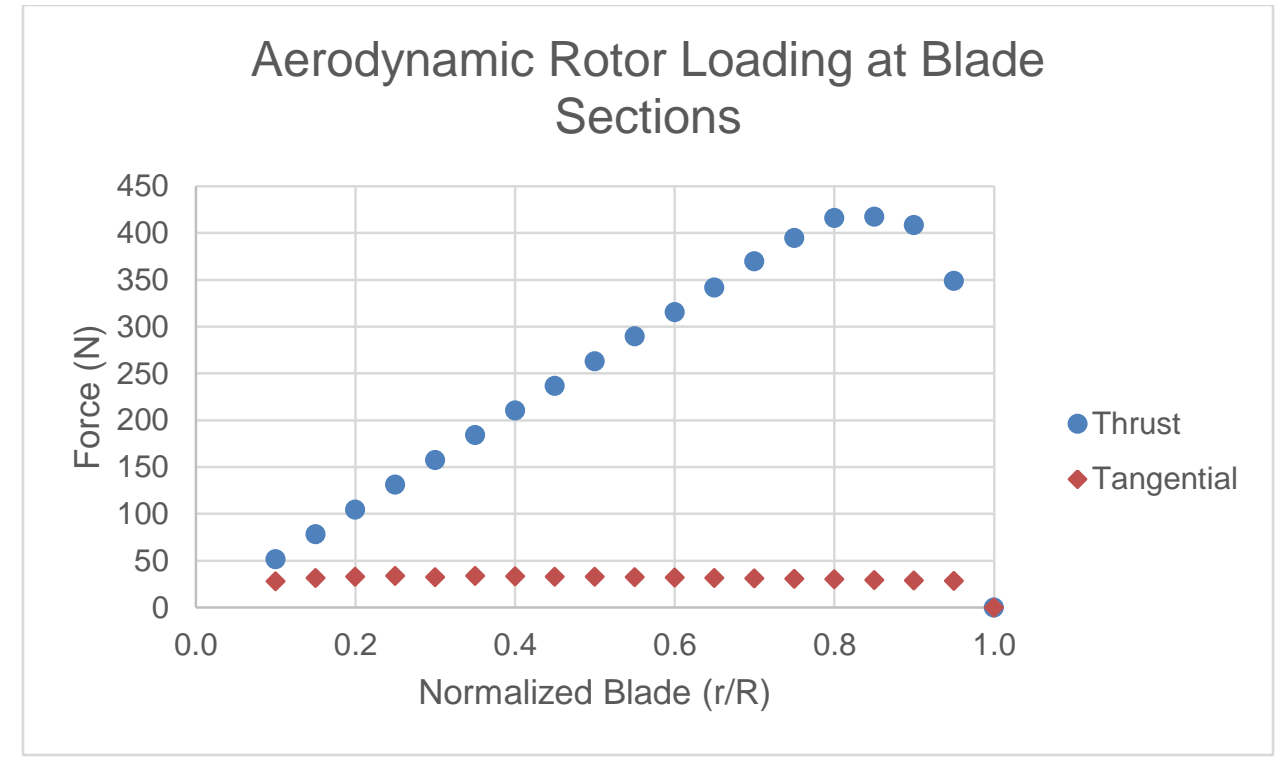

Figure 31 Aerodynamic forces acting on the rotor during normal operation at the design wind speed of 8 miles per hour.

Due to the fact that a rotor blade essentially acts as a twisted, cantilever beam the large thrust loading towards the outer end of the blade, where it is most aerodynamically efficient and produces the largest lift forces, create a large bending moment at the root of the blade. In the blade root reference system this moment is referred to as the flapwise bending moment as seen in Figure 31 above. During normal operation at the design wind speed of 8 miles per hour the "flapwise" bending moment at the root of the blade is approximately 25,600 Newton-meters, or 19,000 foot-pounds. When transformed into the local blade reference system this moment is referred to as the "flatwise" bending moment and is not much less at 25,400 Newton-meters, or 18,745 foot-pounds. The effect of the transformation of forces between the blade root and the local blade reference systems may be seen in Figure 32 below. 


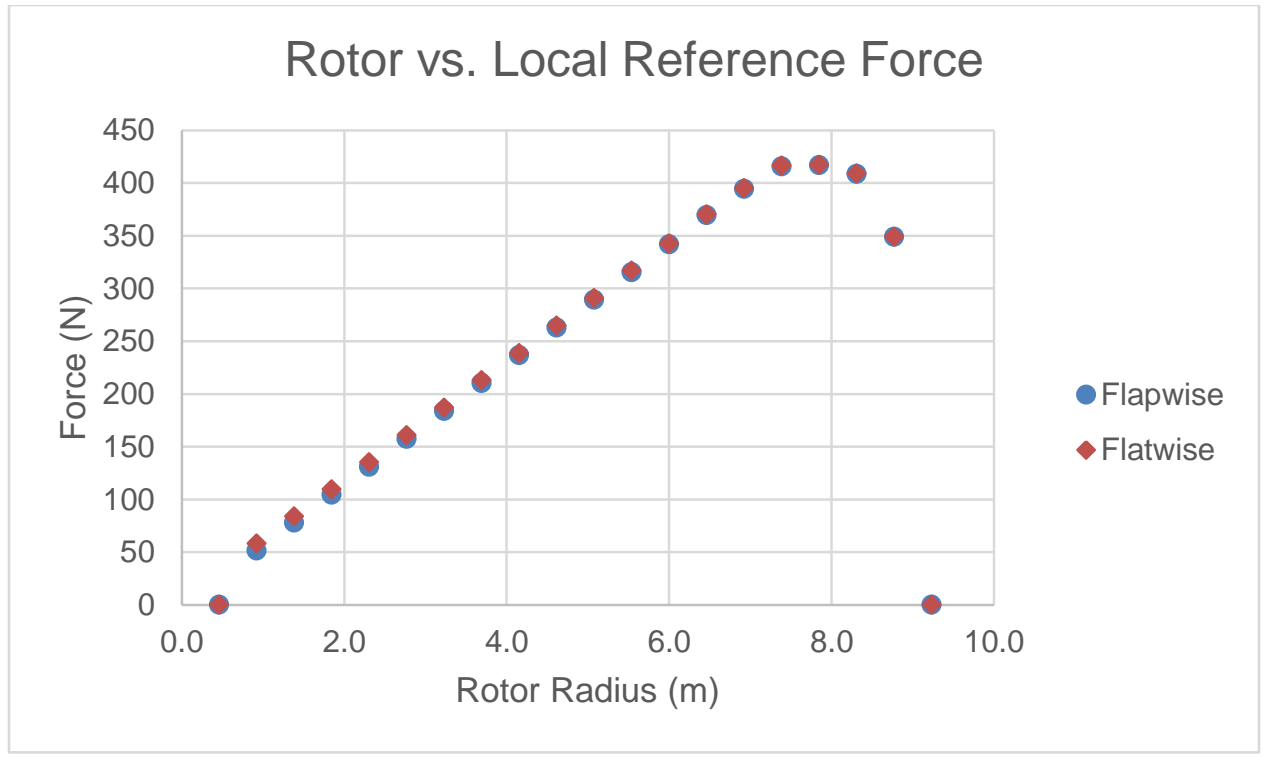

Figure 32 Flapwise and flatwise rotor forces at the design wind speed of 8 miles per hour. Note the slight discrepancy between the two near the blade root where the blade twist is the most severe.

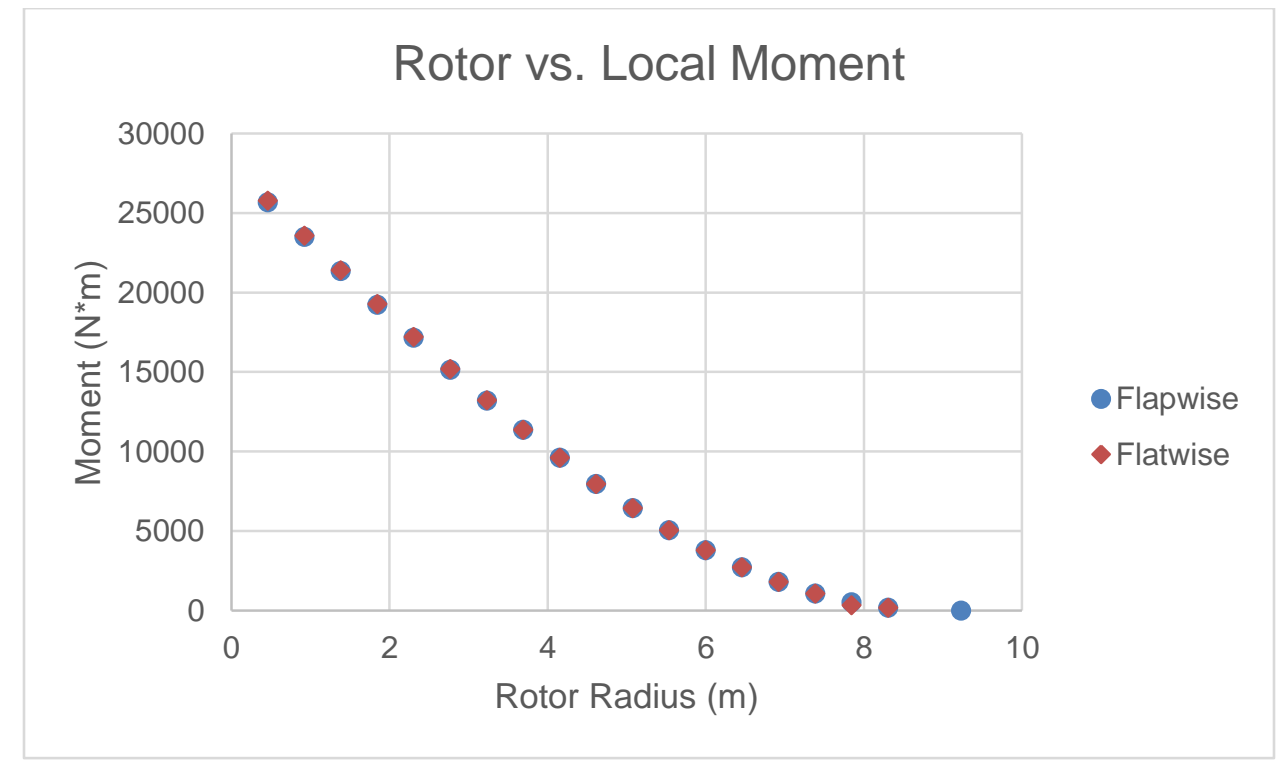

Figure 33 Flapwise and flatwise moments induced by the aerodynamic thrust forces generated during normal rotor operation at the design wind speed of 8 miles per hour.

It can be seen that there is slight difference between the flapwise and flatwise forces near the blade root where the blade section twist angle is highest but 
these differences are shown to be insignificant when the flapwise and flatwise moments are compared as shown above in Figure 33. For comparison, the leadlag and edgewise forces and the moments which they generate along the length of the blade are graphed in Figure 34 below.

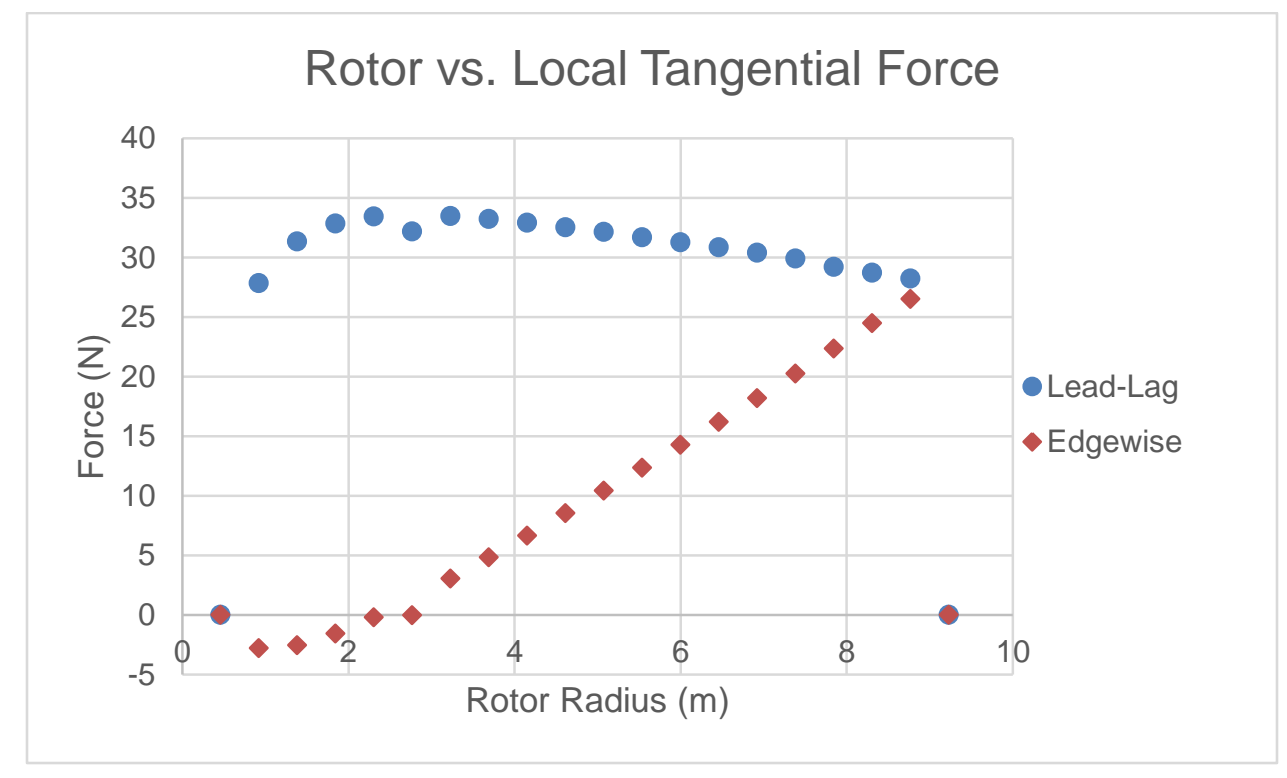

Figure 34 Lead-lag and edgewise forces calculated for normal rotor operation at a the design wind speed of 8 miles per hour. Negative forces caused by severe blade twisting near the rotor root. 


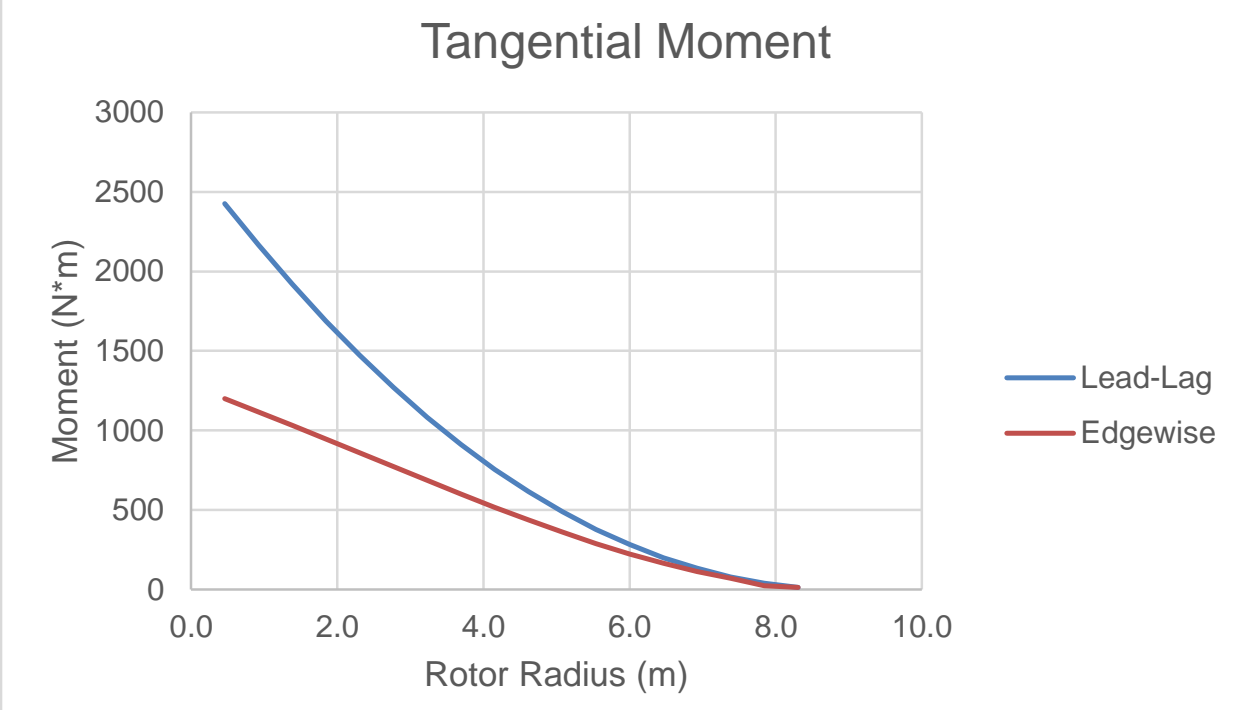

Figure 35 The tangential, or in-plane, moment generated along the blade due to tangential aerodynamic forces at the design wind speed of 8 miles per hour. Note the small magnitude of these moments when compared to the thrust induced flapwise bending moment shown previously.

It can be seen that the total lead-lag force is approximately 8.5 times less than the flapwise force acting on the rotor and the maximum lead-lag moment is 1200 Newton-meters, or 885 foot-pounds, in the blade local reference system. Due to the fact that the edgewise moment is over an order of magnitude less than the flatwise bending moment, it shall be neglected for the purposes of this project.

The aerodynamic loads generated during normal operation increase exponentially due to the relative wind speed being squared in the thrust calculations, as seen in equation 37 . Therefore, it is critical that the induction generator and mechanical braking system be able to control the rotational speed of the turbine otherwise severe loading may cause catastrophic failure. Although high lift coefficients are desirable for a HAWT rotor blade, the danger of the rotor generating too much lift which may overcome the mechanical brake and resistive 
forces from the generator can cause serious problems. However, the NREL SSeries S822 airfoil has a lift-restrained design that is beneficial to the turbine which allows the blade performance and lift force to be more predictable. Aerodynamic loading of an individual rotor blade, as applicable to a three bladed HAWT system, for a range of wind speeds may be seen in Figure 36 below.

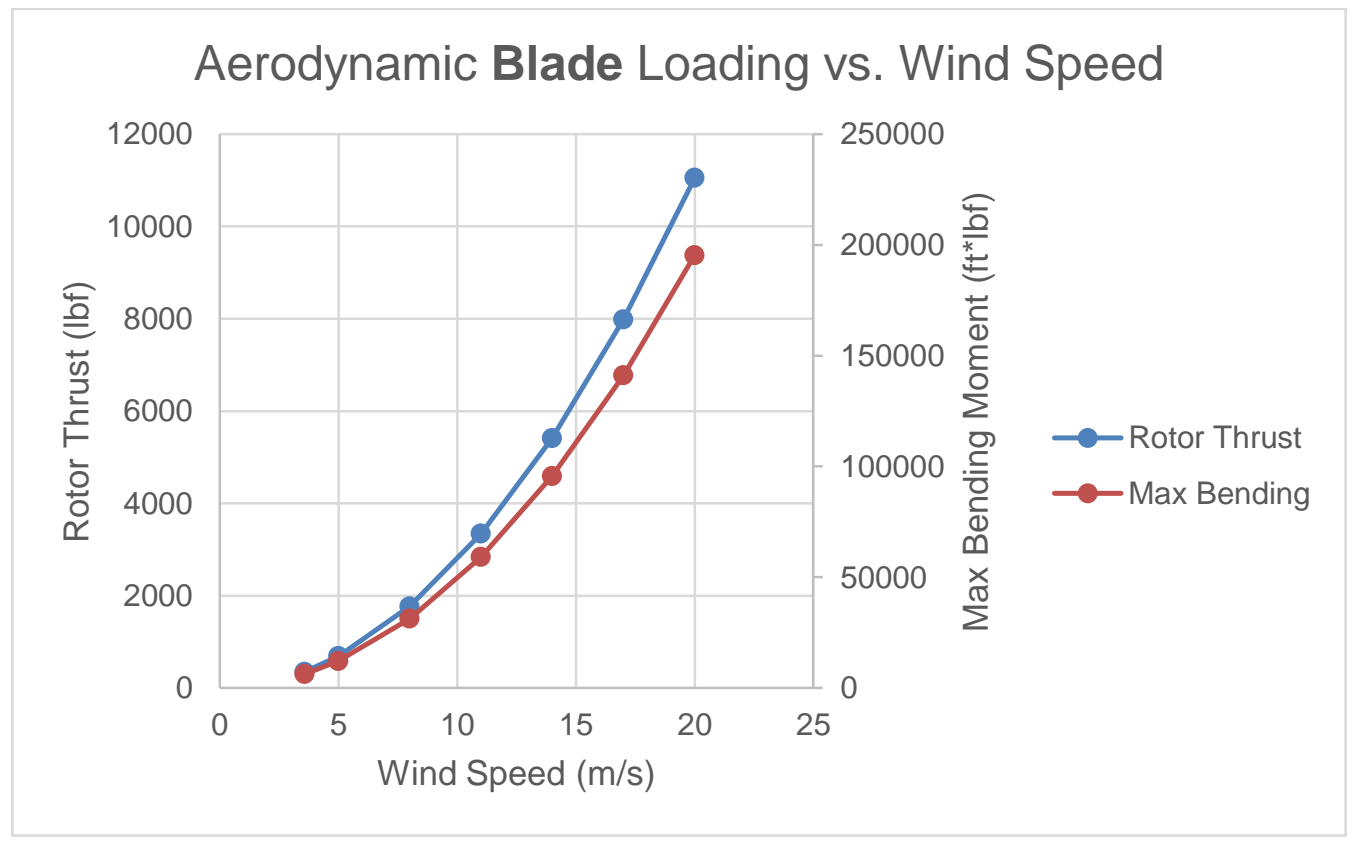

Figure 36 Rotor thrust forces and maximum flapwise bending moment generated due to increasing wind speeds.

\subsubsection{Parked Rotor Subject to Wind Gust Loading}

Aerodynamic loading due to the rotor being parked, or with zero rotor rotation and a mechanical brake being applied to the mainshaft, in extreme wind gust scenarios also needs to be examined. Gust loads are calculated by reviewing meteorological data and calculating the amount of dynamic force implemented onto the parked blade during instances of extreme wind gusts utilizing the equation, 


$$
\text { Dynamic Force }=\frac{1}{2} \rho U^{2} A
$$

The calculated dynamic force imparted onto the parked rotor for different wind speeds are shown in Table 6 below, note that these forces are representative of the forces acting on the entire rotor. In order to calculate the forces acting on an individual blade the rotor force is divided by the number of blades, three.

Table 6 Summary of aerodynamic forces imparted onto a parked rotor at varying wind gust speeds.

\begin{tabular}{|c|c|c|}
\hline Wind Speed (m/s) & Force (N) & Force (lbf) \\
\hline 5 & 139 & 31 \\
\hline 10 & 555 & 125 \\
\hline $\mathbf{1 5}$ & $\mathbf{1 2 4 9}$ & $\mathbf{2 8 1}$ \\
\hline 20 & 2221 & 780 \\
\hline 25 & 3470 & 1123 \\
\hline 30 & 4997 & \\
\hline
\end{tabular}

Wind gusts at the location of the CPWPRC can reach fairly high speeds, it is not uncommon for wind speeds to exceed 30 miles per hour, or 13.4 meters per second, with consistent speeds above 10 miles per hour at times. Therefore, the gust loading scenario which will be examined in this project will consist of a 15 meter per second gust acting upon a stationary rotor which amounts to a total force acting in the flapwise direction of 1250 Newtons, or 281 pounds-force, on the rotor or rather 416 Newtons, or 94 pounds-force, per blade. 


\subsection{Blade Structural Design}

The International Electrotechnical Commission (IEC) defines the loading requirements for wind turbines used in the wind energy industry by the wind speed that the turbine is designed to operate with and by the turbulence characteristics of the incoming wind. Other conditions are also taken into account including the external conditions, such as ice build-up and salt content in the air, and equipment faults such as rotor brake failure. These requirements ensure that turbines which are in operation, usually in large wind farms, near people or buildings have very little chance of failing and causing harm to any people or property. However, the CPWPRC is a single, small, research based HAWT located in an isolated area and will not subjected to such a strict regimen of wind speed class requirements.

This project specified several common loading scenarios, which all turbines can expect to experience during their lifespan, and applied the loading scenario data calculated in the previous chapter in order to verify the structural integrity of the new rotor blades. The procedure used to analyze the structural integrity of the new blade designed in this project may also be incorporated into any future design work as well.

\subsection{Rotor Blade Structural Requirements}

Structural survivability requirements are applied to this project just as they would be to any mechanical design to ensure the ability of the blade to operate without fault for the entirety of the blade's lifespan. A key aspect of this project is that the process of examining loading scenarios, analyzing the effects of said loading on 
the blade structure, and modeling the results of these effects with a FE approach is streamlined so that further loading scenarios may be examined more easily.

Standard design structural requirements are adhered to such as:

- Maximum loading, with safety factor applied, during normal operation causes no fiber failure or matrix cracking

- Infinite life with zero damage as determined by strain model results

- Parked rotor experiences no fiber or matrix damage

Another important requirement when designing a HAWT rotor blade is the stiffness required for the blade tip not to strike the turbine tower. Many factors play a part in the maximum tip deflection of the blade during operation such as thrust loading, vibrational modes, and pressure differences as the blade passes in front of the tower. Tip displacement due to thrust loads was the only factor investigated in this project with the blade stiffness, and therefore the tip displacement, designed to be easily refined by manipulating the number of carbon fiber plies applied along the spar cap.

\subsection{Blade Spar and Skin Design}

Not all modern HAWT rotor blade designs incorporate a spar, including the previous blades used on the CPWPRC designed by Bryan Edwards [11], however this project will investigate the benefits of a spar for several reasons. Firstly, it was found that to capture increased wind energy a much longer blade was needed and with a longer blade comes intensified strength and stiffness requirements. Therefore, by utilizing a spar constructed of a very strong carbon 
fibers the deflection of the rotor blade can be manipulated by adding or subtracting strategically oriented carbon fibers along the blade spar instead of redesigning the composite layup for the entire blade structure. The spar will span the length of the blade, from the connection of the aluminum hub connection to the blade tip, so that the spar will be the main load bearing component of the blade. In this way the outer blade skin may be constructed of a fiberglass-epoxy material which is beneficial in terms of impact resistance, strength, and are much cheaper than carbon fiber.

It is important to design the heavier spar to be close to the leading edge of the blade in order to avoid any blade flutter issues that may arise at higher rotational blade speeds [2]. Blade flutter can cause undesirable blade stress and lead to premature structural failure unless the majority of the blade weight is kept within the first $30 \%$ of the chord length. Therefore, the spar for this project will be incorporated within the blade structure at the quarter-chord distance from the leading edge, or $25 \%$ of the chord length as directed from the leading to the trailing edge, which is important for two reasons. The first reason is, obviously, to mitigate the risk of flutter effects by centering the weight of the spar close to the leading edge of the blade. The second reason is that the aerodynamic forces will not be able to generate a significant twisting moment along the blade since the aerodynamic center is directed along a straight line from the center of the hub connection thru the center of the stiff carbon fiber spar along the quarter-chord location to the blade tip. 
The main purpose of the blade skins is to provide the necessary strength to the besides defining the aerodynamic shape of the blade, are to provide impact resistance without becoming overly heavy. Therefore, fiberglass is the structural material used by nearly all modern wind turbine blade manufacturers due to their high strength, ability to be strained more than carbon fiber, and because fiberglass is much more inexpensive than carbon fiber. The carbon fiber being utilized for this project has a maximum strain of about $1 \%$ while the E-glass being modeled for the blade skin can strain up to $4 \%$ before it fails which is beneficial when designing for good impact resistance. Also, fiberglass is significantly less expensive than carbon fiber and is therefore used as a large portion of the blade material, without any carbon fiber components, on most modern turbines in operation today.

Aerodynamic twist can be of major concern to rotor blade performance, both structurally and aerodynamically. The aerodynamic center, where the aerodynamic force are applied to the blade section planform, is located at onequarter of the chord length directed from the leading to the trailing edge along the chord line. Therefore in order minimize the effect of any aerodynamic twisting of the blade, the center of the rectangular spar is located at exactly one-quarter chord of each blade section. In this way the stiff carbon fiber will resist the twisting moment created by uneven pressure differences across the high and low pressure planform sides which causes the twisting moment about the z-axis of the local blade reference system. 


\subsection{Composite Material Selection}

Modern wind turbine blades are comprised almost completely of some type of fiberglass-epoxy material due to its lightweight, when compared with aluminum, and its ability to handle significant loads. Due to the production requirements of large wind turbine blade manufacturers fiberglass-epoxy composite materials are also useful due to their lower cost as compared to other composite material options. For instance, carbon fiber-epoxy is a stronger, stiffer material than fiberglass-epoxy and is available in a wide variety of configurations including unidirectional fiber and woven cloth but is significantly more expensive than fiberglass by approximately four to five times the cost. However, with advances in manufacturing processes and resource availability the cost of carbon fiber has dropped significantly and more wind turbine blade designs are able to incorporate structurally beneficial carbon fiber to enhance the fully fiberglass blade designs.

Previously the CPWPRC rotor blades were constructed of both carbon fiber and fiberglass. The carbon fiber consisted of $6 \mathrm{k}$ tow AS4 carbon fiber cloth, 0.012 inches thick which weighs 11 ounces per square yard. This carbon fiber cloth is used in conjunction with an E-glass whose strength and stiffness is high enough to be a viable construction material and is commonly used in applications such as boat hulls where weight and strength is important. This combination of carbon fiber, E-glass fiber, and a strong, durable epoxy matrix was used to create the high and low pressure skins of the rotor blades around a CNC machined foam 
mold. The skins were required to handle the entirety of the loading on the blade and therefore incorporated the carbon fiber to strengthen and stiffen the blade.

The material data collected by Bryan Edwards was tested at Cal Poly according to ASTM specifications and is provided in Table 7 below.

Table 7 Composite material testing data collected by Bryan Edwards while constructing the previous rotor blades used with the CPWPRC.

\begin{tabular}{|l|c|c|c|c|}
\hline & \multicolumn{2}{|c|}{ 6k Carbon } & \multicolumn{2}{c|}{ E-Glass } \\
\hline & Average & $\begin{array}{l}\text { Standard } \\
\text { Deviation }\end{array}$ & Average & $\begin{array}{l}\text { Standard } \\
\text { Deviation }\end{array}$ \\
\hline $\begin{array}{l}\text { Tensile Modulus } \\
\text { of Elasticity } \\
(\mathrm{GPa})\end{array}$ & 68.94 & $\mathrm{~N} / \mathrm{A}$ & 20.73 & 0.8 \\
\hline Poisson's Ratio & 0.0775 & $\mathrm{~N} / \mathrm{A}$ & 0.153 & $\mathrm{~N} / \mathrm{A}$ \\
\hline $\begin{array}{l}\text { Ultimate Tensile } \\
\text { Strength (Pa) }\end{array}$ & $7.212 \mathrm{E}+08$ & $0.21 \mathrm{E}+08$ & $2.79 \mathrm{E}+08$ & $0.38 \mathrm{E}+08$ \\
\hline $\begin{array}{l}\text { Ultimate Shear } \\
\text { Strength (Pa) }\end{array}$ & $6.67 \mathrm{E}+07$ & $\mathrm{~N} / \mathrm{A}$ & $7.24 \mathrm{E}+07$ & $0.83 \mathrm{E}+07$ \\
\hline
\end{tabular}

However, due to the lack of detailed material properties that are needed for the FEA process the previous material data is excluded from this project. In lieu of the carbon and E-glass fibers reinforced with an epoxy matrix material used to construct the previous rotor blades, more well-defined composite materials are used for the FEA modeling process. 
The carbon and fiberglass reinforced epoxy materials used to model the blade structure in this project come from the Department of Energy and Montana State University composite material database [12]. These new materials, with property data shown in Table 8, were used in a very similar project by Sandia National Laboratories who designed a 9 meter blade which incorporated a composite spar along the length of the blade.

\begin{tabular}{|c|c|c|c|c|c|c|c|c|c|c|c|c|c|c|c|}
\hline \multirow[b]{3}{*}{ Fabric or Prepreg 1} & \multirow[b]{3}{*}{ lay-up } & \multirow[b]{3}{*}{$\mathrm{V}_{\mathrm{F}} \%$} & \multicolumn{8}{|c|}{ Longitudinal Direction } & \multirow{3}{*}{$\begin{array}{c}\text { Shear } \\
\tau_{\mathrm{TU}} \\
\mathrm{MPa}\end{array}$} & \multicolumn{4}{|c|}{ Transverse Direction } \\
\hline & & & \multicolumn{4}{|c|}{ Elastic Constants } & \multicolumn{2}{|c|}{ Tension } & \multicolumn{2}{|c|}{ Compression } & & \multicolumn{2}{|c|}{ Tension } & \multicolumn{2}{|c|}{ Compression } \\
\hline & & & $\begin{array}{c}\mathrm{E}_{\mathrm{L}} \\
\mathrm{GPa}\end{array}$ & $\begin{array}{c}\mathrm{E}_{\mathrm{T}} \\
\mathrm{GPa}\end{array}$ & $v_{L T}$ & $\begin{array}{l}\mathrm{G}_{\mathrm{LT}} \\
\mathrm{GPa}\end{array}$ & $\begin{array}{l}\mathrm{UTS}_{\mathrm{L}} \\
\mathrm{MPa}\end{array}$ & $\begin{array}{c}\epsilon_{\max } \\
\%\end{array}$ & $\begin{array}{l}\mathrm{UCS}_{\mathrm{L}} \\
\mathrm{MPa}\end{array}$ & $\begin{array}{c}\epsilon_{\min } \\
\%\end{array}$ & & $\begin{array}{l}\mathrm{UTS}_{\mathrm{T}} \\
\mathrm{MPa}\end{array}$ & $\begin{array}{l}\epsilon_{\mathrm{U}} \\
\% \\
\end{array}$ & $\begin{array}{l}\mathrm{UCS}_{\mathrm{T}} \\
\mathrm{MPa}\end{array}$ & $\begin{array}{l}\epsilon_{\mathrm{U}} \\
\%\end{array}$ \\
\hline M9.1 carbon ${ }^{1}$ & {$[0]$} & 50 & 115 & 7.77 & 0.33 & 3.71 & 1813 & 1.58 & -744 & -0.65 & 110 & 23.5 & 0.30 & -104 & -1.34 \\
\hline M9.6 glass $^{1}$ & {$[0]$} & 44 & 43.0 & 9.77 & 0.32 & 3.31 & 1166 & 2.71 & -505 & -1.2 & 81 & 36.3 & 0.37 & -174 & -1.78 \\
\hline
\end{tabular}

Table 8 Material property data used for Sandia 9m blade FEA model. The new materials that were used for the FEA modeling of the blade structure are unidirectional prepreg composites containing either fiberglass or carbon reinforced with an epoxy matrix. These new materials have been thoroughly tested and have well documented results which is necessary for an accurate FEA model to be generated. Also, these particular fiberglass and carbon prepreg composites were chosen due to the fact that they have similar ultimate strengths as compared to the materials tested and used for Sandia National Labs' blade design. Fatigue data relating to the infinite life requirement of the Sandia 9 meter blade was referenced in regards to this project in order to determine whether or not the infinite life requirement was met here. 
Due to the FEA software of choice, ABAQUS, having a very user-friendly material property manager any material changes that may be required are easily implemented. Also, defining the different composite sections of the blade is facilitated by the composite layup editor which allows for the user to apply previously defined material properties for individual composite plies as outlined in section 6.2.2. 


\subsection{CAD Model}

A very important step in designing a new rotor blade is producing an accurate 3dimensional CAD model to be used for the blade's overall geometry verification as well as to be converted into an importable file for the FEA process.

Solidworks was utilized to generate the necessary CAD model due to Solidworks' ability to make changes quickly and easily throughout the drafting process.

Solidworks models can be easily altered if any changes to the design are required after the initial CAD model is finished and can also integrate many of the complicated geometrical features of the rotor blade more easily than other CAD software program available.

The process of generating a CAD model for the optimized blade geometry calculated previously entailed importing airfoil curves, sketching the necessary blade components on each individual blade section sketch, the spar, leading and trailing edge, and the hub connection, lofting each blade component separately, and combining all the blade components into one overall assembly. Each one of these steps required significant effort and are described in such detail in the following report sections for the advantage of future rotor blade designers. 


\section{CAD Model Generation and FEA Flowchart}
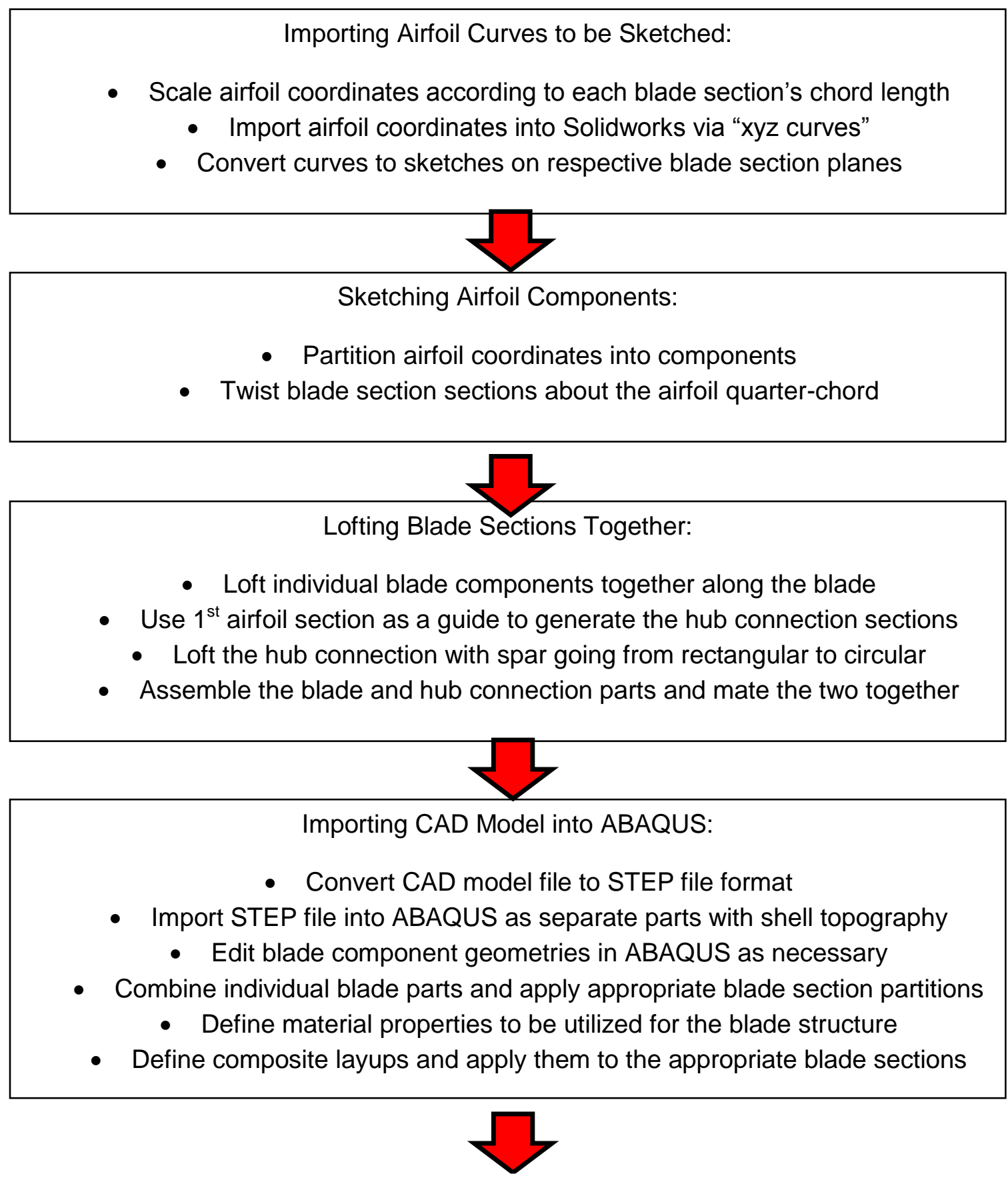

(continued on next page) 
Meshing and Applying Loads to ABAQUS Blade Model:

- Mesh each blade component separately and verify mesh quality

- Apply appropriate loading and boundary conditions for loading scenarios desired

- Designate the gravity vector direction and rotational body forces

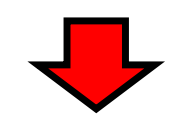

Running Model Jobs and Investigating FEA Results:

- Create a job for each loading scenario or modeling technique required

- Run the job and monitor for warnings or errors and correct model if necessary

- Utilize ABAQUS contour plot tools and investigate stress and strain values throughout the blade structure

- Investigate any composite structure damage and modify composite layup to prevent structural failure.

- Perform linear perturbation step to determine the blade mode frequencies.

Figure 37 CAD modeling and FEA procedure flowchart.

\subsection{Importing and Sketching Airfoil Curves}

Two dimensional airfoil planform coordinates for the S823 and S822 airfoils are easily accessible through the NREL website and have their $x$ and $y$ coordinates of the airfoil normalized with respect to the chord. It is standard practice to define normalized airfoil coordinates by chord length so that individual airfoil curves may be scaled per its required chord length. In order to transform the given normalized airfoil coordinates into airfoil curves which are to be imported into Solidworks the optimized chord lengths calculated at each blade selection, in chapter 3 , are applied to the normalized airfoil coordinates. Therefore, uniquely 
scaled $\mathrm{x}$ and $\mathrm{y}$ coordinates are generated for each blade section and may be imported into Solidworks for the CAD modeling process to begin. The result of importing each properly scaled airfoil planform into Solidworks as a xyz curve is shown in Figure 38.
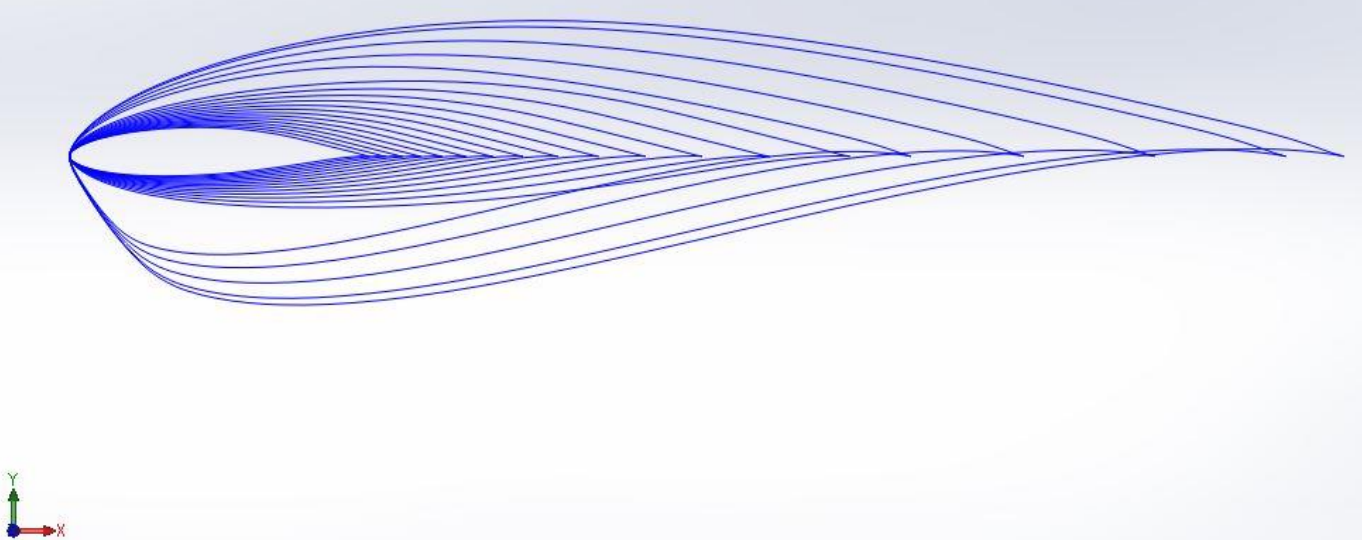

${ }^{*}$ Front

Figure 38 Imported, scaled airfoil curves to be used for CAD modeling prior to the necessary twist being applied at each blade section.

In order to position the newly generated airfoil curves onto their appropriate radial section of the blade twenty reference planes are positioned parallel to the initial front plane at the equally spaced radial intervals exactly where the aerodynamic loading BET calculations were performed for. Then the airfoil curves are converted to a sketch on their respective reference planes and twisted about their aerodynamic center, one-quarter of the length of the section's airfoil chord length directed down the chord line from the leading edge, to the optimum blade twist angle calculated previously as shown in Figure 41. Prior to twisting the airfoil sketches however, it is beneficial to draw the spar and bond sections onto 
the airfoil at the appropriate locations along the chord line before applying the proper amount of blade twist. The blade section airfoil sketch twisting process is completed by selecting the required reference plan, and using the "convert entity" control to convert the imported airfoil curve into a sketch on the selected reference plane. A line is then drawn from the leading edge of the airfoil to the trailing edge, a circle whose center is located at the exact leading edge of the airfoil and whose radius is specified to be the quarter-chord distance of that particular airfoil is drawn, and the airfoil curve is rotated about the intersection point of the circle and the chord line drawn previously. After the full airfoil sketch is rotated into position the blade components need to be made into unique sketches so they may be lofted individually. This required the airfoil sketch for each blade section to be copied, every line removed except those of the particular blade component being sketched, this sketch of the individual blade component is then renamed in the feature tree, the airfoil sketch is then copied over the renamed blade component, and the process is repeated until all four blade component sections are sketched for each blade section, as shown in Figure 39. 
The results of this blade section sketching and twisting procedure for each blade section are shown in Figure 40 with the leading edge, spar, trailing edge, and bond sections sketched on each airfoil curve.
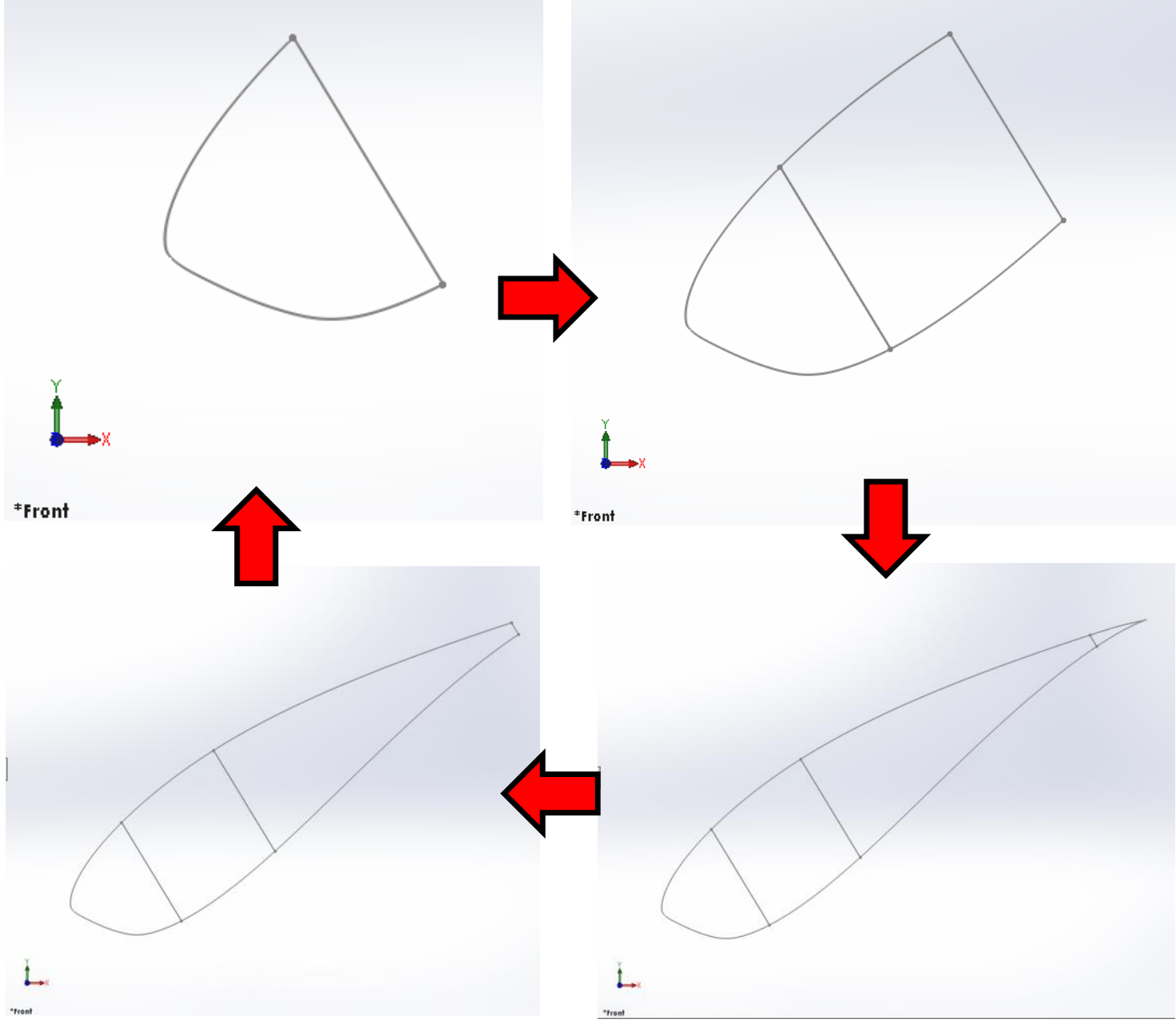

Figure 39 Individual airfoil component sketching procedure shown clockwise starting from upper left. 


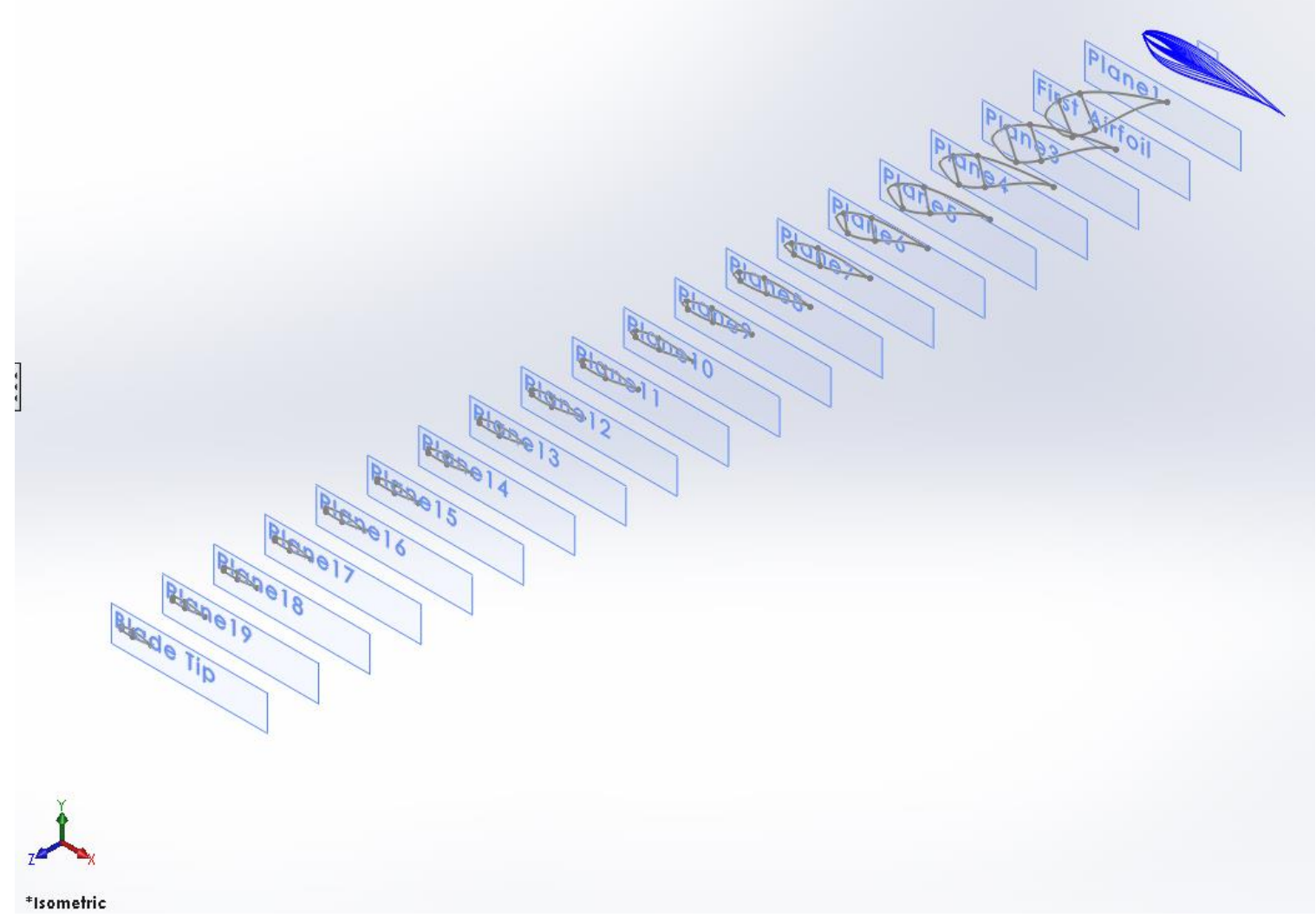

Figure 40 Airfoil sketches drawn on planes respective of their radial blade location along the blade with the final plane labeled as the blade tip. Imported airfoil curves are shown in blue at the plane representing the axis of rotation. 


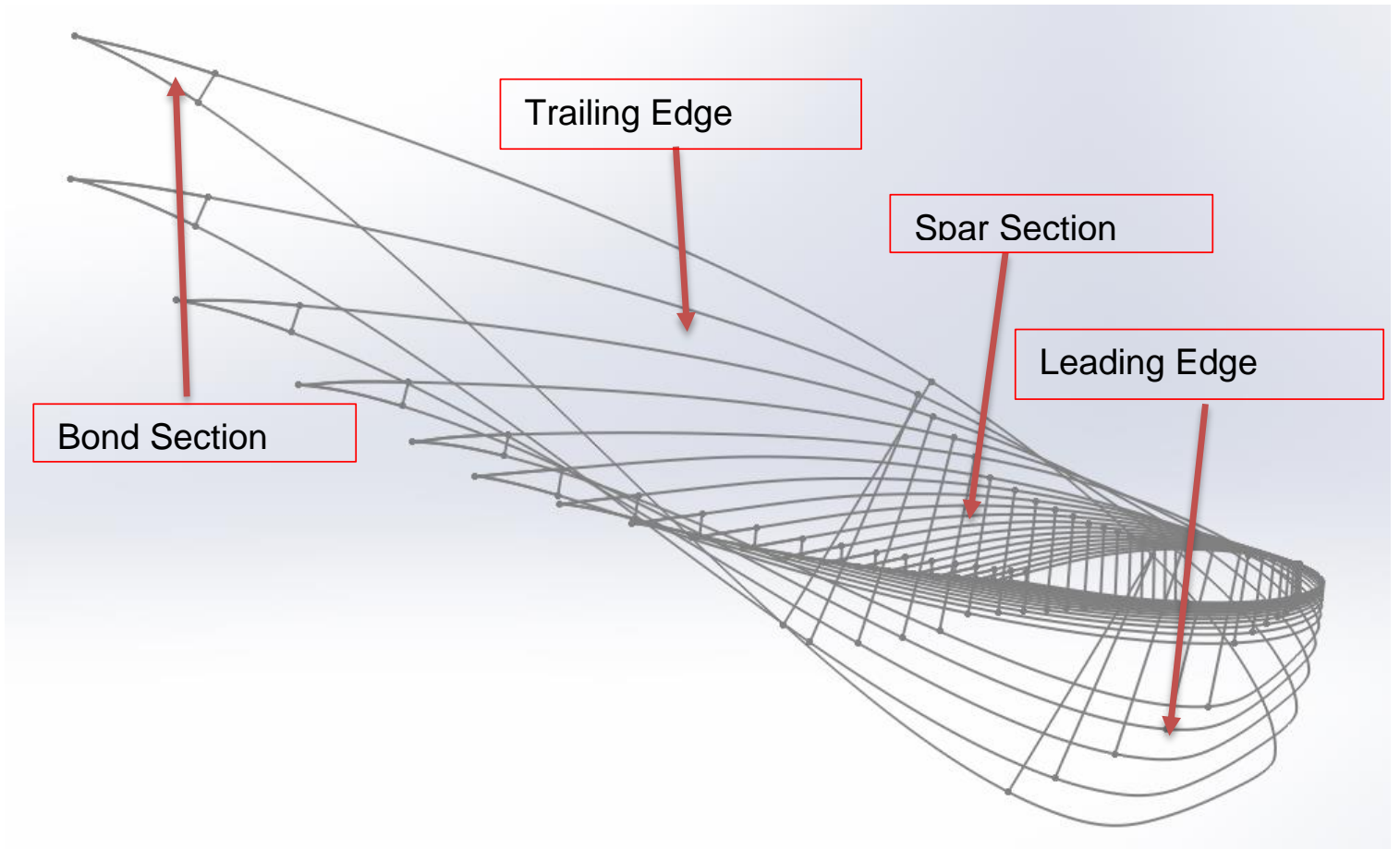

Figure 41 Twisted and fully sketched blade sections including the twisted outer airfoil curves and inner sketch lines representing the individual blade parts.

With each blade section sketch applied to its respective radially spaced reference plane in accordance with the optimized blade geometry calculated previously in chapter 3 the overall shape of the blade begins to take shape. The aerodynamically driven blade sections are now ready to be lofted together to form a 3-dimensional, solid CAD model of the new rotor blade design.

\subsection{Lofting Blade Sections}

Due to the geometrical complexity of the rotor blade its three dimensional features are not able to be generated all at once. It was found that attempting to use a single loft to generate the overall blade shape failed due to the sweeping curves of the outer skins which rapidly converge at the trailing edge. A single loft also produced invalid and imprecise geometry when imported into ABAQUS 
which could not analytically model the long, sweeping curves and sharp edges properly. Therefore, the leading edge, spar, trailing edge, and what is referred to as the "bond" section are lofted separately in order to provide shorter curves which are easier for ABAQUS to accurately import. The "bond" section at the trailing edge is given its name due to the fact that it is at this point where the high and low pressure sides of the blade are joined together without the aid of an internal flange such as what used at the leading edge.

It was determined that using solid lofts, as opposed to lofts composed of a thin shell which is a more visually realistic CAD model, were more appropriate when imported into ABAQUS as is discussed further in chapter 6 of this report. Whichever lofting procedure is used however, the user must be careful when lofting the individual blade component sketches together. If the lofted sketches are selected from the list of sketches, presented by Solidworks in the feature tree which includes all the features of a particular part drawing, the lofting procedure may fail due to automatic lofting point selections made by Solidworks causing excessive distortion. This occurs due to the fact that Solidworks does not specify the guiding line which the loft follows when selecting the sketches from the part drawing feature tree. Therefore, the user should specify the guiding line of the loft manually in the drawing viewport so that the lofting procedure does not fail. If excessive distortion occurs when lofting sketches together the loft preview will disappear and the user will have to correct the issue for the loft preview to reappear. The completed loft selection of the spar blade component sketches is shown in Figure 42 where the transparent loft preview is displayed. 


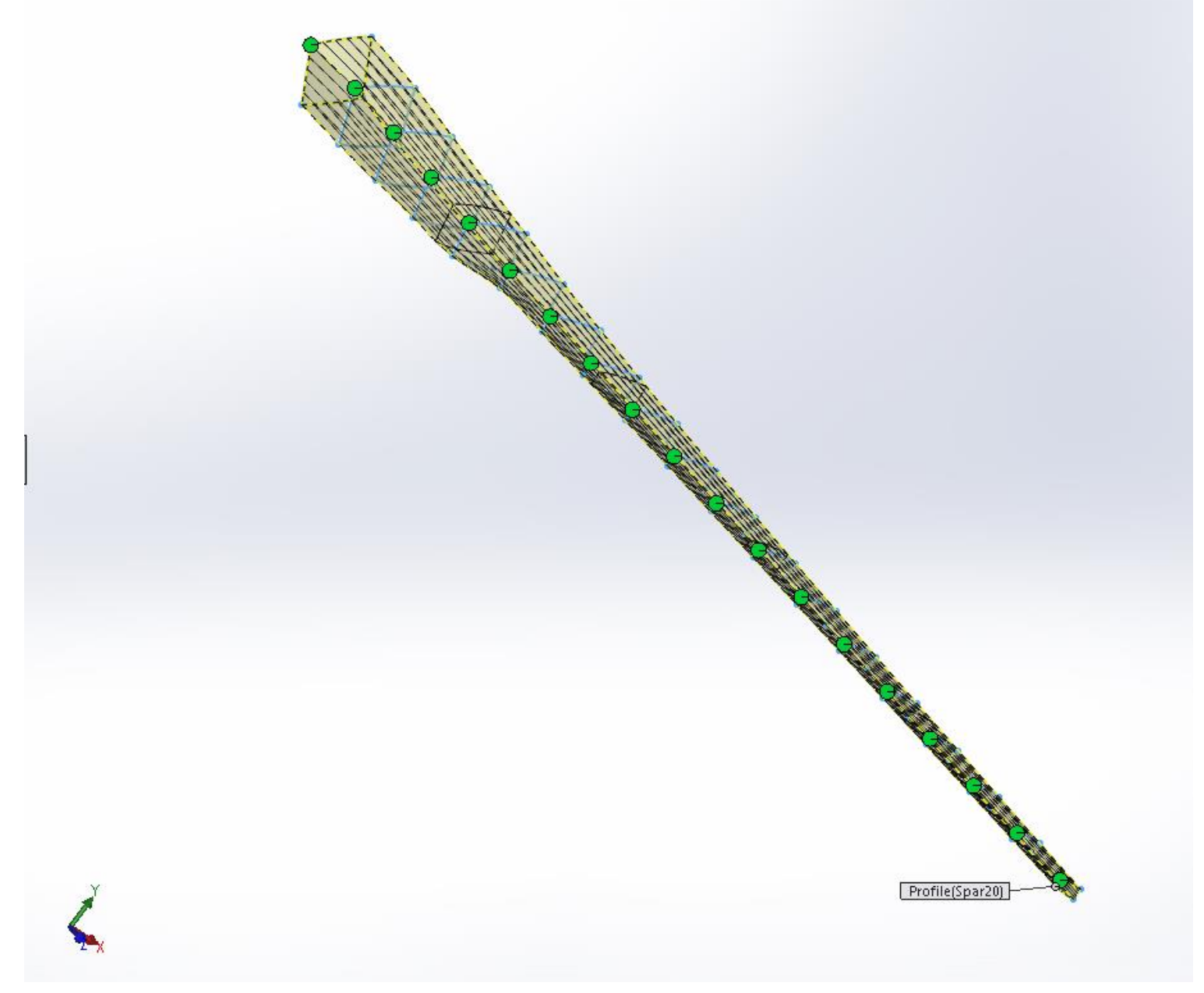

Figure 42 Spar lofting procedure completed with each individual spar blade section selected correctly and ready to be lofted.

This same procedure was carried out for the remaining blade components which may be completed in any order since each blade section sketch is defined with a unique sketch. Figure 43 shows a completed leading edge loft with the remaining spar, trailing edge, and bond sections sketched but without being lofted. Figure 44 shows the leading edge and spar lofts when completed with the remaining trailing edge and bond lofts remaining and finally Figure 45 shows the completed blade with all four lofts complete. 


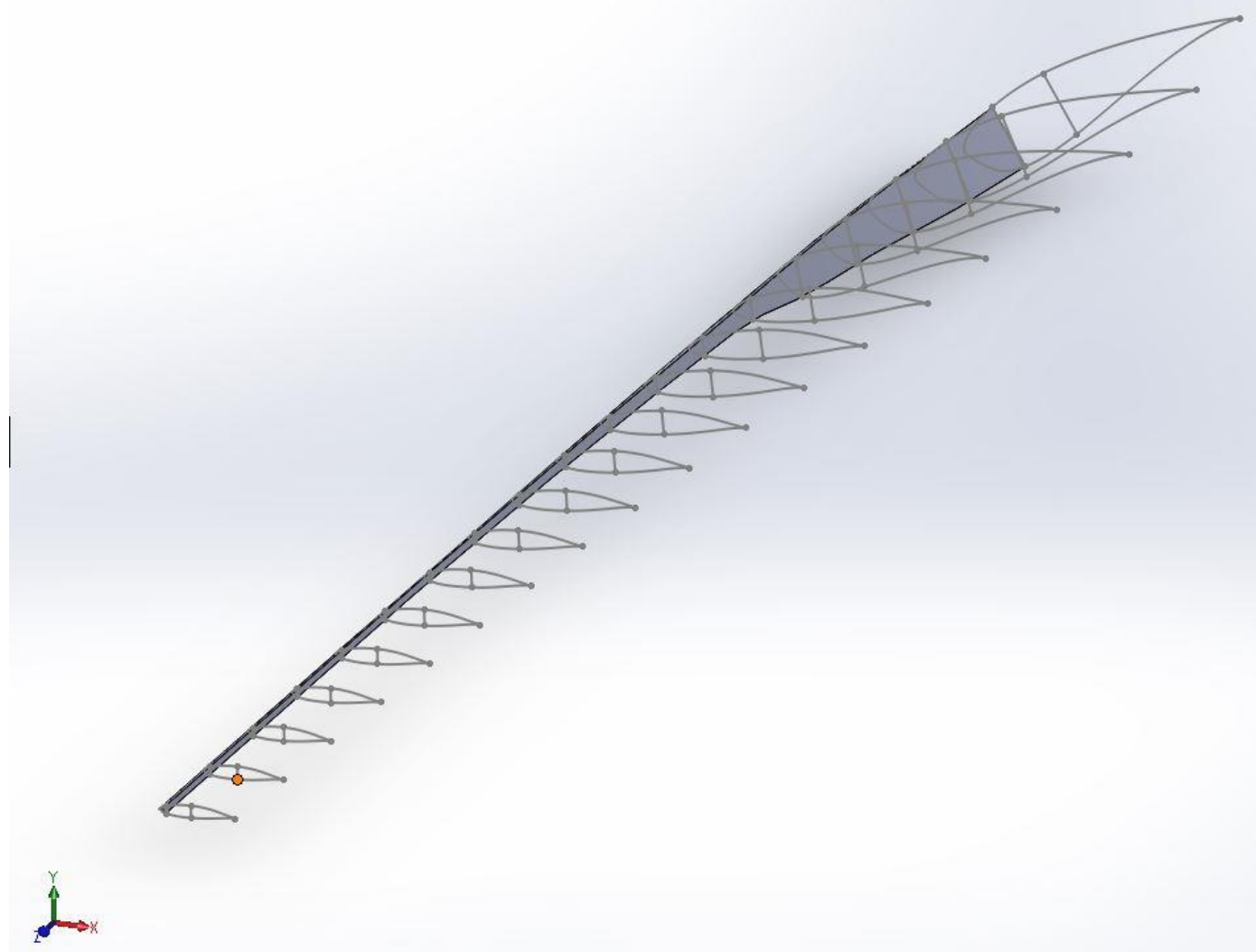

Figure 43 Leading edge loft completed with the spar, trailing edge, and bond section sketches not yet lofted. 


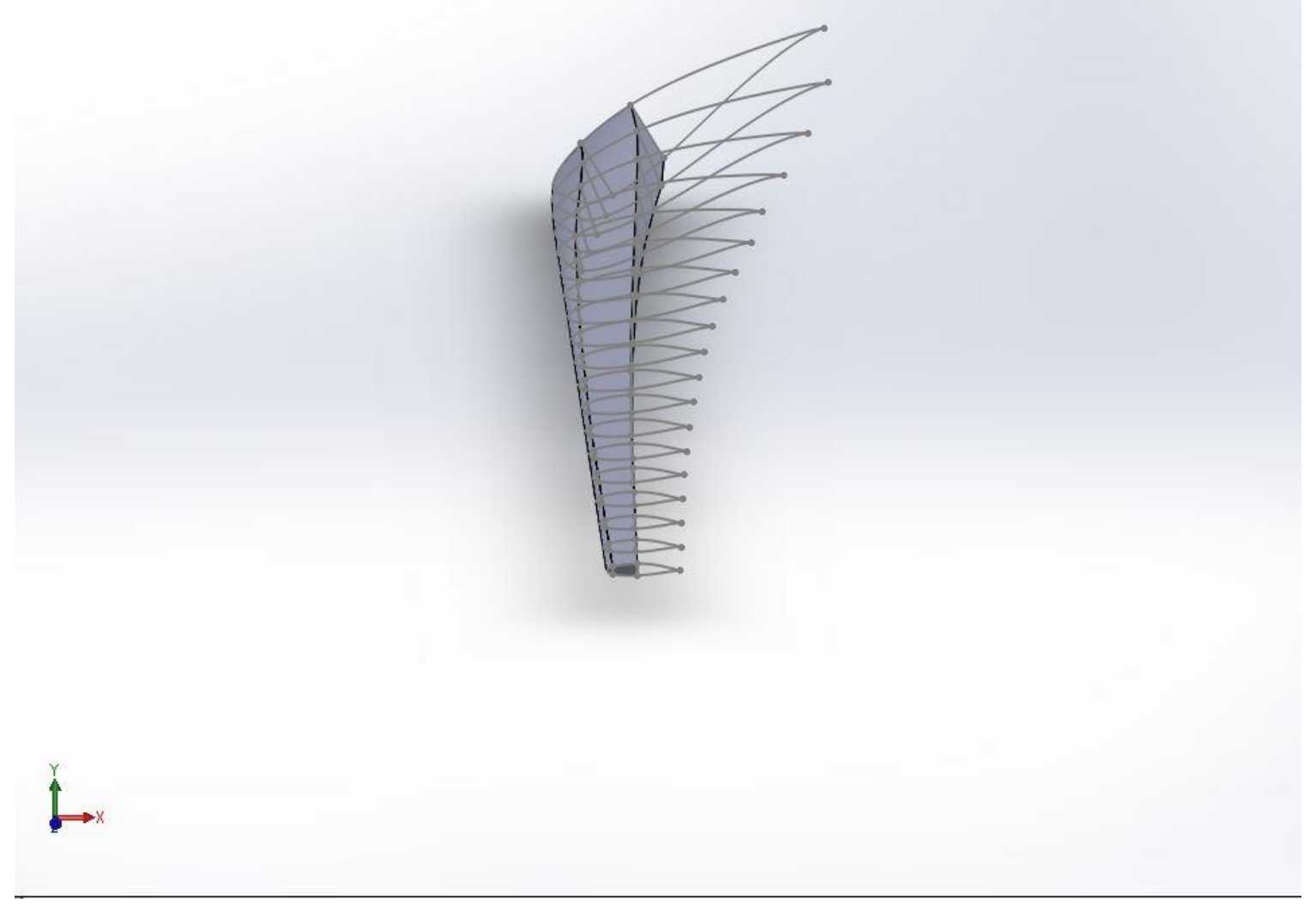

Figure 44 Leading edge and spar lofts completed with full airfoil sketches still shown. 


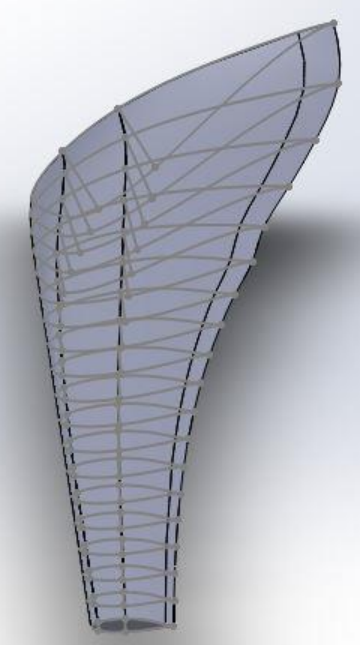

Figure 45 All blade components lofted with each overall blade section airfoil shown in grey.

The aerodynamically driven blade sections, described previously, and the structurally driven hub connection sections, from the aluminum hub interface to the second blade section, are drawn separately due to their complexity. The rotor blade sections between the aluminum hub and the first aerodynamically designed airfoil section require significant attention due to the fact that the maximum thrust generated bending moment as well some of the most complicated geometrical features are present here. Since the first airfoil section has the longest chord length which must transition itself into a 0.254 meter, or 10 inch, diameter circle at a distance of approximately one meter, guided lofting of the airfoil section needs to be exact or the FEA procedure will show significant 
stress concentrations in this area. Figure 46 shows how the rectangular spar section is lofted into the circular hub connection section with four guiding lines, which are created using 3-dimensional sketching techniques directed from the corners of the rectangular spar to four, equidistant points on the circular sketch.

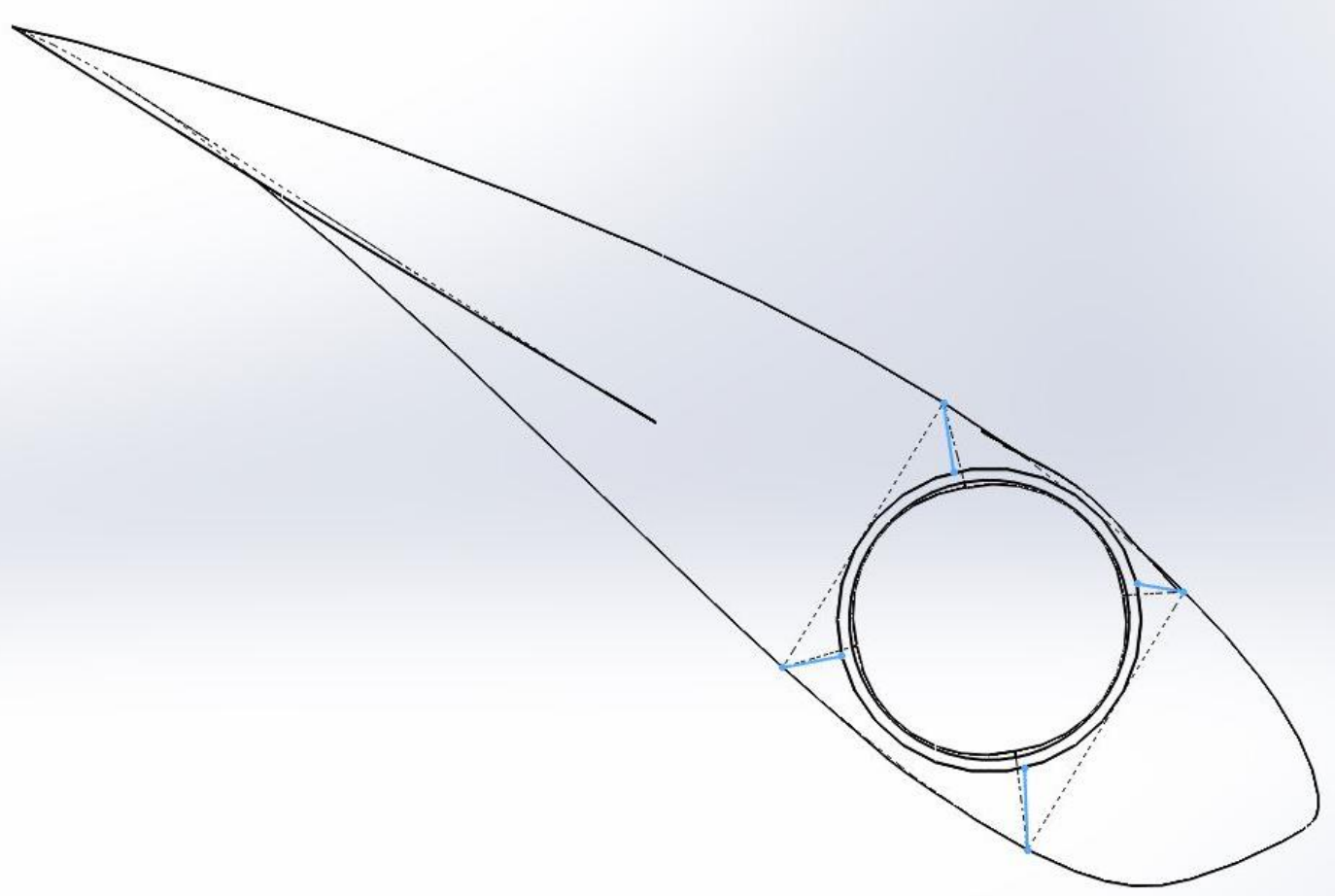

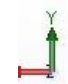

Figure $463 D$ guided lofting lines utilized for the hub connection transitional loft from the rectangular to circular spar sections highlighted in blue.

The completed hub connection section is shown in Figure 47 with the copied first aerodynamically driven airfoil section transitioning into the structurally driven hub connection part. The circular tube, or root tube, is created using an extruded cut 
and is the only part to require internal geometry specification prior to importing the CAD model to ABAQUS.
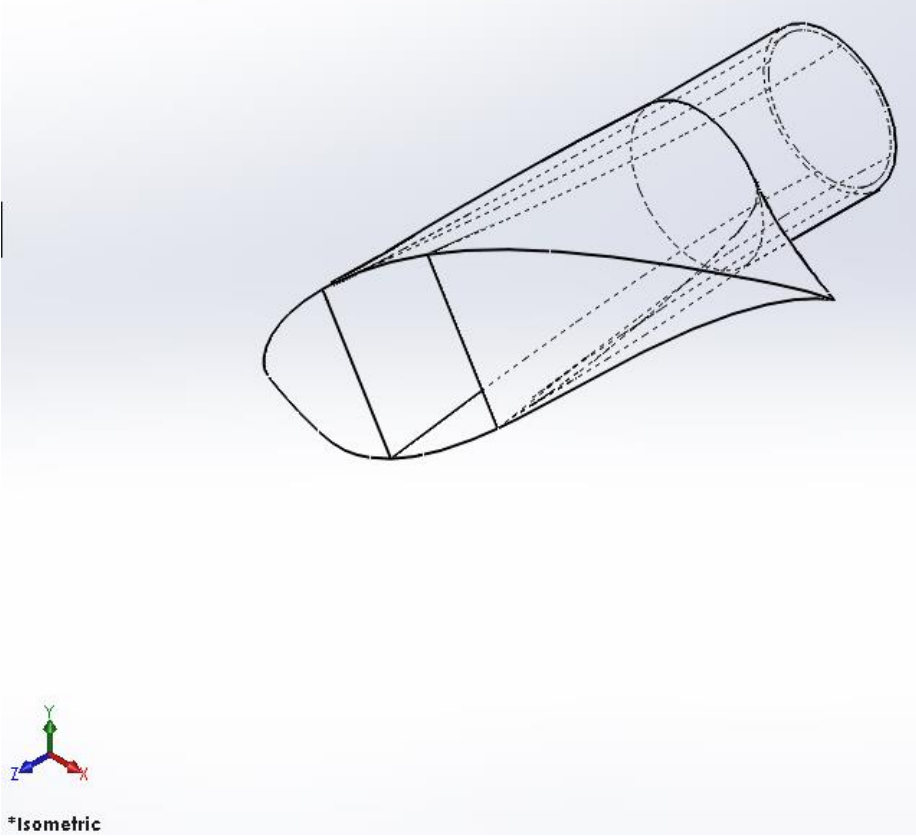

Figure 47 Isometric view of hub connection blade section with internal features denoted by dashed lines.

The first airfoil section sketch used in the hub connection CAD model was copied directly from the aerodynamic blade model so as to ensure that the spar and blade skin matched completely without any gaps or non-realistic features. 


\subsection{Assembling the Blade}

In order to complete the blade model the main overall blade components, the aerodynamically-driven airfoil part model and the structurally-driven hub connection part model, were joined in a Solidworks assembly file. The four individual component of the aerodynamically driven blade model are fixed relative to one another so the only mates required to fully define the assembly were between the hub connection part and the spar component of the blade.

The mates used to join the two parts directly were coincident mates applied at two of the spar corners to ensure the copied first airfoil section of the aerodynamic blade sections and the hub connection sections were aligned relative to all three axis. In order to facilitate the application of the thrust loading scenarios when the CAD model is imported into ABAQUS for structural analyses, the reference planes used for the individual blade components were aligned with the global Solidworks reference planes. Therefore, when imported into ABAQUS the $x, y$, and $z$ axis of the CAD model will coincide with the global coordinates automatically generated in ABAQUS which then coincide with the blade root reference system as described in section 3.4.1. This allows blade thrust loads to simply be applied in the y axis of ABAQUS' default reference system instead of defining a new reference system in ABAQUS. The completed blade assembly is shown in Figure 48 with all the required mates applied properly. 


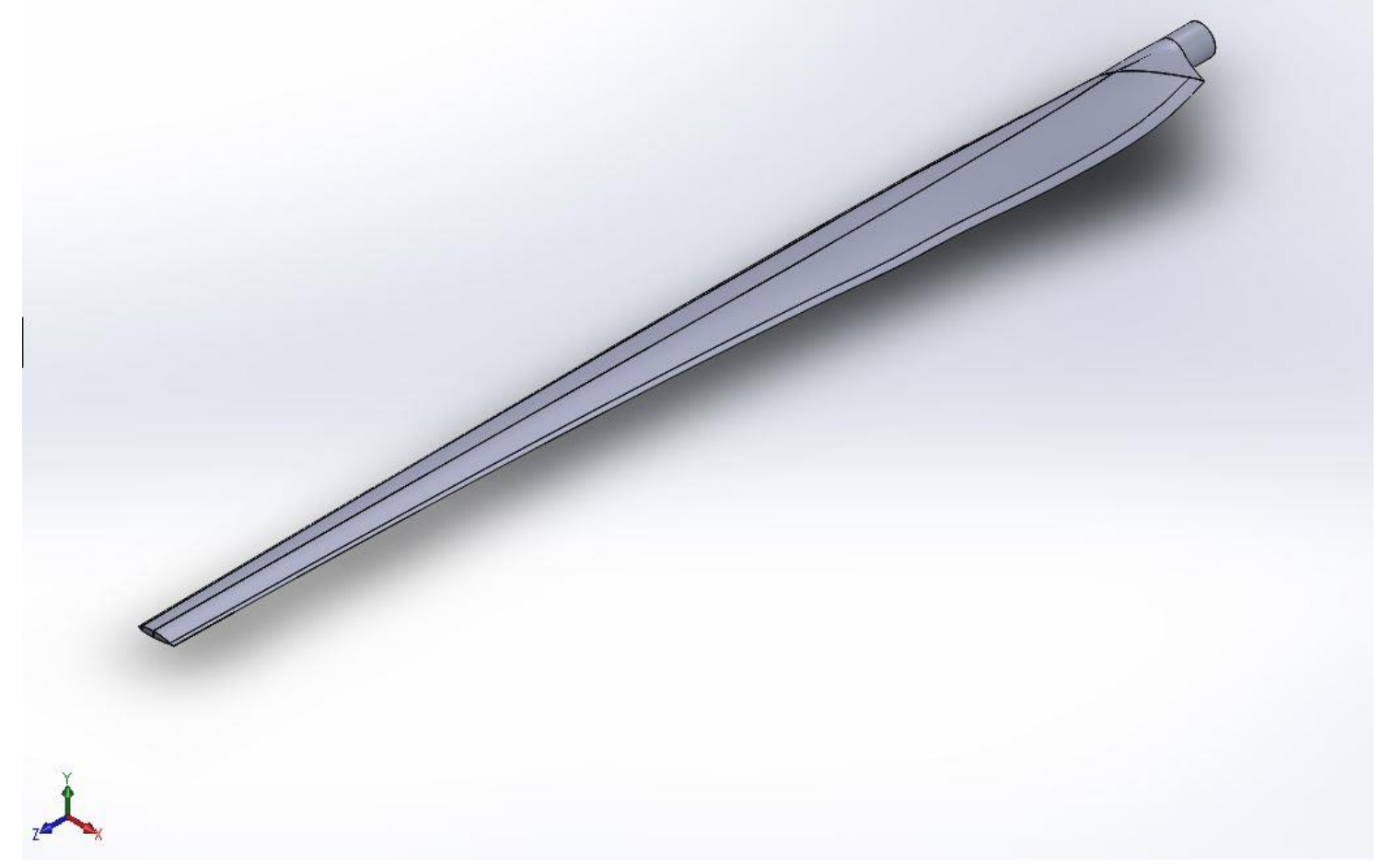

Figure 48 Final assembly of the aerodynamically driven blade sections and the structurally driven hub connection section.

\subsection{File Transfer to FEA Software}

The main goal of generating a CAD model of the blade is not simply to demonstrate visually how the rotor blade should look once manufactured but is to allow for the complicated geometry of the rotor blade to be more easily transferred into the FEA program being employed to perform the structural analysis portion of this project. ABAQUS has the capability to develop basic two dimensional sketches and three dimensional models but does not have the ability to accurately generate the geometry of the rotor blade that is required for a useful 
FEA procedures to be performed. Therefore, there must exist a way for the complete rotor blade model generated in Solidworks to be transferred to ABAQUS without significant distortion of the model's geometrical features.

The CAD software Solidworks and the FEA software ABAQUS are both owned by the same company, Dassault Systemes, with newer versions of the software packages becoming more compatible with each other which is a benefit to this project. There exists a plug-in feature of Solidworks', an "associative interface," and ABAQUS that generates a direct importation port in ABAQUS for the easy exchange of a Solidworks assembly into ABAQUS which also allows dual model refinement in both Solidworks and ABAQUS. This means that even after the model is imported from Solidworks into ABAQUS the Solidworks model can be modified while the ABAQUS model regenerates itself to mimic these changes. Obviously this plug-in option was explored during the course of this project and several different Solidworks models were designed for the specific purpose of utilizing this plug-in so that the exact, solid features of the rotor blade would be modeled without any FE constraints being needed. However, it was determined that the plug-in would only be able to import a three dimensional solid part which can only be modeled as a continuum shell element instead of the more appropriate conventional shell element so the plug-in option was discarded.

One file transfer technique that can be used with nearly any CAD software option is to save a CAD model as a file extension that is compatible with ABAQUS' analytical geometry modeling techniques. There are ten importable file types that can be utilized in this fashion but some are better than others in regards to 
retaining the geometrical accuracy of the CAD model and not producing imprecise or invalid geometrical features in ABAQUS. For instance, the VDA file format is generally used to transfer surface models between CAD programs and is in wide use in the automotive industry to do just that. However, when during this project it was attempted to transfer the CAD rotor blade model to ABAQUS in the VDA file format the imported geometry contained many invalid entities that could not be resolved with the geometry edit tools in ABAQUS which led to the model to be abandoned. The parasolid file format was also attempted and although it is a useful file format to transfer data between CAD software and mechanical structure modeling programs such as MSC ADAMS it was not able to avoid producing invalid entities in ABAQUS which again caused the parasolid file format to be abandoned. After attempting to fix the invalid or imprecise geometrical entities with the geometry editing tools available in ABAQUS and having little success it was found that the only file format that did not produce invalid entities, with only minor imprecise entities, was the STEP file format. The STEP file format is a standardized neutral file format which is compatible with many different CAD and FEA programs which makes it a useful tool for this project. With only minor geometry editing needed the STEP file format of the CAD rotor blade model generated in Solidworks is ready for the FEA procedure to commence with the meshing procedure. 


\subsection{Finite Element Modeling}

With such a complex system of forces and geometry throughout the rotor blade it is imperative that a wind turbine designer be able to identify areas of high stress, strain, and maximum tip deflection in the wind turbine's rotor blade. High stress concentrations can lead to a failure of the blade under certain loading scenarios and must be addressed. Also, in order to ensure that the blade tip does not strike the wind turbine's tower during normal operation or during extreme wind gusts the blade stiffness must be high enough so that the blade tip remains a safe distance in front of the tower for an upwind turbine design such as the

CPWPRC. However, for the purposes of this project a maximum tip deflection requirement was not set but is easily refined by adding or removing plies from the carbon spar cap. The calculations required to determine these stress and strain requirements are very complicated with assumptions needed in order to attempt to perform them by hand. Therefore, the FEA approach was necessary to fully analyze the wind turbine rotor blades.

FEA consists of utilizing small elements that consist of a certain number of interconnected nodes which form together in a mesh comprising the entirety of the model. This mesh can either be coarse or fine depending on the section of the model being analyzed, with a finer mesh being used in order to more accurately model the flow and magnitude of stresses in complex geometrical areas or high stress areas of the blade, while a more coarse mesh is used to model areas of the blade that do not show signs of high stress or deflection in order to make the model less computationally expensive. However, care must 
be taken to not allow the less accurate coarse mesh stress and strain calculations hinder the accuracy of the finer mesh areas. A thorough FEA requires a considerable amount of computing power and therefore time to fully complete an analysis of the blade model hence coarse meshing will be employed as much as possible with a fine mesh being reserved for use around the blade root structure where both complex geometry and high stress concentrations must be accurately modeled for a successful composite structure design.

\subsection{Importing the CAD Model}

When the Solidworks model that is in the STEP file format is imported into ABAQUS it must be brought in as multiple parts, not a single part, in order for no invalid entities to be generated during the ABAQUS geometry configuration process. During the process of importing the CAD model into ABAQUS the geometry of the CAD model is modeled as a series of edges and faces in the part module of ABAQUS which produces a representation of the part as accurately as possible however problems may result if the part's CAD geometry is redundant, too complex, or uses reference geometry that must be eliminated within ABAQUS. The part topology must be specified as being a shell and not a solid or wire for the model to be appropriately modeled as a deformable, composite structure in a three-dimensional modeling space. By specifying the imported CAD model as a shell the outer faces of the solid lofted parts, leading edge, spar, trailing edge, and bond section, are designated as a shell face with no internal features. Once the model has was imported properly the geometry was checked with a query option displayed under the "Tools" menu bar section to 
verify that there does not exist any invalid entities or ubiquitous imprecise entities. Any part that contains an invalid entity will not be able to be meshed and therefore is useless to this project. It should be noted that the bond section and trailing edge lofts are imported into ABAQUS as a single part automatically so a total of four parts are generated by ABAQUS, the leading edge, spar, trailing edge, and hub connection parts.

If any invalid or imprecise entities are detected then the "Geometry Edit" tool is needed to be utilized to fix any edges, faces, or to convert the part's geometry by means of an analytical method or by re-computing the geometry of the parts with less tight tolerances. Most imprecise edges or faces are correctable by applying the "repair small," "remove redundant entities," and "stich" geometry editing techniques. Otherwise the entirety of the part may be edited such that ABAQUS converts the part to an analytical representation or by changing the precision of the part's geometry. If a non-critical feature of the part contains an imprecise entity after this process is complete it will not be hugely detrimental to the accuracy of the model but the majority of imprecise entities should be removed or repaired if possible. Of the four parts imported into ABAQUS only two contained imprecise entities after basic geometry editing steps which included the leading and trailing edges, as shown in Figure 49 and Figure 50. However, it was determined that these imprecise entities did not distort the FEA results or cause any other problems. 


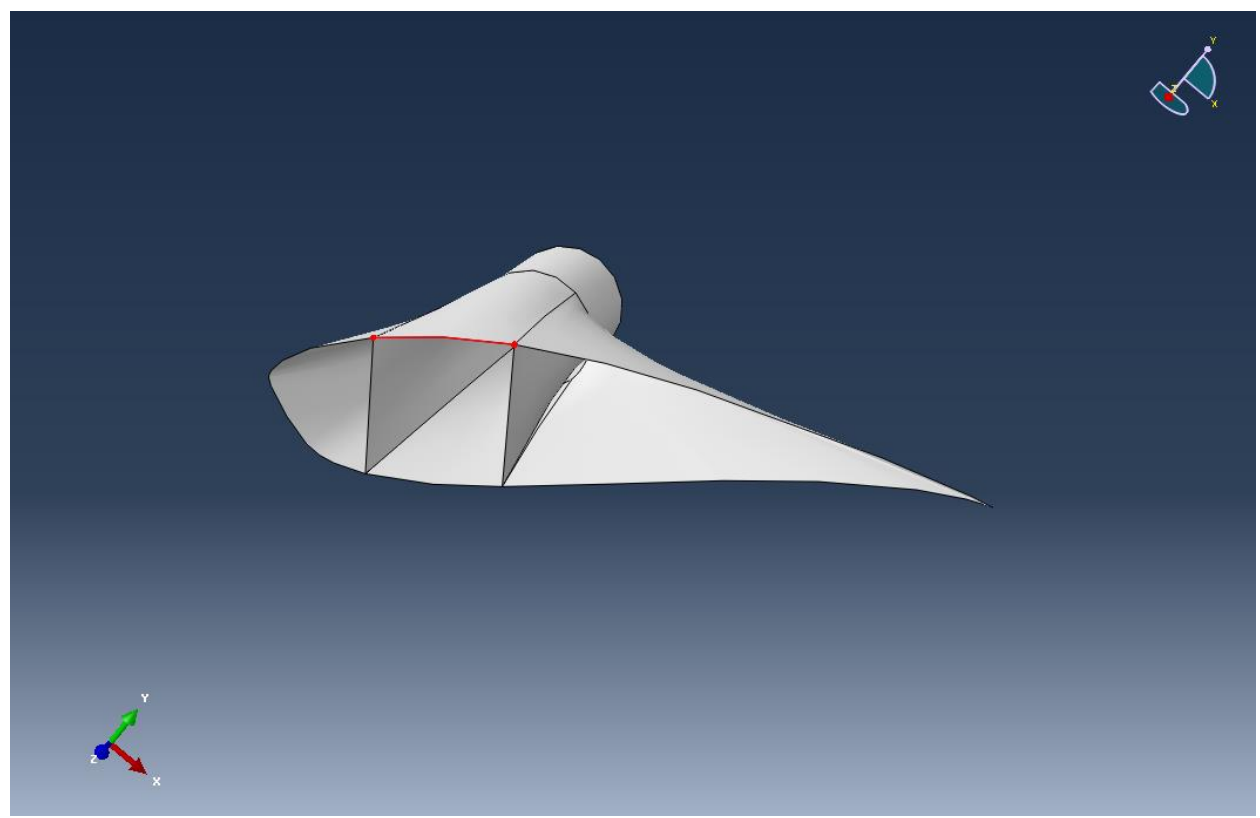

Figure 49 Imported hub connection part with imprecise lines highlighted in red.

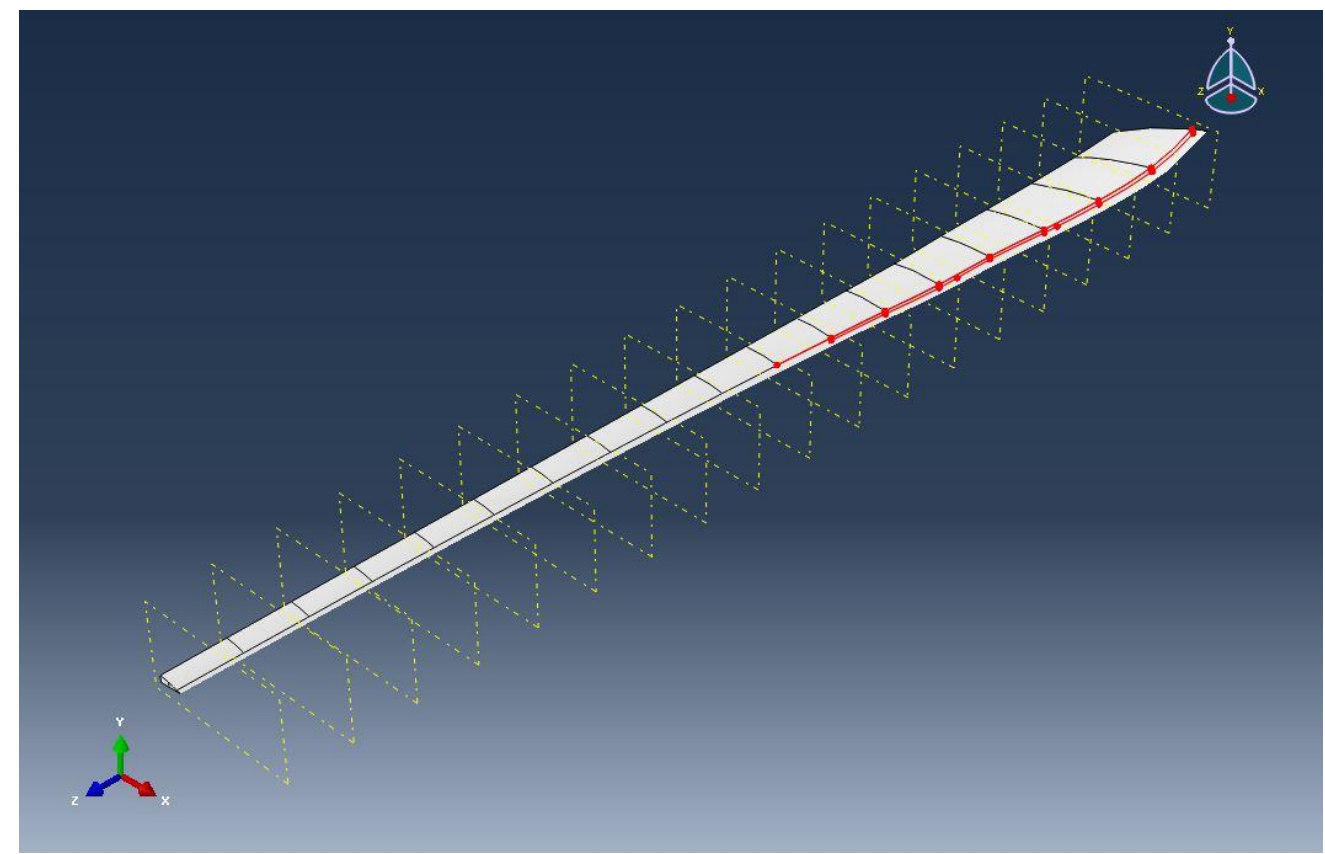

Figure 50 Trailing edge imprecise entities highlighted in red. 


\subsection{ABAQUS Model of Blade}

With the overall wind turbine rotor blade CAD model properly imported into the FEA software program of choice for this project, ABAQUS, much work is still required for the FEA process to yield useful results. Due to the complicated geometry of the blade design it was necessary to import the overall blade model as four separate parts that must be joined in such a way that when forces and constraints are applied to the model that the four parts act as a continuous entity and not independently of each other. Also, the composite lay-up schedules must be properly oriented, given the appropriate material properties, and applied to the appropriate blade sections so as to represent a realistic model of the blade that is to be fabricated and tested in the future. One of the most important parameters of this project is the application of the loading scenarios which the rotor blade will experience in operation while operating in normal and abnormal external conditions. Therefore, the aerodynamic loads calculated previously must be accurately applied to the model such that the forces applied generate a realistic response from the rotor blade.

After properly defining all the required blade structure specifications, applying aerodynamic, gravity, and rotational forces, the blade model must be meshed adequately for FEA to be performed. Meshing the blade structure is one of the most important steps in the FEA process and must be verified to be of good quality or the results of the analysis are useless. Therefore, much care must be taken to ensure the mesh applied to the blade structure contains quality elements which are not overly distorted with elements applied in varying density according 
to the structural complexity of the blade sections. This project successfully demonstrated how to generate a quality mesh on even the most complex geometries of the HAWT rotor blade, or any other rotor blade design, such as at the hub connection and the transition between the two airfoil designs used.

Each step of the finite element analysis performed with the commercially available software program ABAQUS are detailed in the following sections.

\subsubsection{ABAQUS Geometry Editing and Verification}

With the CAD model successfully imported into ABAQUS and the geometrically invalid or imprecise entities corrected for, each of the four imported parts must be slightly modified and joined together to model the continuous structure of the rotor blade. This was accomplished by removing redundant part faces which were generated during the importation process and constraining the individual parts so they each act as one deformable part.

Several unsuccessful methods of converting the imported CAD model into a simply yet realistic model for FEA purposes failed due to a variety of reasons until, per the advice of Dr. Shuster of California Polytechnic University San Luis Obispo, a viable method of modeling the imported CAD parts was found. According to his suggestions for proceeding with the FE model, several redundant faces were removed and a series of constraints were imposed on the nodes which are meant to act as a continuous structure. Since each individual blade component was imported as an individual part whereas in reality they are all interconnected, several redundant faces were generated. These faces 
included all internal faces except those of the spar which were used to model the shear web of the rectangular spar. In total there were seven faces which were removed, as shown in Figure 51, in ABAQUS using the "remove face" tool in the "Part Module."
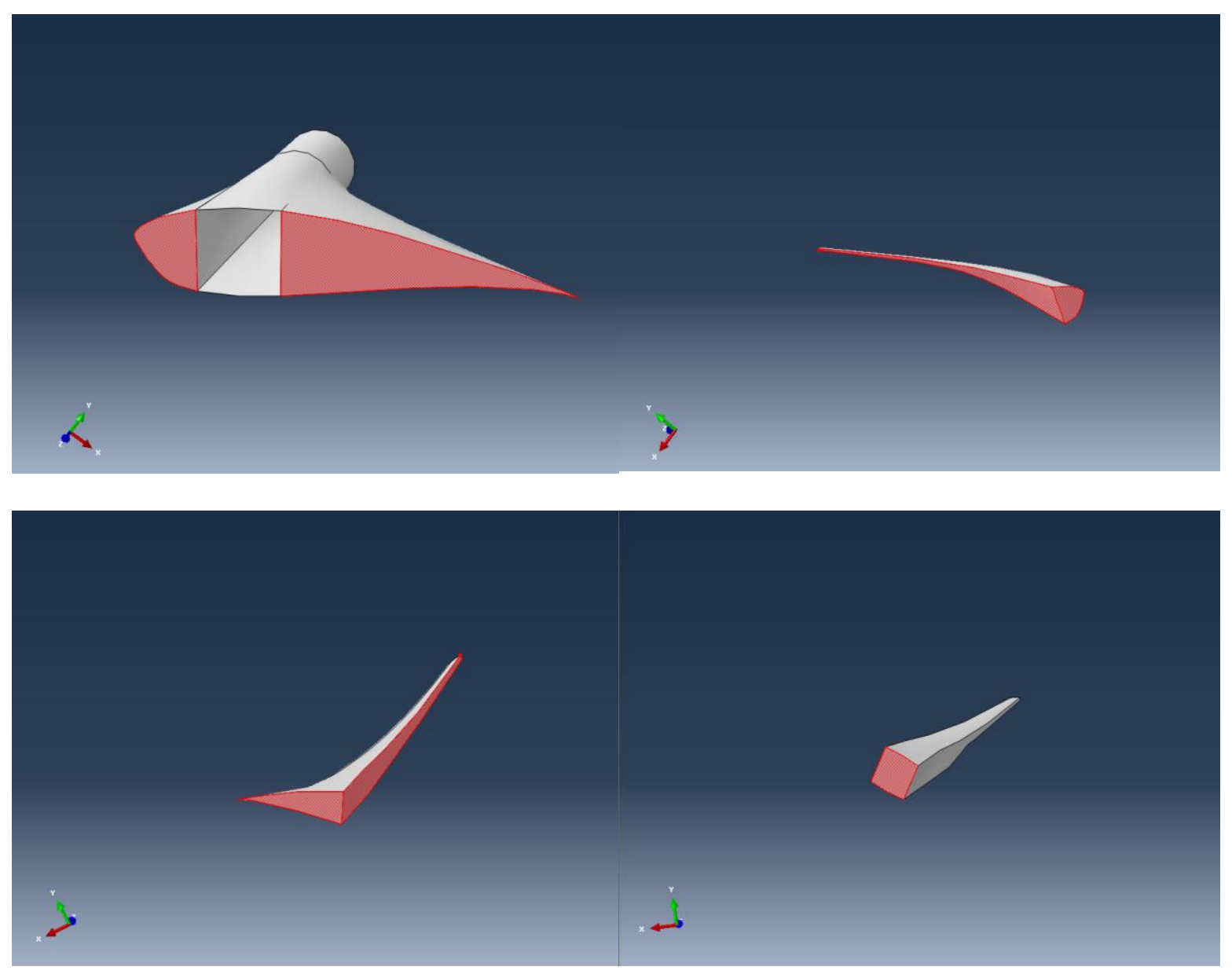

Figure 51 Removed faces for each part highlighted in red.

With the redundant faces removed constraints are now required to combine the parts into a realistic continuous structure. As per the advice of Dr. Shuster tie constraints were utilized to join the four parts into one. This was accomplished by incorporating five tie constraints into the model which combined the spar to the leading and trailing edges as well as the hub connection part to the three 
aerodynamic blade parts. The edges of each part were defined in a "set," were labeled appropriately, and called upon when applying the tie constraints so that each edge matched perfectly with its mate. An example of the spar to trailing edge tie constraint is shown in Figure 52 below, where the two sets are highlighted in red. The sets defined on the spar edges are designated as the master surface while the other edges were designated as the slave surface with each node's degrees of freedom tied to one another. At the completion of this procedure the four parts imported into ABAQUS from the Solidworks CAD model are now representative of the overall blade geometry acting as a continuous structure. 


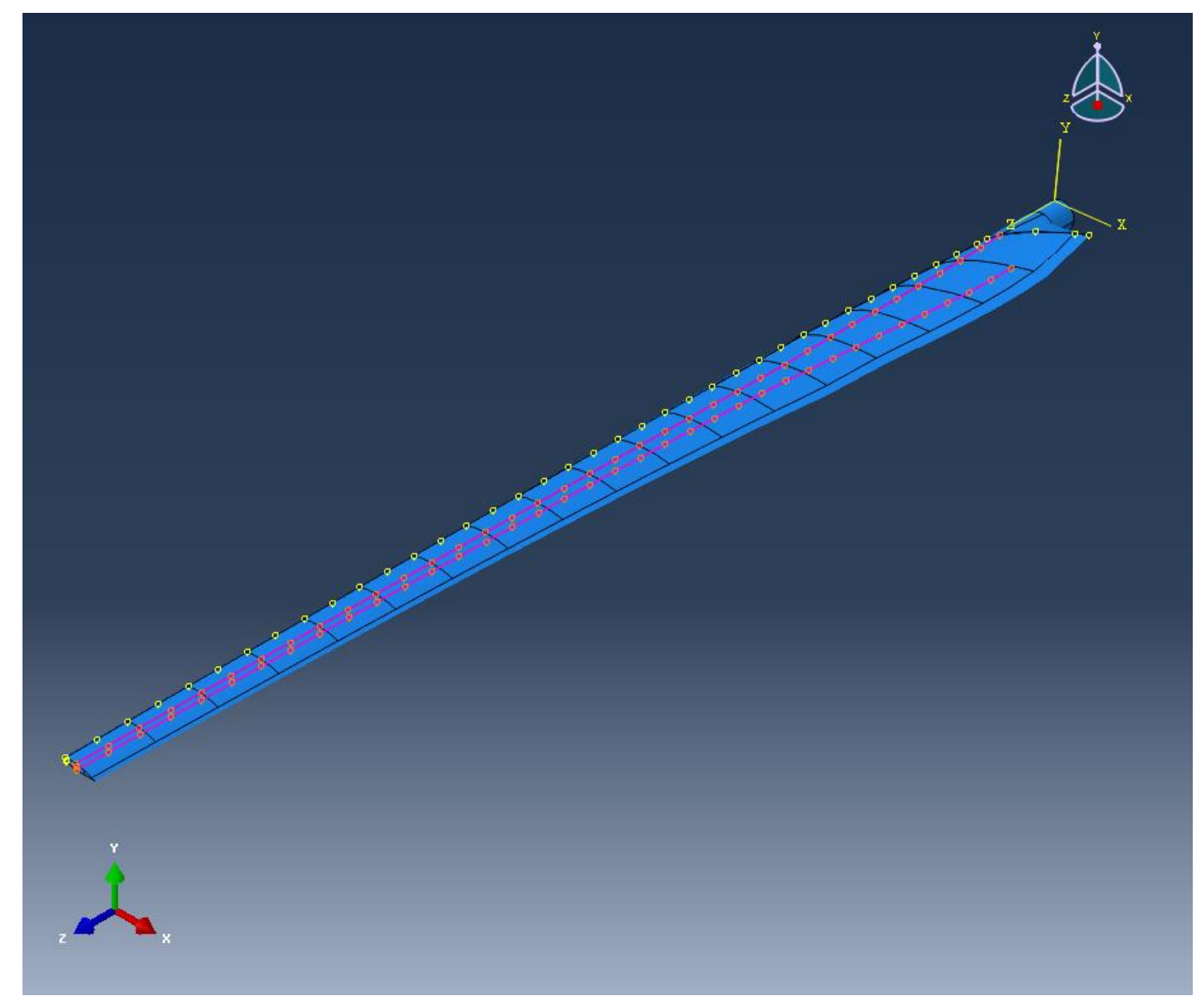

Figure 52 Tie constraint between the spar and the trailing edge highlighted in red. Another important aspect of this FEA model is the partitioning of blade sections such as was performed during the BET aerodynamic analysis. By partitioning each part of the blade model, leading edge, spar, and trailing edge, the aerodynamic forces calculated at the end of each blade section may be easily applied to their respective blade sections. Also, by separating the rotor blade into the 20 sections in which it was analyzed each blade section may be examined and modified in order to further refine the blade model which is beneficial to other aspects of the FEA procedure. 
Partitioning the blade was accomplished by establishing 20 equally space datum planes radially along the blade just like was done in the CAD modeling process. After the datum planes are generated and verified to be accurate, such as the final datum plane is at the exact blade tip, the blade is partitioned where each datum plane intersects the parts of the blade. This is easily performed by utilizing the "Partition Cell: Use Datum Plane" tool in ABAQUS' Part Module for the leading edge, spar, and trailing edge.

\subsubsection{Composite Lay-up Schedule}

FEA software programs have different methods of defining material properties, whether the material is defined as isotropic, orthotropic, or anisotropic with some programs being simpler than others. User-specified materials may also be incorporated into many FEA projects with some degree of difficulty but give excellent results in most cases where complicated material modeling is required. For the purposes of modeling composite materials effectively and easily ABAQUS is one of the better FEA software programs available. With ABAQUS the user may specify an elastic lamina type material and then input the relevant modulus of elasticity, Poisson' s ratio, and shear modulus in the appropriate material orientations very easily utilizing a graphic-user-interface, or GUI.

One of the main reasons that ABAQUS was chosen to perform the FEA portion of this project is that it contains very useful tools for defining and analyzing composite structures. ABAQUS has a unique part feature tool which allows the user to name particular plies, assign these plies to a region of the model, specify the material properties, thickness, coordinate system, rotation angle from which 
ever coordinate system is designated, and the number of integration points for each ply. In this way the rotor blade has its individual components properly modeled with the exact composite lay-up schedule applied to the appropriate regions of the model. For instance, the composite lay-up for the spar cap and shear web portion of the spar is shown in Figure 53 and Figure 54, respectively, with the composite reference coordinate system applied so that it exactly matches the composite analysis performed on those regions by standard calculations for verification.

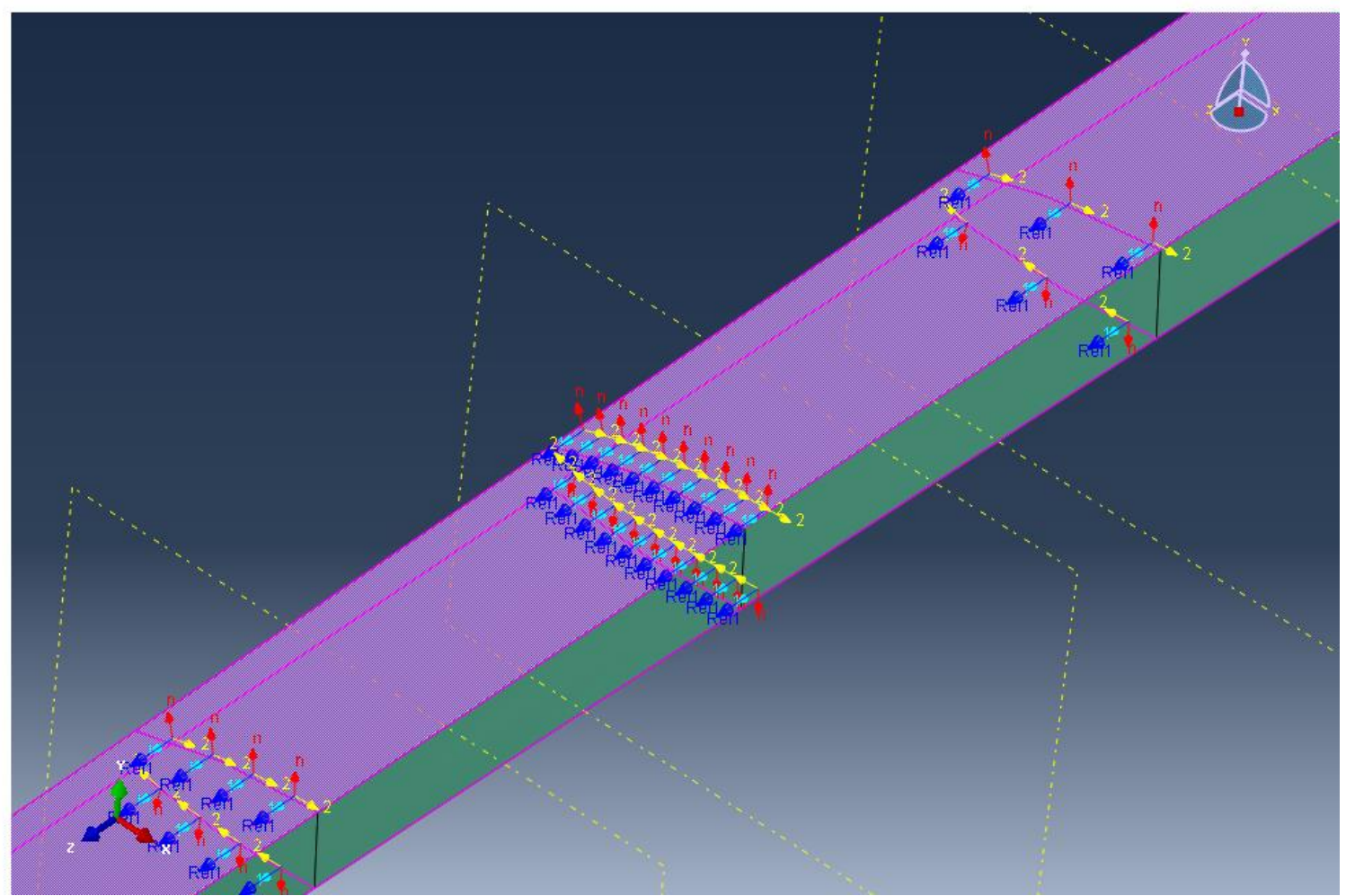

Figure 53 Composite section layup orientation for the spar cap shown with the $0^{\circ}$ orientation reference shown in blue and the laminate normal direction in red. 


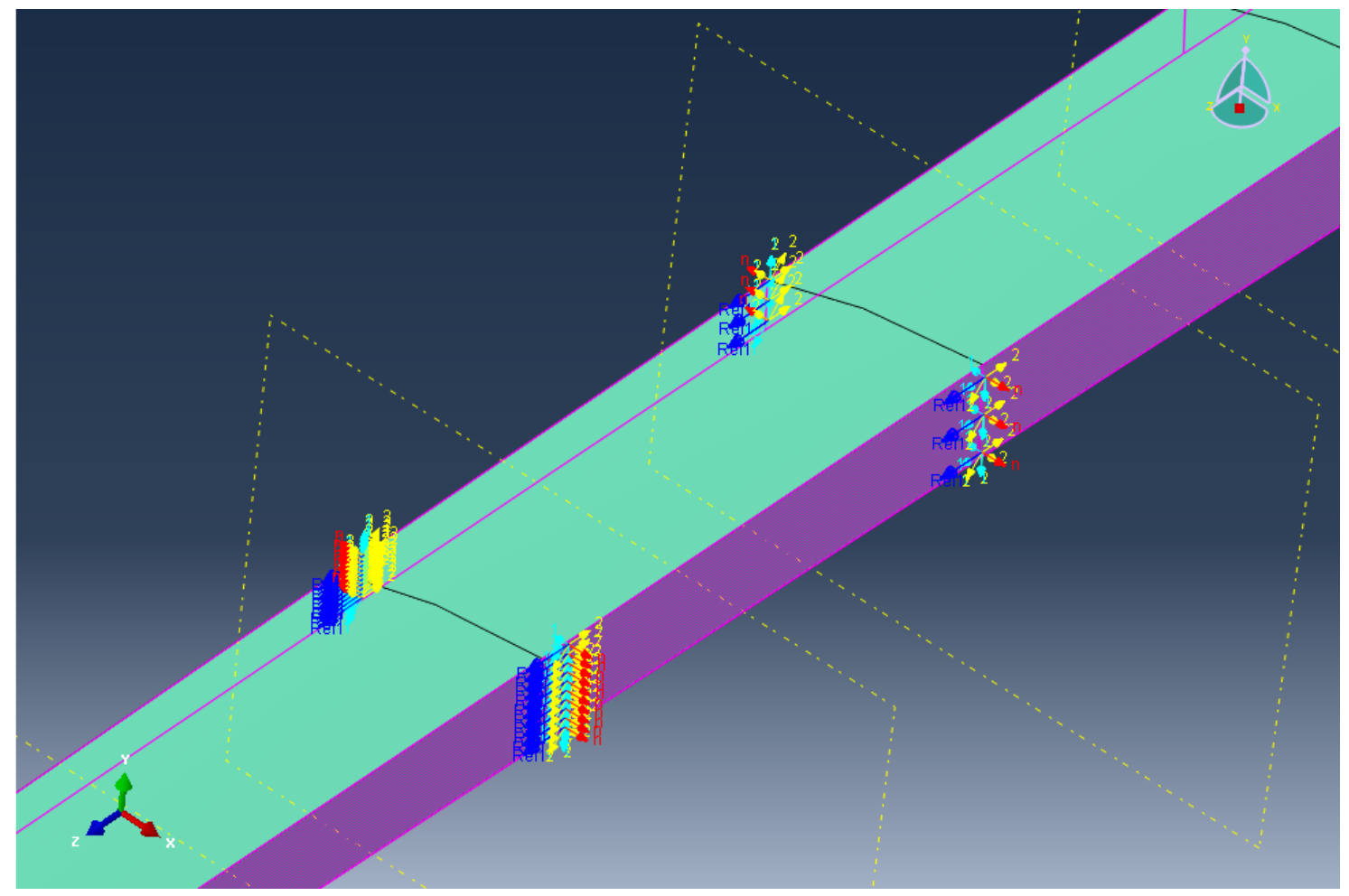

Figure 54 Composite section layup orientation for the shear web shown with the $0^{\circ}$ orientation reference shown in blue and the laminate normal direction in red.

By applying the proper composite layup schedule to the necessary areas of the rotor blade the areas of high stress are strengthened while areas of low stress are not over-designed in an attempt to reduce the amount unnecessary material as well as overall weight.

The spar, which includes the spar cap and shear web, is the only component of the rotor blade that will be constructed with a carbon-fiber and epoxy composite material due to the fact that the spar is the load bearing portion of the design and will experience the highest stresses. Meanwhile the blade skins, or the outer exposed portions of the blade, will be constructed of a fiberglass and epoxy composite material. The rotor blade skins are responsible for maintaining the critical aerodynamic qualities of the blade while also being able to absorb impact 
damage without failing more easily than the carbon-fiber composite material which cannot be strained as much as the fiberglass. The composite schedule of each rotor blade component is shown in Table 9.

Table 9 Composite layup schedule and materials used for this project.

\begin{tabular}{|c|c|c|}
\hline Region & Composite Schedule & Material \\
\hline Spar Cap & {$\left[0_{2} / \pm 45\right]_{s}$} & Carbon \\
\hline Shear Web & {$\left[90_{3} / \pm 45_{3}\right]_{s}$} & Carbon \\
\hline Skin & {$[0 / 90 / \pm 45]_{s}$} & Fiberglass \\
\hline End Cap & {$[0 / 90]$} & Fiberglass \\
\hline
\end{tabular}

For simplicity, this project employed the same composite layup schedule along the entire length of the blade. However, many rotor blades constructed of composite materials have different layup schedules which change radially along the blade. This practice of dropping-off plies is a weight saving technique which allows for a sufficiently strong blade root, where the bending moments are highest as shown previously, and a thin, light structure towards the outer blade sections where loads are not as great.

If a future rotor blade designer is inclined to model this stepped-down composite layup technique it would be a simple task to modify this model to do so by simply selecting the blade sections which are partitioned into multiple, equally spaced, radial blade sections and applying whatever composite layup schedule is called for. 


\subsubsection{Model Mesh Application}

FEA is a very powerful tool due to its ability to accurately model almost any structure as a large number of elements that are all analyzed and interconnected which provides a clear picture of all the stresses, strains, and other important parameters throughout the model. As the number of elements, with their respective nodes, increases the accuracy of the model generally increases along with the amount of computations that must take place. Therefore, it is desirable to use enough elements so that accurate results are produced without generating an overly fine mesh which does not significantly increase the accuracy of the FEA results and is unnecessarily computationally expensive. An important aspect of any mesh is the type of element used to create the individual elements. For this project, a linear, quadrilateral shell element with four nodes per element was chosen for its ability to incorporate the composite structure efficiently and accurately. In ABAQUS this element is referred to as an "S4" element and utilizes the default element settings for element hourglassing and finite membrane strains.

Therefore, it is important when performing a FE analysis that a mesh convergence study be performed so as to limit the computational expense while ensuring the accuracy of the model. Due to the nature of this project containing four joined parts that are meshed separately from one another this presented an interesting challenge. Mesh quality is a large factor in producing useful results in any FEA process with elements of lesser quality, if the quadrilateral element being used is highly distorted for instance, that element will not be able to 
accurately model the stress and strain representative of the actual system.

Therefore, the mesh quality of each element was examined and determined to be acceptable when the number, or percentage, of analysis warnings for a particular part approaches 0 . When meshing a part with ABAQUS' mesh generating feature the program will let the user know if any elements generated are of unusable quality or of poor quality while assigning each of these elements to an element set found in the file's input database. A graph showing the convergence of the model and its individual parts as assessed by the model resulting in a unique tip deflection is shown in Figure 55. One of the more complicated parts to be meshed is the trailing edge which has its individual mesh convergence graph shown in Figure 56 where it should be noted that the number of analysis warnings increased with the inclusion of more elements rather than decreasing as one would expect. This goes to show that the quality of the mesh improves or decreases not only due to the number of elements used but due to the way the mesh generator attempts to apply the mesh. 


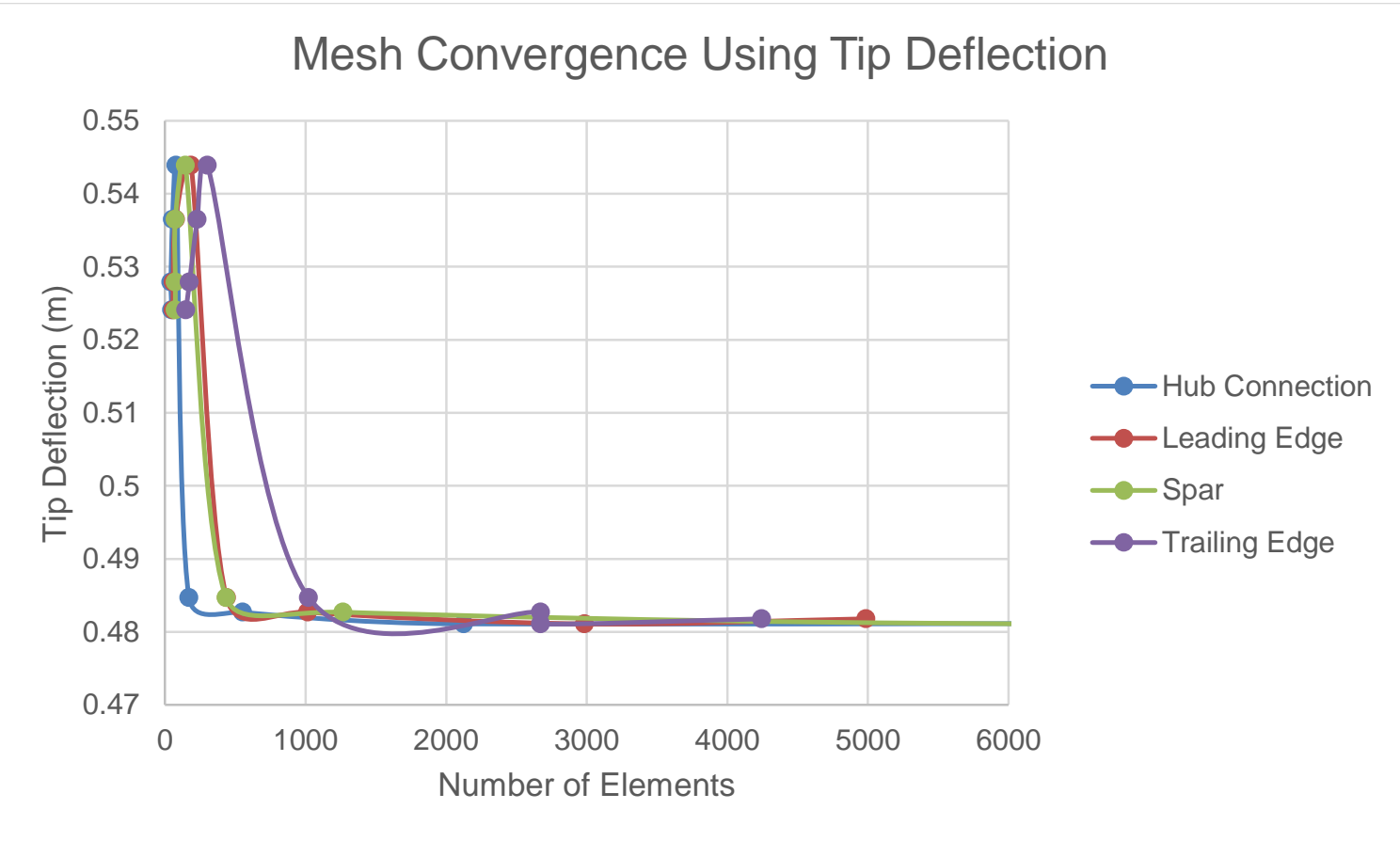

Figure 55 Mesh convergence study with all four of the blade components.

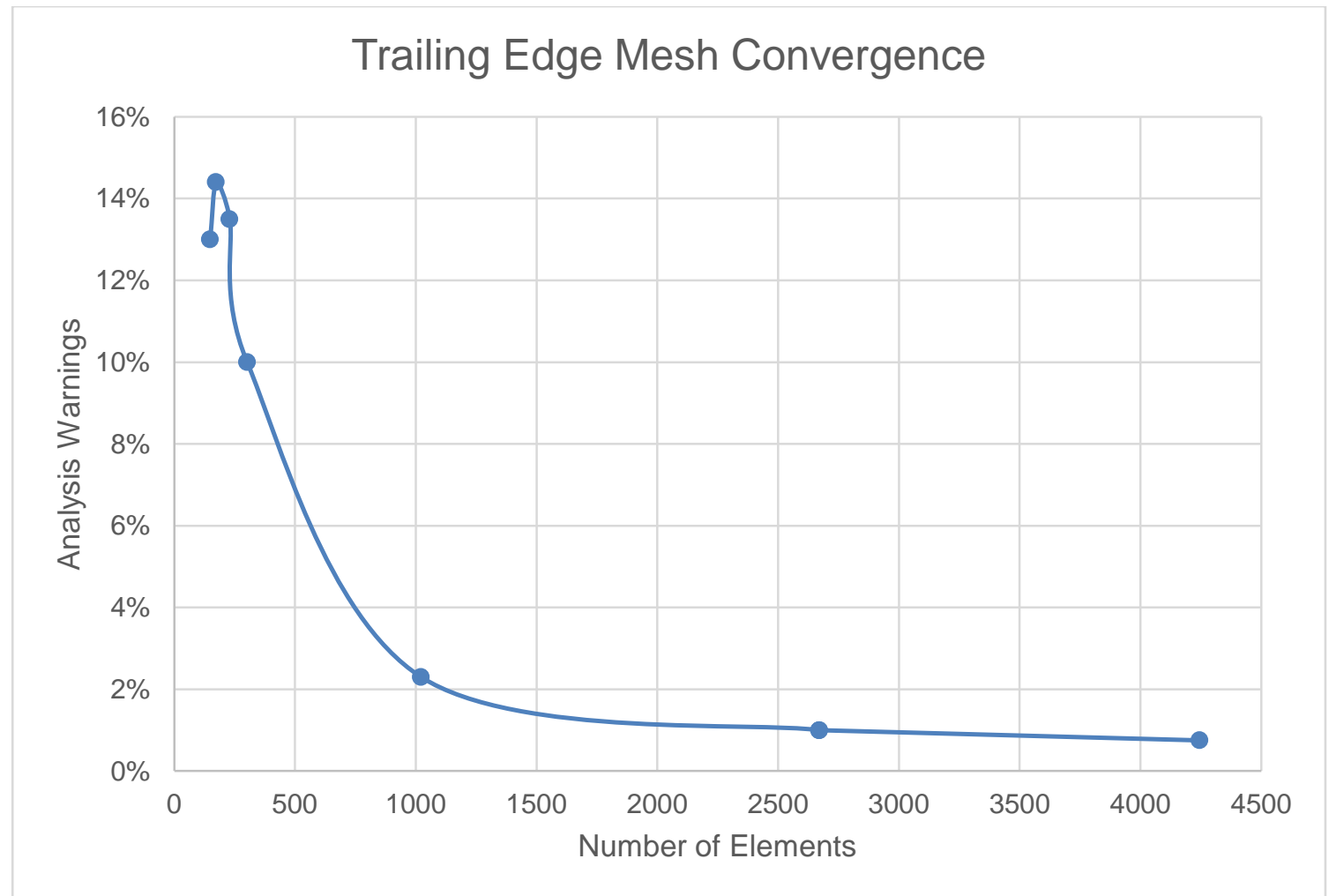

Figure 56 Mesh convergence of the trailing edge component only. 
Another method of generating the best mesh possible is to use local seeding to increase the number of elements on a particular region while leaving the global seed size, and therefore the number of elements, the same.

Mesh controls are utilized to direct the mesh generator to how the particular features of the model should be meshed. For instance, the structured mesh control attempts to apply pre-established mesh patterns to the model topographies which is generally only useful with simple features that do not contain curves, fillets, or other complex geometry. The swept mesh control option creates a mesh by internally generating the mesh on an edge of the part being meshed and sweeps that mesh along a path which is very useful when meshing large, sweeping curves such as the blade skin. The mesh generation control that allows the user the least amount of control is the free meshing technique which does not follow any paths or pre-established patterns. For this project, the blade skin mesh will be generated via the swept mesh control, the spar will be a structured mesh to provide as accurate results as possible, and the small end of the blade will be allowed to mesh freely. The hub connection will need to have its geometry edited more heavily than other parts and will be meshed with the blade skin mesh controlled by swept meshing controls while the spar will be meshed with a structured pattern as shown in Figure 57. 


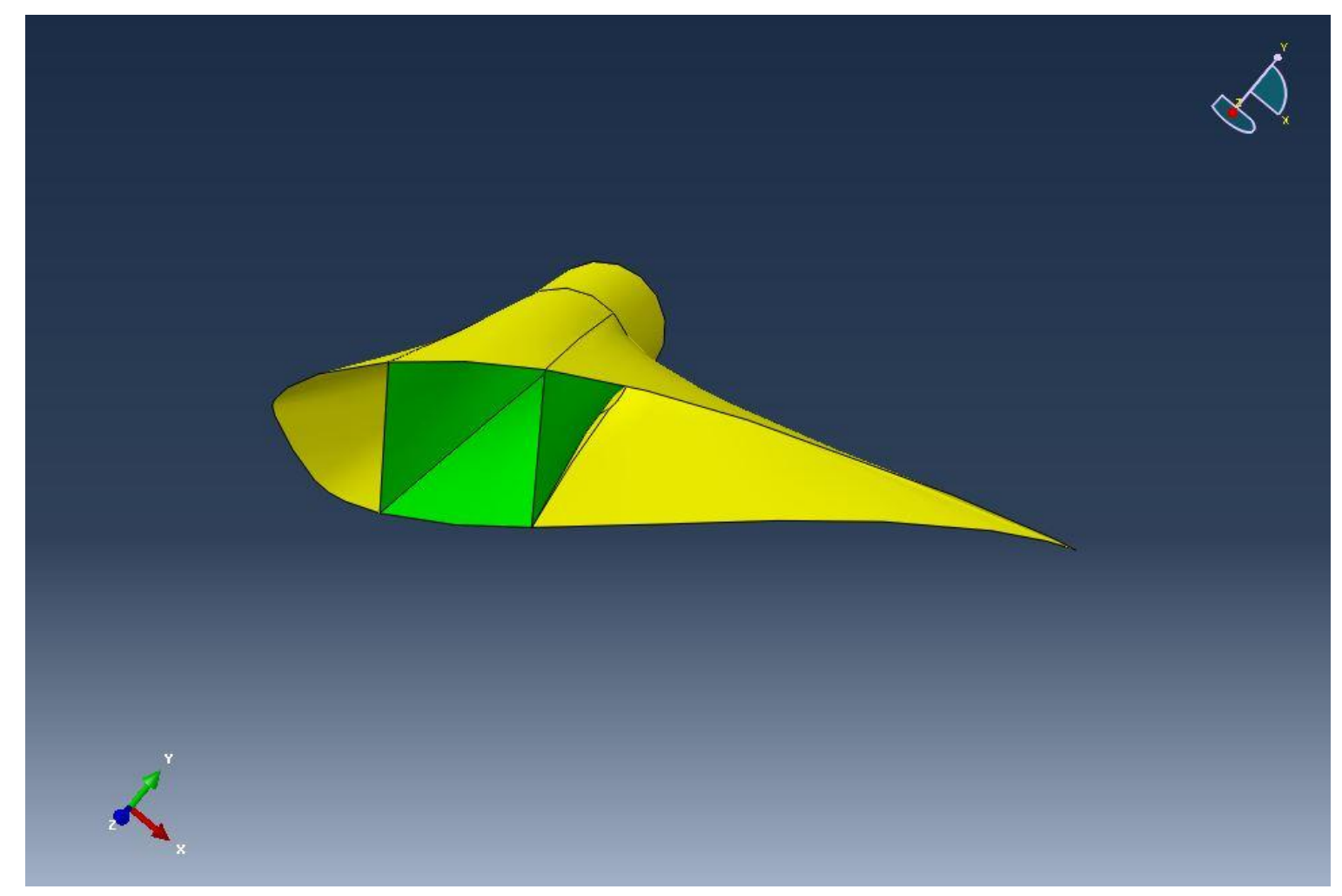

Figure 57 Mesh controls used for the blade hub connection. Swept mesh controls shown in yellow and structured mesh controls in green.

The structured mesh controls applied to the rectangular spar section generates a great mesh quality with zero errors or warnings, and the swept meshing technique utilized for the sweeping geometry of the blade skin generates a good quality mesh without over complicating the mesh, as shown in Figure 58. 


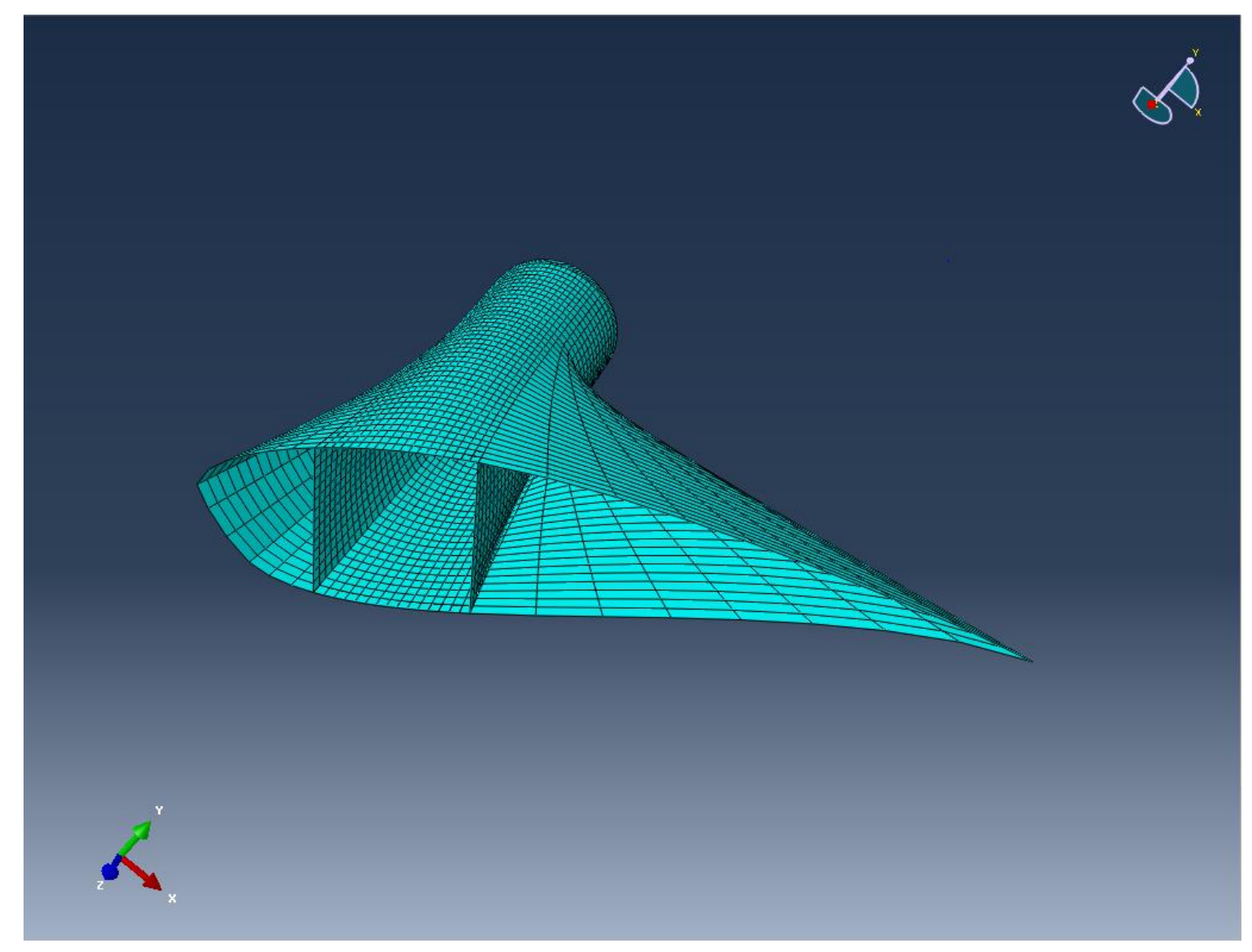

Figure 58 Fully meshed hub connection section with fine mesh along spar and cylindrical blade root.

The final mesh of the overall rotor blade model, which can be seen in Figure 59, contains 28,183 elements and a total number of variables of 172,074 . By locally seeding regions that experience high stress in combination with a properly refined global mesh throughout the model and utilizing recommended S4 shell elements capable of realistically modeling the composite structure very accurate results were obtained. 


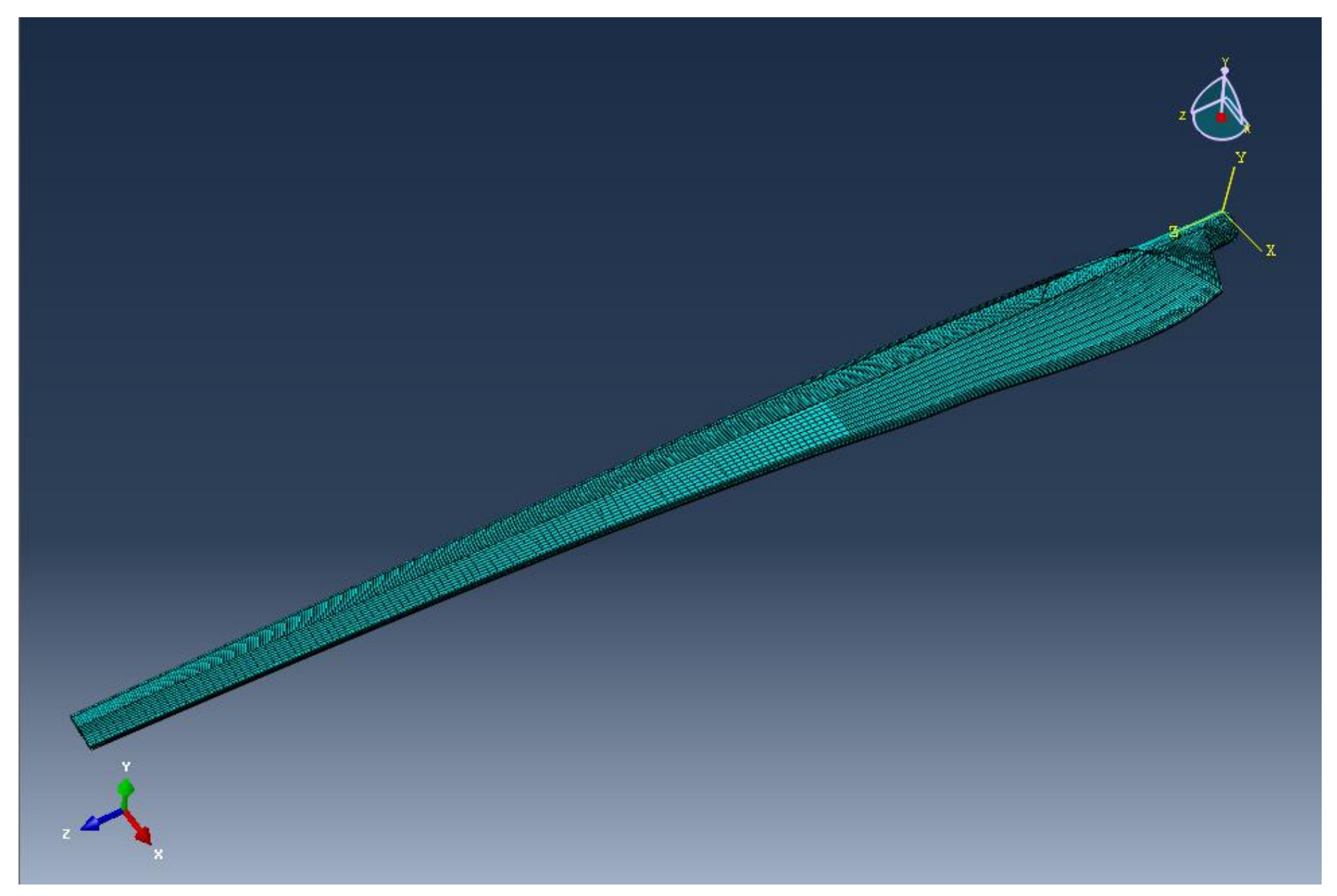

Figure 59 Rotor blade with completed mesh including local seeding at blade root sections. 


\subsubsection{Loading Scenarios and Constraints}

Besides the proper mesh implementation, loading and constraint definitions are of paramount importance to any FEA model with the usefulness of the results hinging on this being as realistic as possible. The only constraint required for a HAWT rotor blade is that of the connection between the composite blade structure and the aluminum rotor hub. This connection is meant to be a fixed connection with no rotation or translation occurring between the two components via a circular, six bolt pattern attaching the blade to the hub. In order to model the ideal situation, the face of the blade which is normally in contact with the hub has an encastre constraint applied which does not allow rotation or translation with respect to all three axes, as shown by orange arrows in Figure 60. Two methods of applying aerodynamic loads were attempted for this project, one in which concentrated forces were applied to the load bearing spar and another in which a pressure force is applied to the high pressure side of the blade along the spar as well. It was found that both methods of applying loads provided similar results however, the pressure loading method was selected since it is more realistic. Along with aerodynamic loads the direction of a gravity force vector is specified and a rotational body force is applied with the gravity vector applied such that the blade is at the three o'clock position, when viewed upwind, and the rotational speed of the blade is 26 revolutions per minute, as shown in Figure 62 .

The loading scenarios in which the blade is operating under normal conditions utilizes the pressure loading application method while the parked rotor blades are modeled with the concentrated force application method. All forces directly 
applied, either with pressure or concentrated forces, are the aerodynamic forces calculated by BET as described in chapter 3 with their magnitude relative to the loading scenario being modeled.

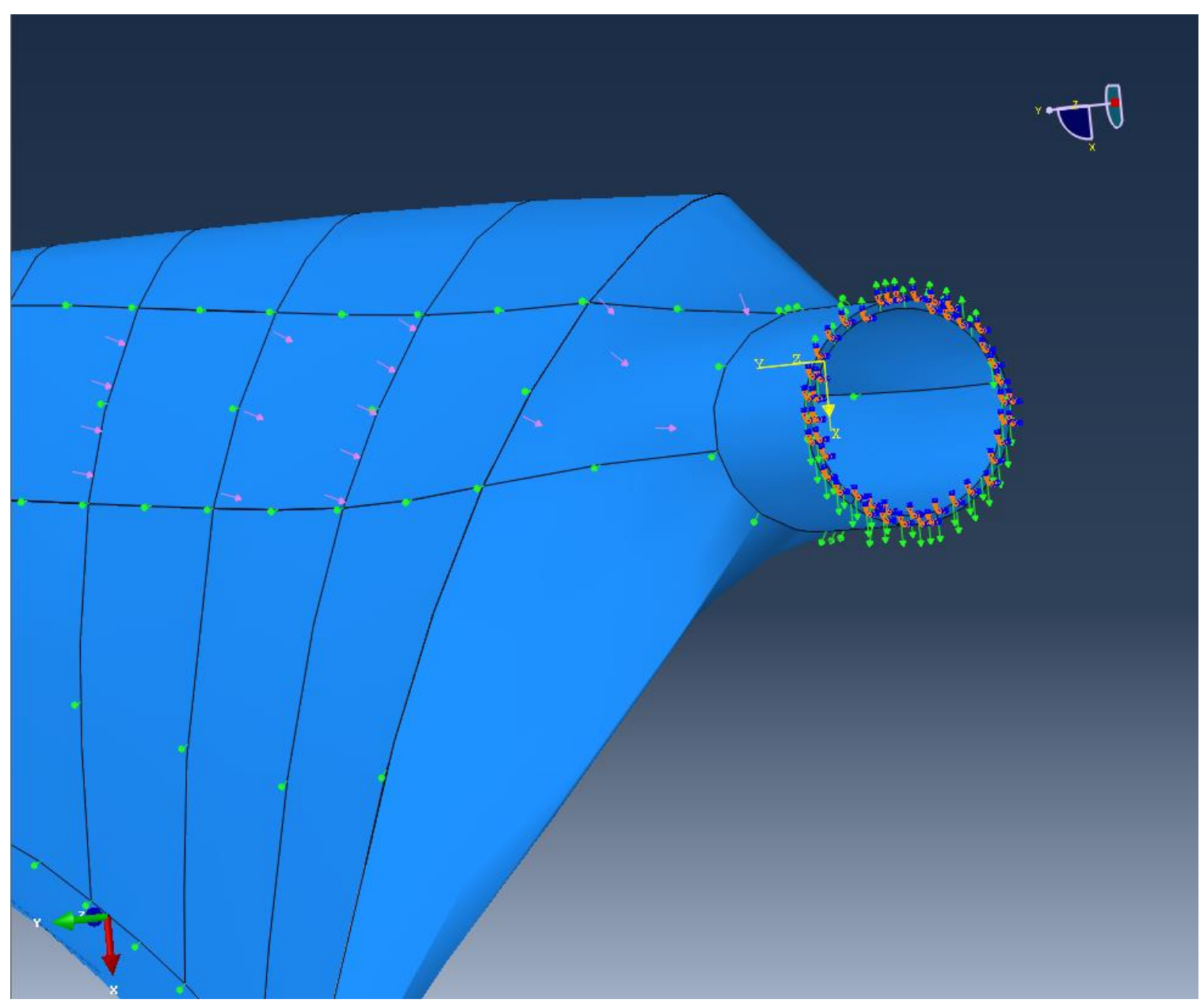

Figure 60 Boundary conditions shown as orange arrows at the blade to hub interface, pressure forces shown as pink arrows, rotational body forces shown in green and the gravity vector shown in yellow along the $x$ axis datum. 


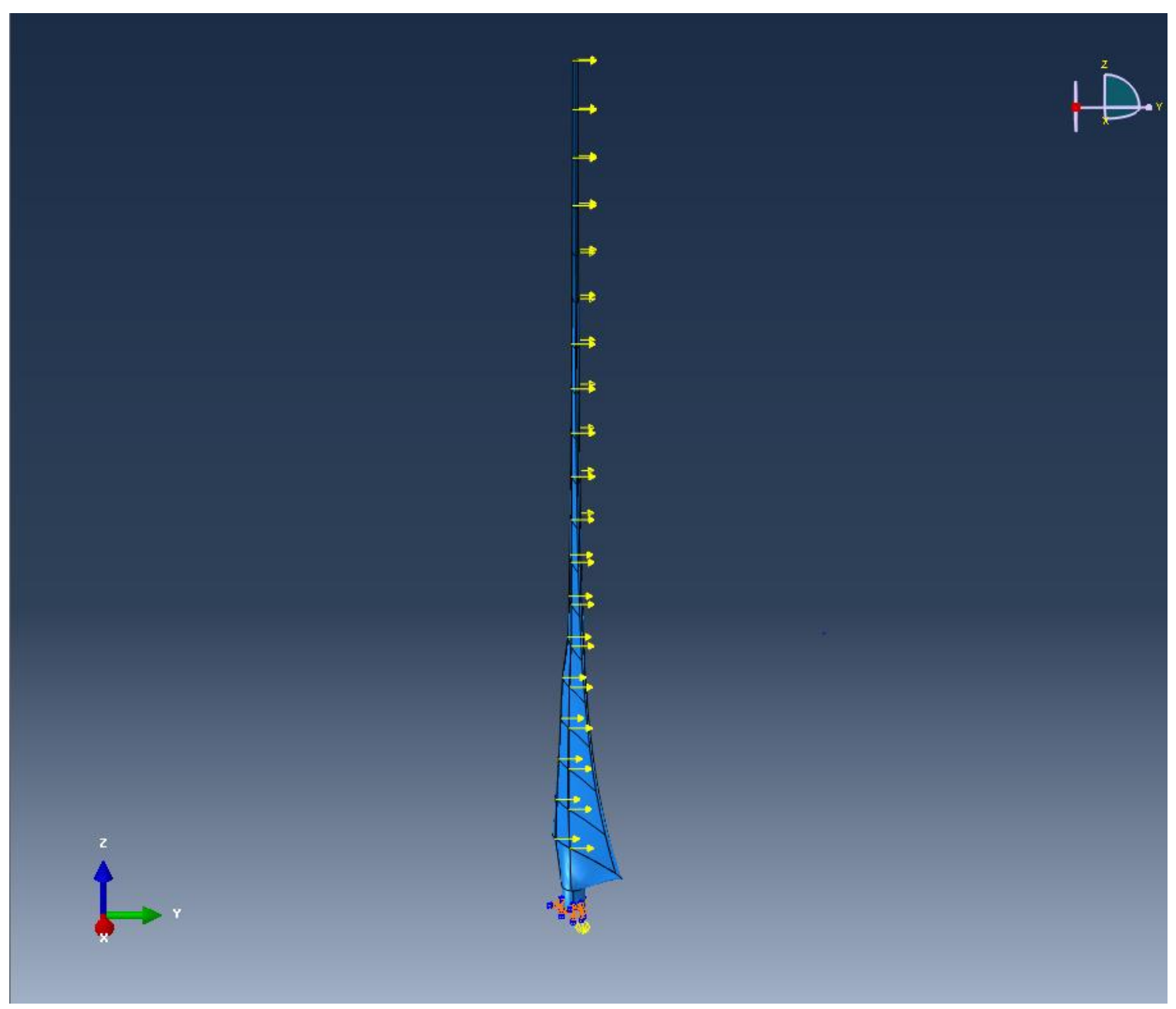

Figure 61 Concentrated force load application model with forces shown as yellow arrows at their respective blade sections for the parked rotor model. 


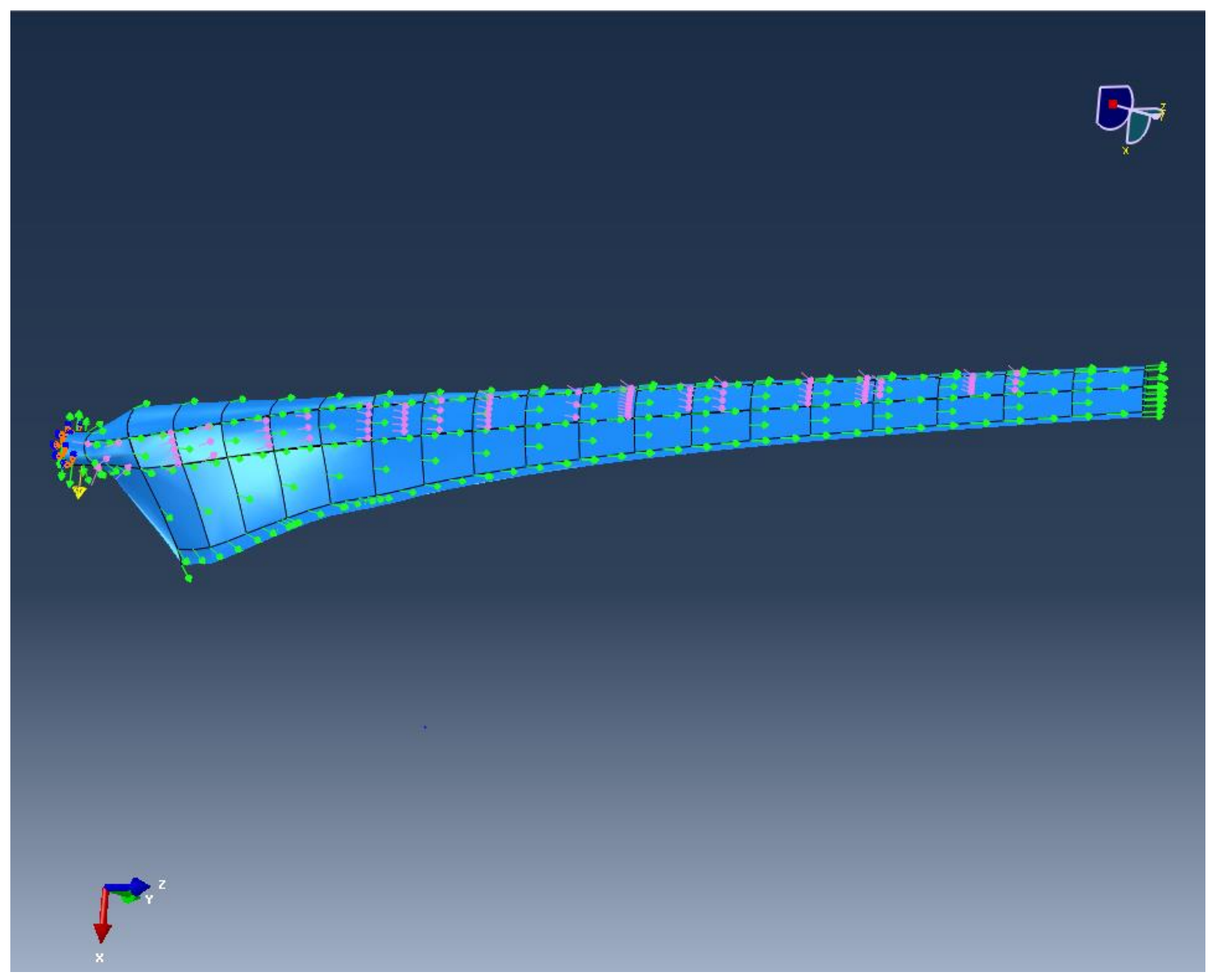

Figure 62 Pressure loading application shown with pink arrows along the spar during normal operation.

\subsection{Results of ABAQUS Modeling}

FEA is a valuable tool for engineers due to its ability to accurately define the stress and strain throughout a model very accurately when properly utilized. For this project, the FEA process was meticulously applied to the wind turbine rotor blade which was analyzed with classic aerodynamic techniques that have been shown to be reliable by industry leaders in wind turbine technology for many years. After the proper application of loads, constraints, and material properties which define the rotor blade model as realistically as possible ABAQUS is able to produce very useful results which aid the designer in verifying the effectiveness 
of this optimized blade design. The types of results that are of paramount importance to this project include the stress and strain throughout the blade during normal and parked operating conditions. Since the blade is a composite structure composed of several different ply types each with varying fiber directions these stresses and strains were evaluated throughout the entirety of the composite layup. In this way the structural integrity of critical plies, those which experience the highest stresses and strains, are examined very closely. Examining these results allows the designer the ability to predict whether the blade structure will fail and where.

\subsubsection{Blade Stress}

One of the most important aspects of any structural analysis is the determination of the stresses generated throughout the structure and how they affect the performance of the design. The presence of stress concentrations can lead to premature failure of the structure and cause other subcomponents to fail as well and must be addressed in the design process. Therefore, a main function of the structural analysis of a HAWT rotor blade is to identify the magnitude and location of the stress concentrations and use this information to modify the design of the composite laminate layup so that any load bearing components can handle the forces exerted on it.

One of the most useful stress and strain analysis tools ABAQUS contains for use with composite structures is the envelope plot. The envelope plot allows the user to view the highest or lowest value of a model variable throughout a composite structure, such as stress or strain in the longitudinal and transverse fiber 
directions as well as shear values, or in individual plies. The position in each ply which ABAQUS evaluates the requested model variable may be specified as each integration point used per ply, element centroid, or element nodal positions. The plies in which the highest or lowest values are calculated for whichever model variable is requested are called the critical plies. These values are then compared with known ultimate stress and strain data to determine if and where ply failure has occurred and to identify composite sections which have very low stress and strain values and can withstand having plies removed. The longitudinal and transverse critical ply stresses are shown in Figure 63 and Figure 64 for the overall model where it can be seen that the carbon fiber spar cap contains the largest longitudinal stresses while the fiberglass skins have lower stress values. Figure 65 shows the maximum shear stress values found in the critical plies of every composite section where the effect of the load bearing spar being evident as well. 


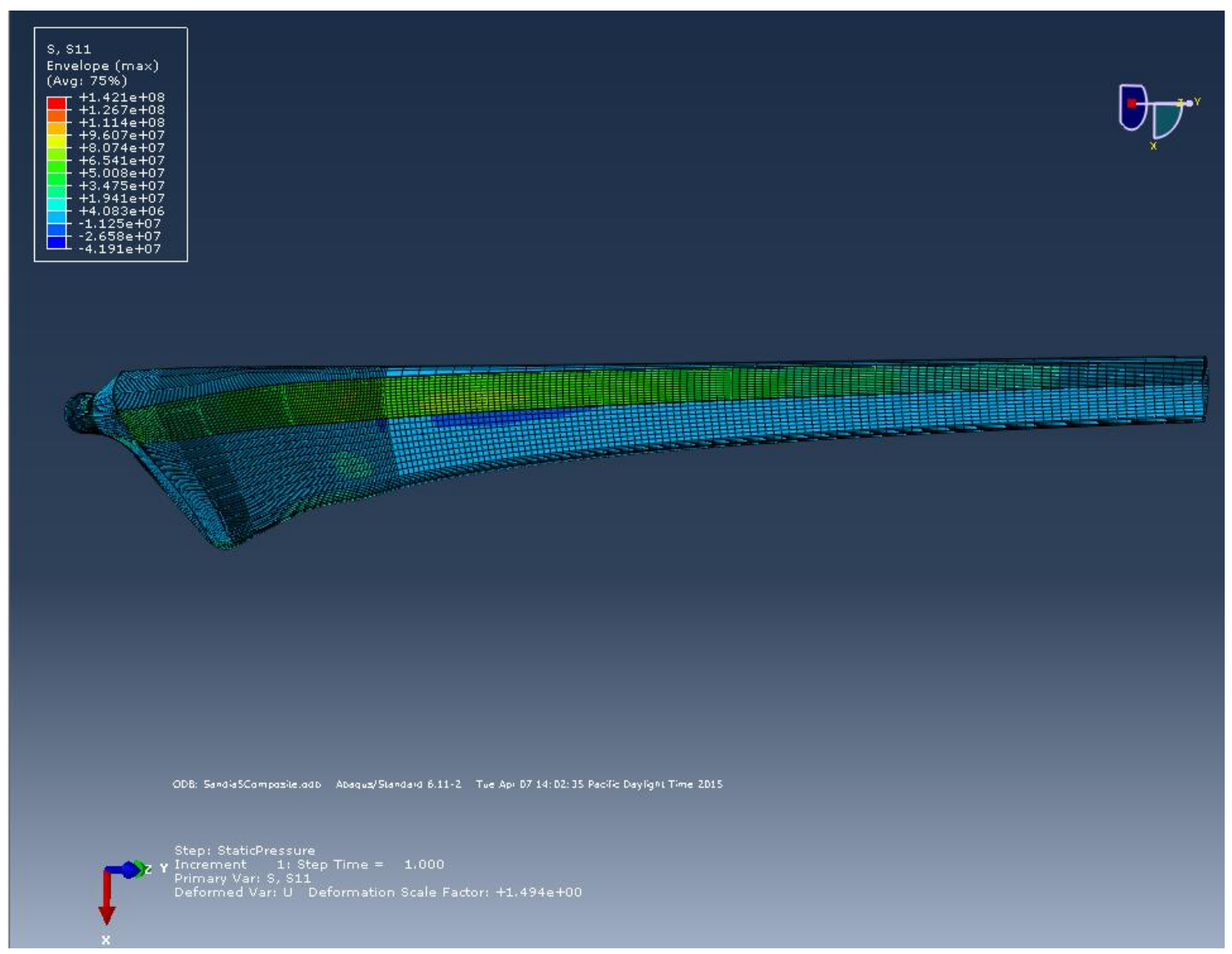

Figure 63 Critical ply longitudinal stresses for the overall blade model undergoing normal operation with a wind speed of $11 \mathrm{mph}$. 


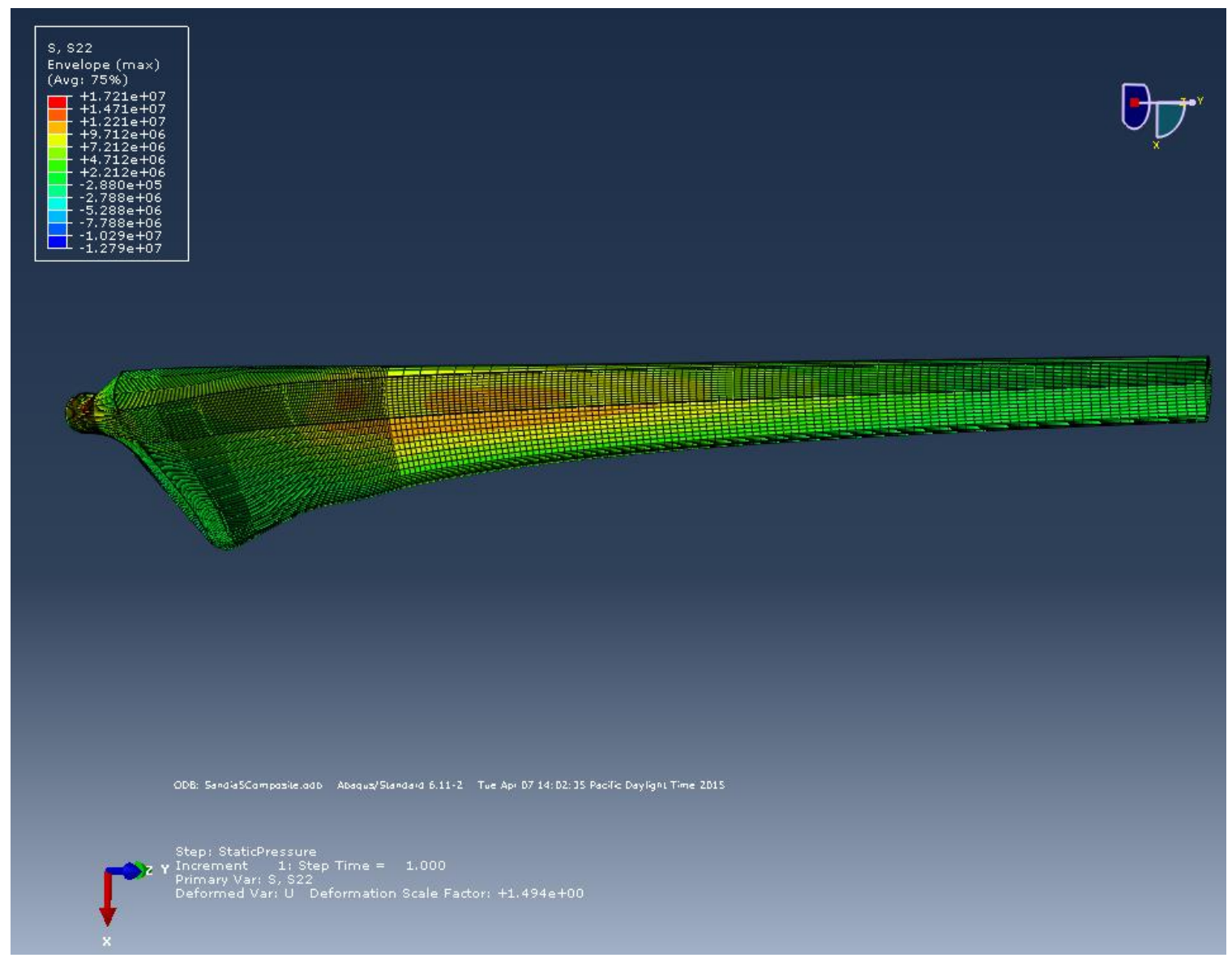

Figure 64 Critical ply transverse stresses for the overall blade model undergoing normal operation with a wind speed of $11 \mathrm{mph}$. 


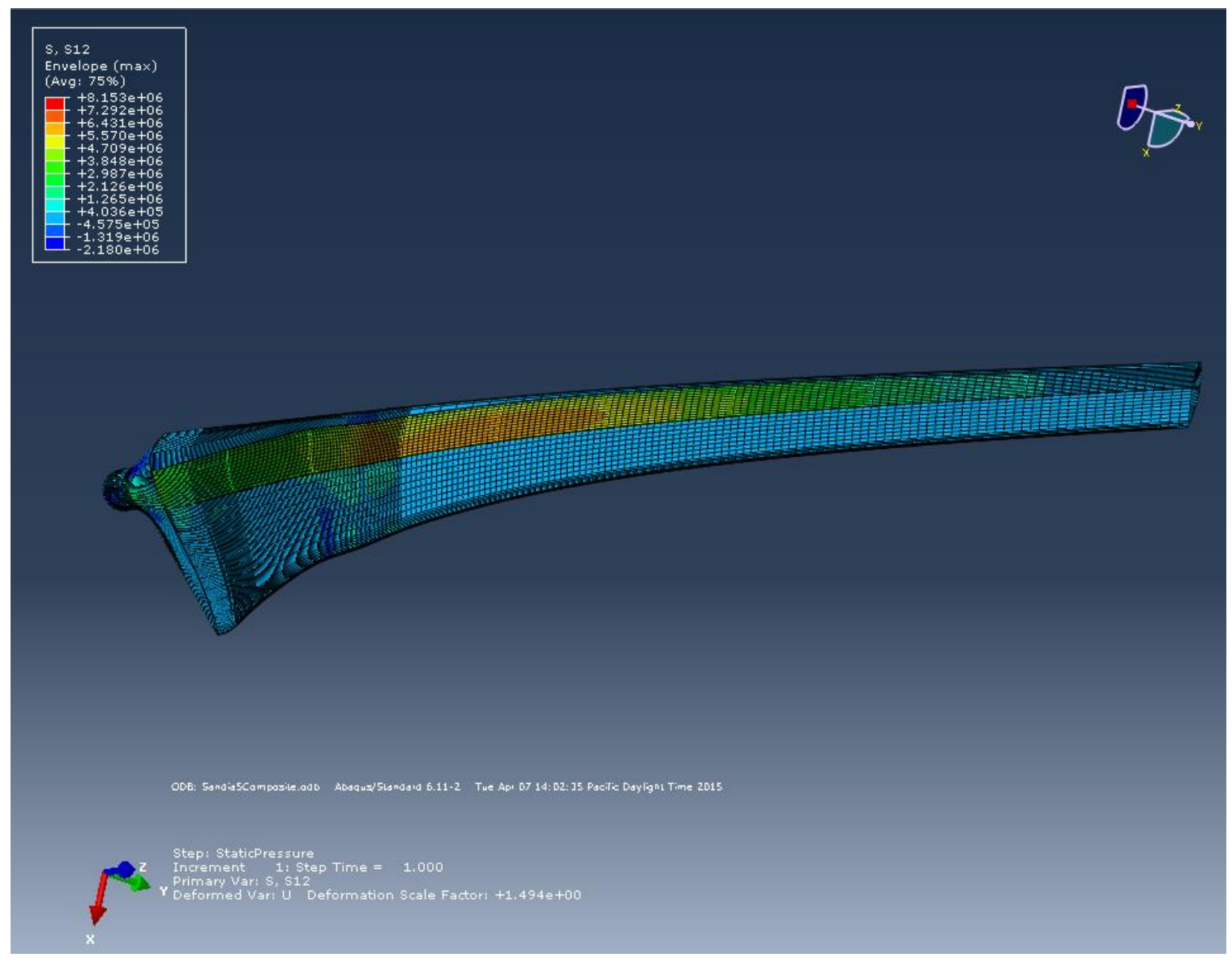

Figure 65 Critical ply shear stresses for the overall blade model undergoing normal operation with a wind speed of $11 \mathrm{mph}$.

By investigating the critical plies of each composite section, the plies which have the highest computed stress and strain values of all the plies in the laminate, it was determined that stress concentrations existed at the root and airfoil transitional sections of the spar. Due to the fact that the carbon fiber spar is the load bearing component of the blade and the largest bending moments were expected to occur at the base of the blade this was expected and further verifies the accuracy of the FEA model. Figure 66 and Figure 67 show the critical ply stresses in the longitudinal and transverse directions, respectively, for the carbon fiber plies at the blade root. 


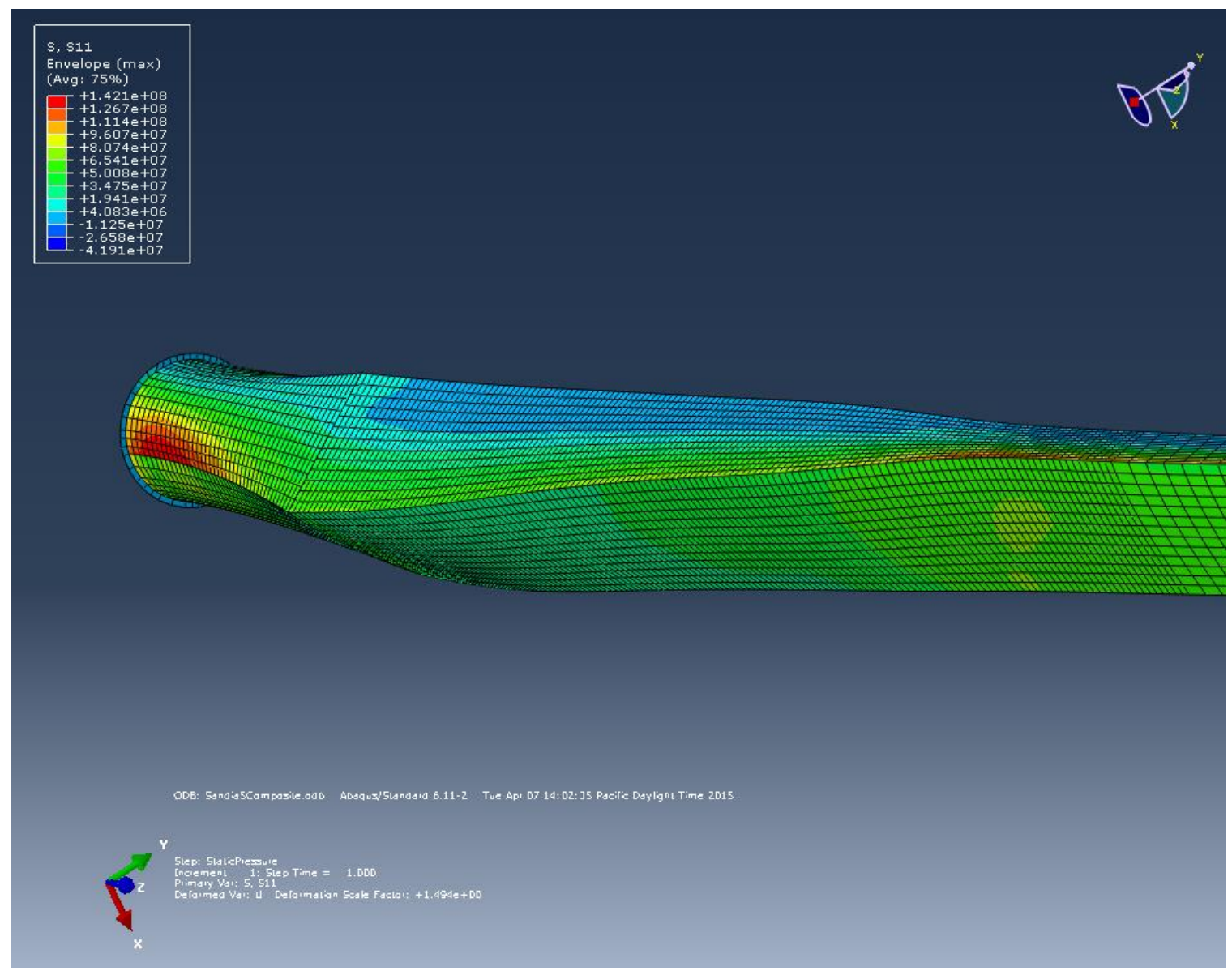

Figure 66 Longitudinal fiber stress concentrations at the spar root tube and airfoil transitional sections with opposing compressive stresses shown in blue. 


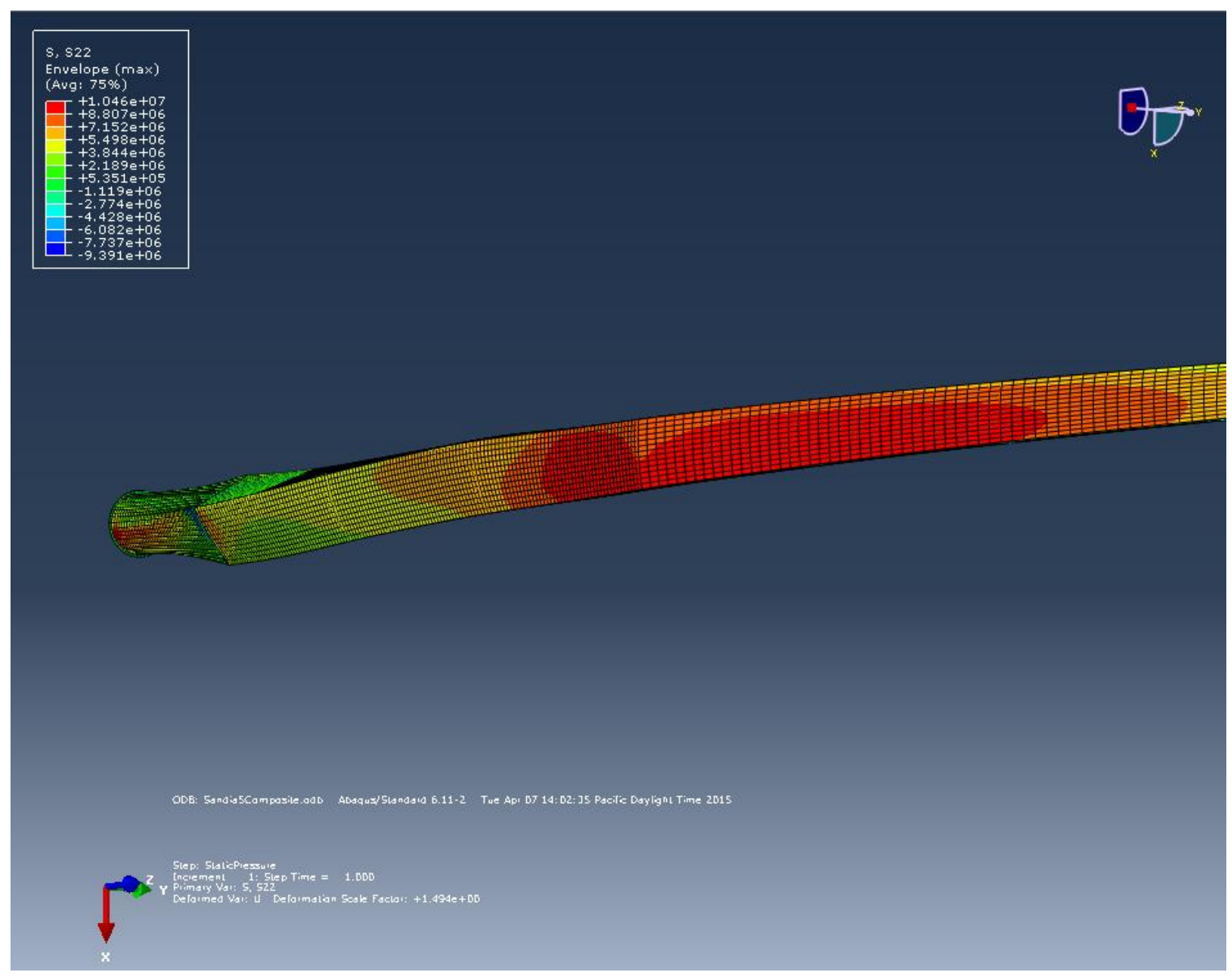

Figure 67 Transverse fiber stresses along the high pressure side of the spar concentrated at the airfoil transitional sections and root tube.

The load bearing spar acted exactly as it was designed to do by mitigating the stresses along the blade. Stress concentrations found at the airfoil transitional sections between the thicker $\mathrm{S} 823$ and the thinner $\mathrm{S} 822$ airfoils can be further reduced by applying the $S 823$ airfoil further down the blade radially to allow for a larger spar near the blade root. This larger spar should lessen the stress values found at the airfoil transitional blade sections. Also, additional plies may be added along the spar near the blade root to further reinforce the blade structure at these high stress areas. Table 10 summarizes the maximum stresses 
predicted at the critical plies and compares each of them to the known ultimate values of the material being stresses and determines the safety factor generated.

Table 10 Summary of critical ply stresses with safety factors computed with known ultimate stress values.

\begin{tabular}{|c|c|c|c|c|c|}
\hline \multirow[t]{2}{*}{ Material } & \multicolumn{2}{|c|}{$\begin{array}{c}\text { Critical Ply Longitudinal } \\
\text { Stress (MPa) }\end{array}$} & \multicolumn{2}{|c|}{$\begin{array}{c}\text { Critical Ply Transverse } \\
\text { Stress (MPa) }\end{array}$} & \multirow{2}{*}{$\begin{array}{l}\text { Shear } \\
\text { Stress } \\
\text { (Mpa) }\end{array}$} \\
\hline & Tensile & Compressive & Tensile & Compressive & \\
\hline $\begin{array}{c}\text { M9.1 } \\
\text { Carbon }\end{array}$ & 142.1 & -41.9 & 10.46 & -9.39 & 8.15 \\
\hline $\begin{array}{l}\text { Safety } \\
\text { Factor: }\end{array}$ & 12.76 & 17.76 & 2.25 & 11.08 & 13.50 \\
\hline $\begin{array}{l}\text { M9.6 } \\
\text { Glass }\end{array}$ & 51.10 & -26.66 & 17.21 & -12.80 & 3.40 \\
\hline $\begin{array}{l}\text { Safety } \\
\text { Factor: }\end{array}$ & 22.82 & 18.94 & 2.11 & 13.60 & 23.82 \\
\hline
\end{tabular}

\subsubsection{Composite Structure Damage}

Along with basic stress, strain, and displacement analyses ABAQUS is able to perform a damage analysis calculation by selecting "Failure/Fracture" options from the field output request manager. For this project, the Hashin damage initiation criterion was chosen which determines whether the fiber or matrix components of the composite structure fail due to tension or compressive stresses on each element. The Hashin criterion takes into account stresses in the fiber longitudinal and transverse direction as well as both in and out-of-plane 
shear forces and is regarded as a very good predictor of composite structure failure. Any Hashin failure value of 1.0 or higher indicates that failure has initiated in either the fiber or matrix being investigated due to either tensile or compressive forces. Table 11 summarizes the results of the Hashin damage criterion for all three loading scenarios modeled.

Table 11 Hashin failure index summary for all loading scenarios with a value of 1.0 or higher indicating damage initiation.

\begin{tabular}{|c|c|c|c|c|}
\hline $\begin{array}{c}\text { Loading } \\
\text { Scenario }\end{array}$ & Fiber Tension & $\begin{array}{c}\text { Fiber } \\
\text { Compression }\end{array}$ & $\begin{array}{c}\text { Matrix } \\
\text { Tension }\end{array}$ & Compression \\
\hline $\begin{array}{c}\text { Operation at } \\
8 \mathrm{mph}\end{array}$ & 0.001551 & 0.01083 & 0.1222 & 0.04435 \\
\hline $\begin{array}{c}\text { Normal } \\
\text { Operation at } \\
11 \mathrm{mph}\end{array}$ & 0.006161 & 0.04338 & 0.2375 & 0.09691 \\
\hline $\begin{array}{c}\text { Parked Rotor } \\
\text { at } 33.5 \mathrm{mph}\end{array}$ & 0.0004105 & 0.002439 & 0.0231 & 0.01698 \\
\hline
\end{tabular}

It can be seen that all the failure indexes are well below the 1.0 threshold for damage to initiate. This extremely high safety factor was by design in order to ensure that this model did not fail under any circumstance. Also, the overall blade stiffness is directly related to the number of carbon plies aligned radially along the blade and can be manipulated to increase or decrease blade stiffness. 
Therefore, an excess of carbon plies were employed to limit the tip deflection of the blade during normal operation so that the blade tip does not strike the HAWT tower, leading to a very strong spar.

\subsubsection{Blade Strain}

It is important to investigate the strain levels found throughout the blade structure as well in order to determine the fatigue lifespan of the blade and ensure no strain related failures occur. The Department of Energy and Montana State University have an ongoing project with the goal of creating a database of composite material data properties including fatigue strain limits on carbon fiber and fiberglass materials [13]. Using this data, as shown in Figure 68, it can be seen that by keeping the maximum tensile and compressive strains of the carbon fiber spar below $1 \%$ and $0.75 \%$, respectively, then this model can be expected to not fail for up to $1 \mathrm{E} 8$ cycles before failure may occur. 

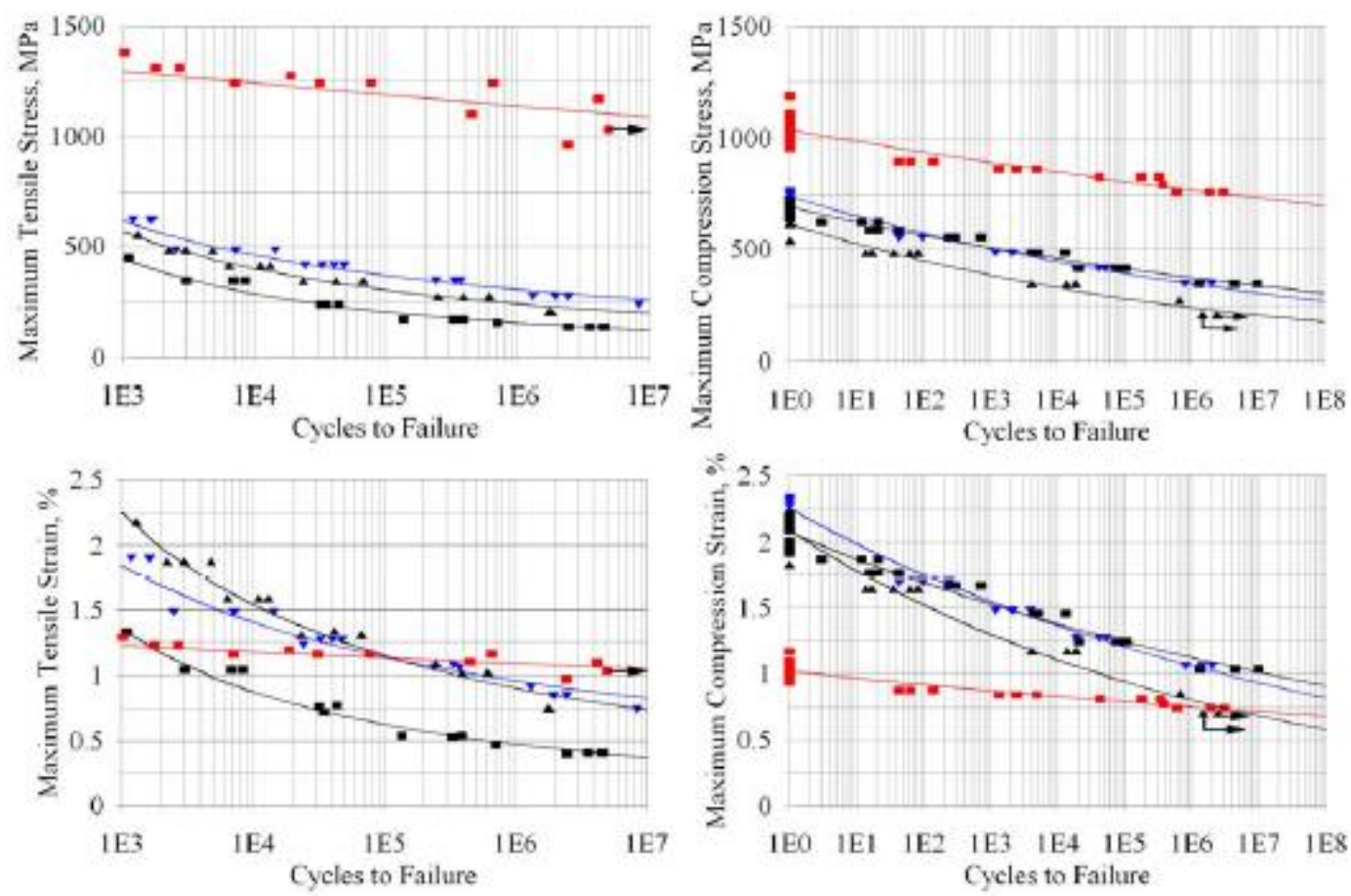

E-Glass: QQ1 (*) and E-LT-5500 (^), Windstrand: WS1 ( ), Carbon: P2B (*)

Figure 68 Fatigue coupon testing data of commercially-available composite materials from DOE/MSU database.

Again utilizing the envelope plotting tool in ABAQUS to determine the maximum strain values found at any ply throughout the blade, the necessary strain data was determined for all loading scenarios. The loading scenario with the highest strain values was the model in which the rotor was operating normally and subject to a wind speed of 11 miles per hour which is the model and was therefore investigated very thoroughly. Critical plies which were subject to the highest strains were found to corresponded to the critical plies that were located at the areas of highest stresses as shown in Figure 69, Figure 70, and Figure 71. 


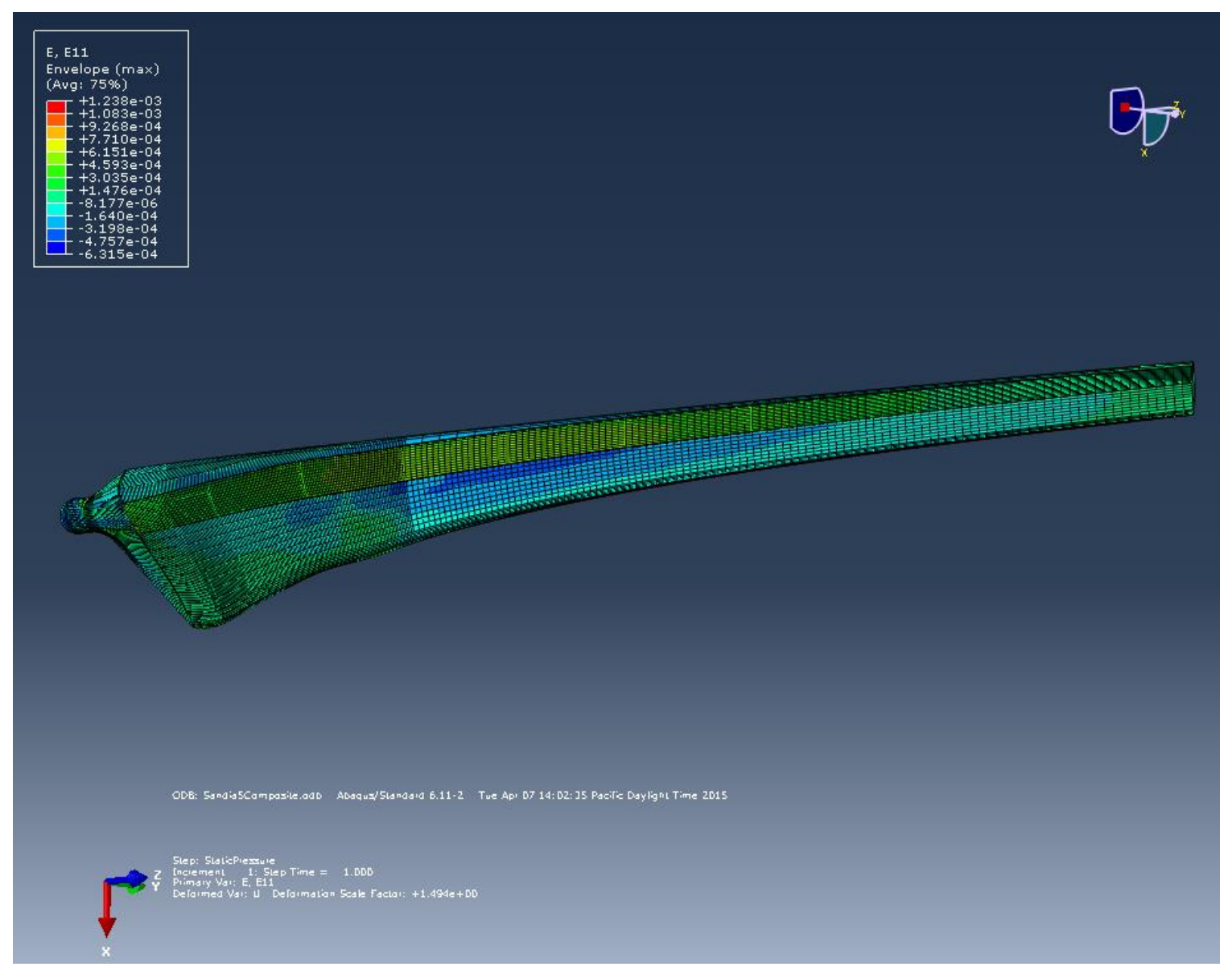

Figure 69 Longitudinal strain envelope plot showing higher strain values along the blade spar as viewed from an upwind position. 


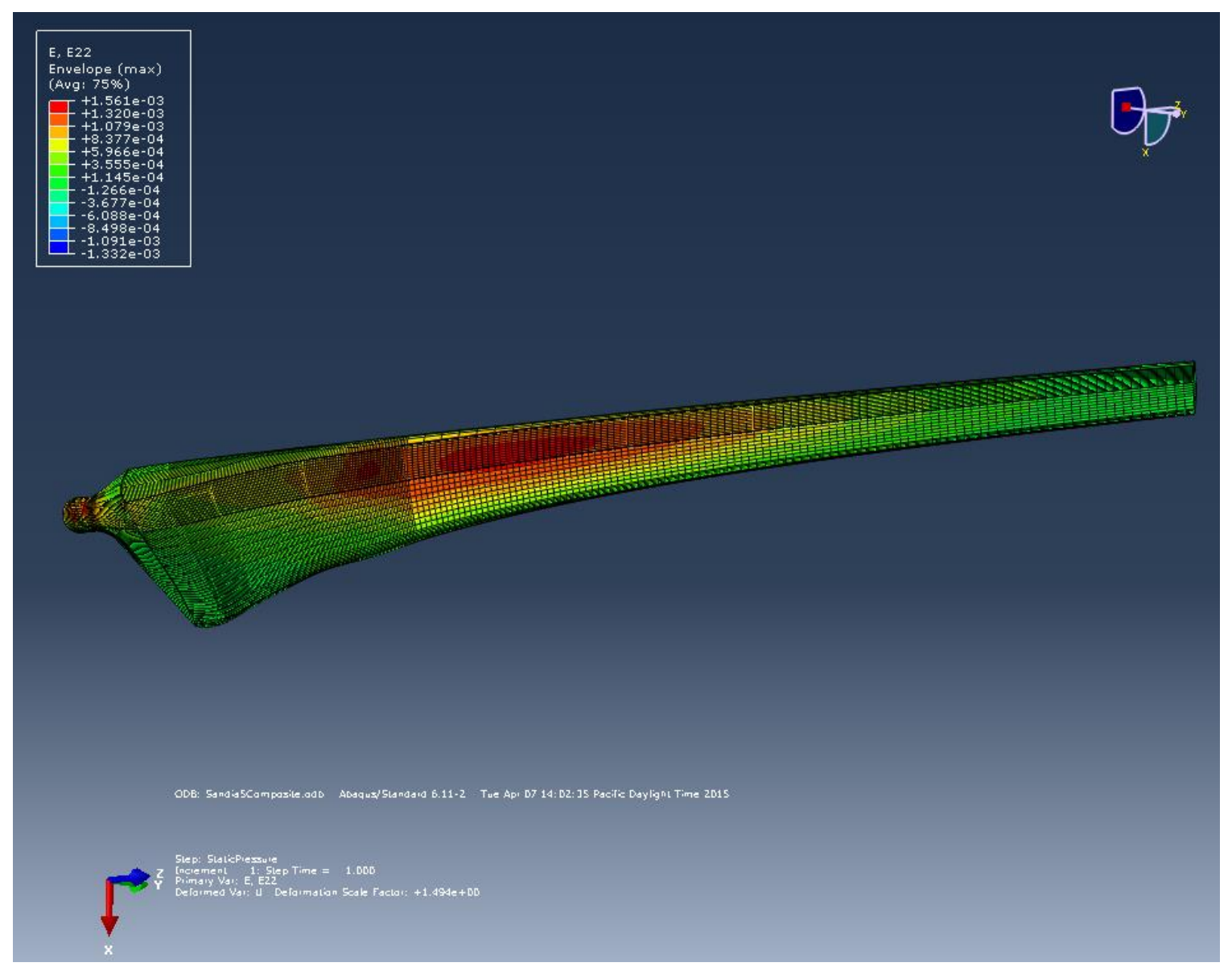

Figure 70 Transverse strain envelope plot showing higher strain values at the airfoil transitional blade sections and root tube, as viewed from an upwind position. 


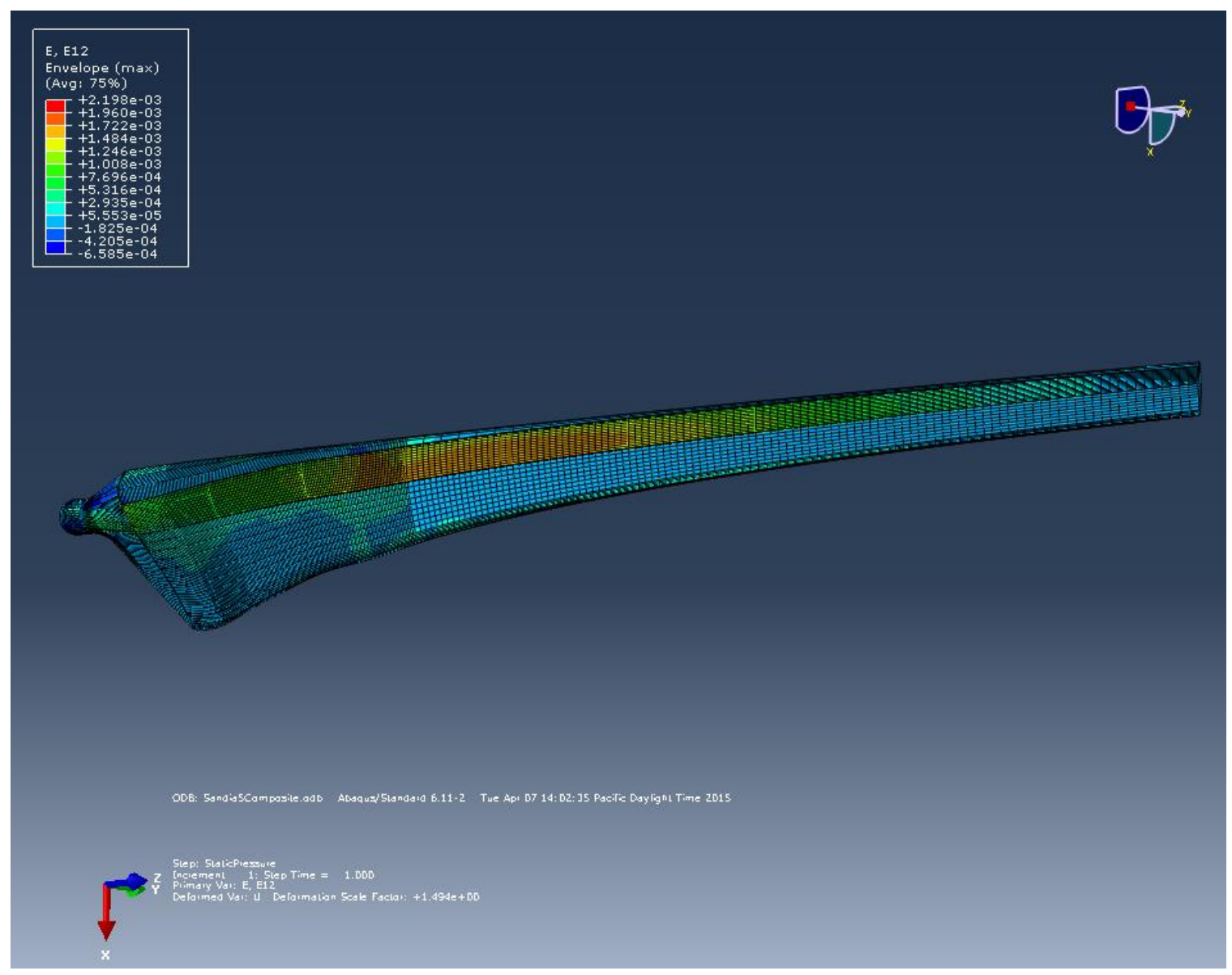

Figure 71 Shear strain envelope plot showing higher strain values along the blade spar with the highest shear strain values predicted at the airfoil transitional blade sections.

A summary of the maximum strain values in the longitudinal and transverse fiber directions is shown in Table 12 where it can be seen that neither the carbon fiber nor the fiberglass plies were strained higher than their known ultimate strain values. Safety factors calculated via known ultimate strain data correspond well with the safety factors calculated previously in regards to the material ultimate stress values. 
Table 12 Maximum strain values for critical plies during normal operating with a wind speed of $11 \mathrm{mph}$.

\begin{tabular}{|c|c|c|c|c|}
\hline Material & $\begin{array}{c}\text { Maximum } \\
\text { Longitudinal } \\
\text { Tensile Strain (\%) }\end{array}$ & $\begin{array}{c}\text { Safety } \\
\text { Factor }\end{array}$ & $\begin{array}{c}\text { Laximum } \\
\text { Longitudinal } \\
\text { Compressive } \\
\text { Strain (\%) }\end{array}$ & $\begin{array}{c}\text { Safety } \\
\text { Factor }\end{array}$ \\
\hline M9.1 Carbon & 0.12 & $\mathbf{1 3 . 1 7}$ & 0.055 & $\mathbf{1 1 . 8 2}$ \\
\hline M9.6 Glass & 0.115 & $\mathbf{2 3 . 5 7}$ & 0.063 & $\mathbf{1 9 . 0 5}$ \\
\hline
\end{tabular}

\subsubsection{Blade Tip Deflection}

A critical parameter to a HAWT rotor blade design is the blade tip deflection which is controlled by the stiffness of the blade with the stiffness being dictated in this project mainly by the use of a spar. As described previously the spar is constructed of high strength, high stiffness carbon fiber that is several times greater than the fiberglass fibers that make up the blade skin. Therefore, the blade tip deflection is controlled by the amount of carbon fiber used along the spar and can be altered to conform to whatever is necessary for the blade tip to not come into contact with the HAWT tower. It should also be noted that the vibrational, linear perturbation model demonstrated how the blade tip deflection can more than double in magnitude when the rotor blade is operating at one of its natural frequencies.

The FEA results of each loading scenario are examined in order to determine the maximum tip deflection with respect to each scenario, with the results compiled in Table 13. As was expected, the higher operational wind speeds increased the 
blade tip deflection by 12.2 inches while the blade tip of the parked rotor undergoing a strong wind gust only deflected 3.8 inches.

Table 13 Summary of tip deflection for each loading scenario modeled.

\begin{tabular}{|c|c|c|}
\hline Model Scenario & Tip Deflection (m) & Tip Deflection (in) \\
\hline Normal Operation 8 mph & 0.3047 & 12.0 \\
\hline Normal Operation 11 mph & 0.6146 & 24.2 \\
\hline Parked Rotor with 15 m/s Wind Gust & 0.09615 & 3.8 \\
\hline
\end{tabular}

It is evident that this blade has a very high stiffness due to the fact that the 30 foot rotor blade tip deflects only 2 feet when subjected to the highest operation wind speeds modeled.

Natural blade vibrations can cause serious problems during turbine operation and should be investigated so as to ensure the blade does not strike the tower or allow the blade fail in any way. Therefore, an ABAQUS model to go through a linear perturbation step in which the first 10 eigenvalues of the characteristic equations of the blade, or vibrational modes, are calculated. These modes and their respective frequency values are shown in Table 14 alongside the vibrational mode frequencies of the tower. 
Table 14 Vibrational modes with their respective frequencies of both the blade and tower.

\begin{tabular}{|c|c|c|c|}
\hline $\begin{array}{c}\text { Vibrational } \\
\text { Mode }\end{array}$ & $\begin{array}{c}\text { Cantilever Mode } \\
\text { Type }\end{array}$ & $\begin{array}{c}\text { Blade Frequency } \\
(\mathrm{Hz})\end{array}$ & $\begin{array}{c}\text { Tower Frequency } \\
(\mathrm{Hz})\end{array}$ \\
\hline 1 & $1^{\text {st }}$ Flapwise & 2.75 & 0.584 \\
\hline 2 & $1^{\text {st }}$ Edgewise & 4.75 & 0.834 \\
\hline 3 & $2^{\text {nd }}$ Flapwise & 9.48 & 2.805 \\
\hline 4 & $2^{\text {nd }}$ Edgewise & 15.98 & 4.673 \\
\hline 5 & $3^{\text {rd }}$ Flapwise & 19.78 & 4.959 \\
\hline
\end{tabular}

Figure 72 thru Figure 74 displays the deformed blade during the first four vibrational modes where the rotor blade is demonstrating the typical mode shapes of a typical cantilever beam. 


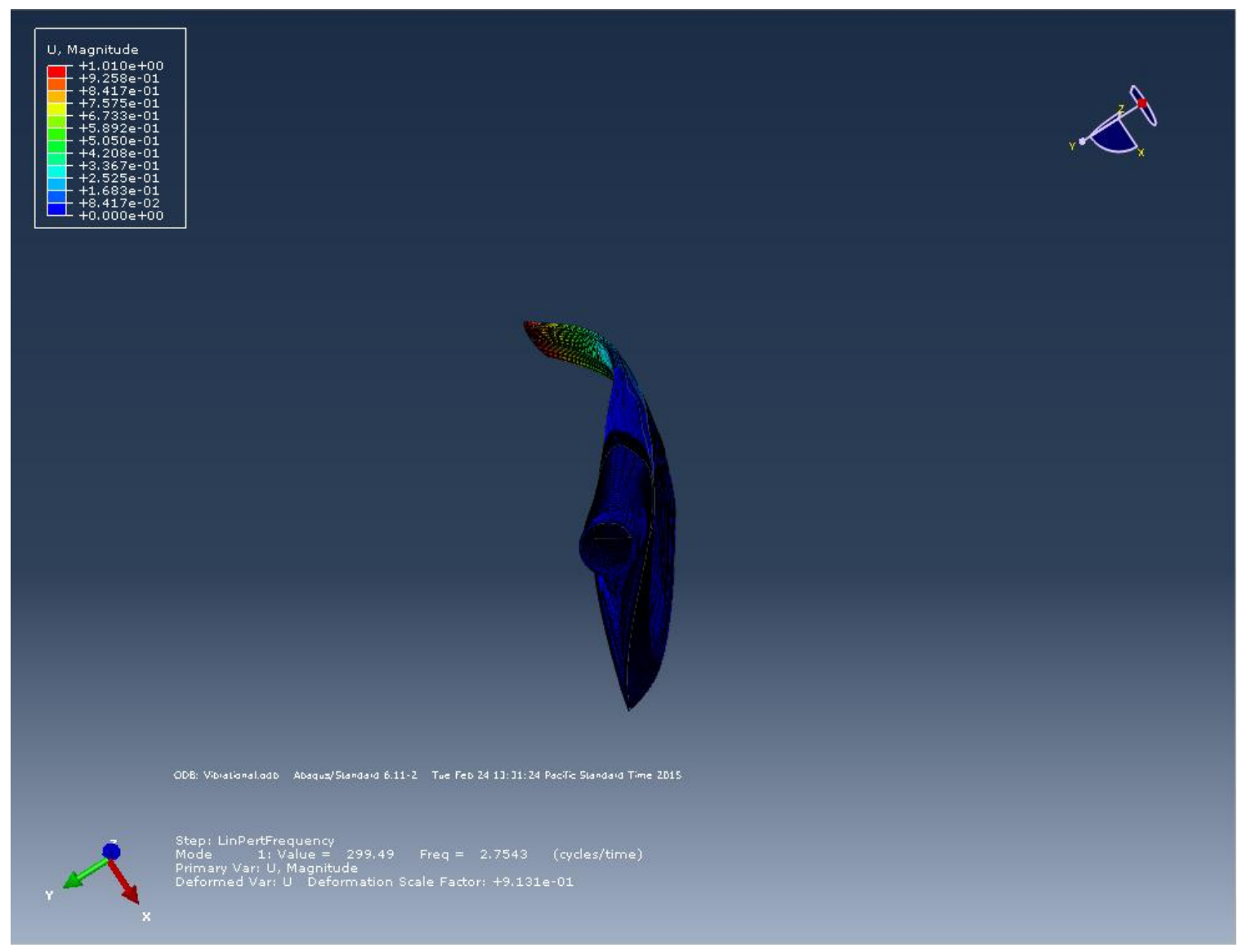

Figure 72 First flapwise bending mode shown at a frequency of $2.75 \mathrm{~Hz}$. 


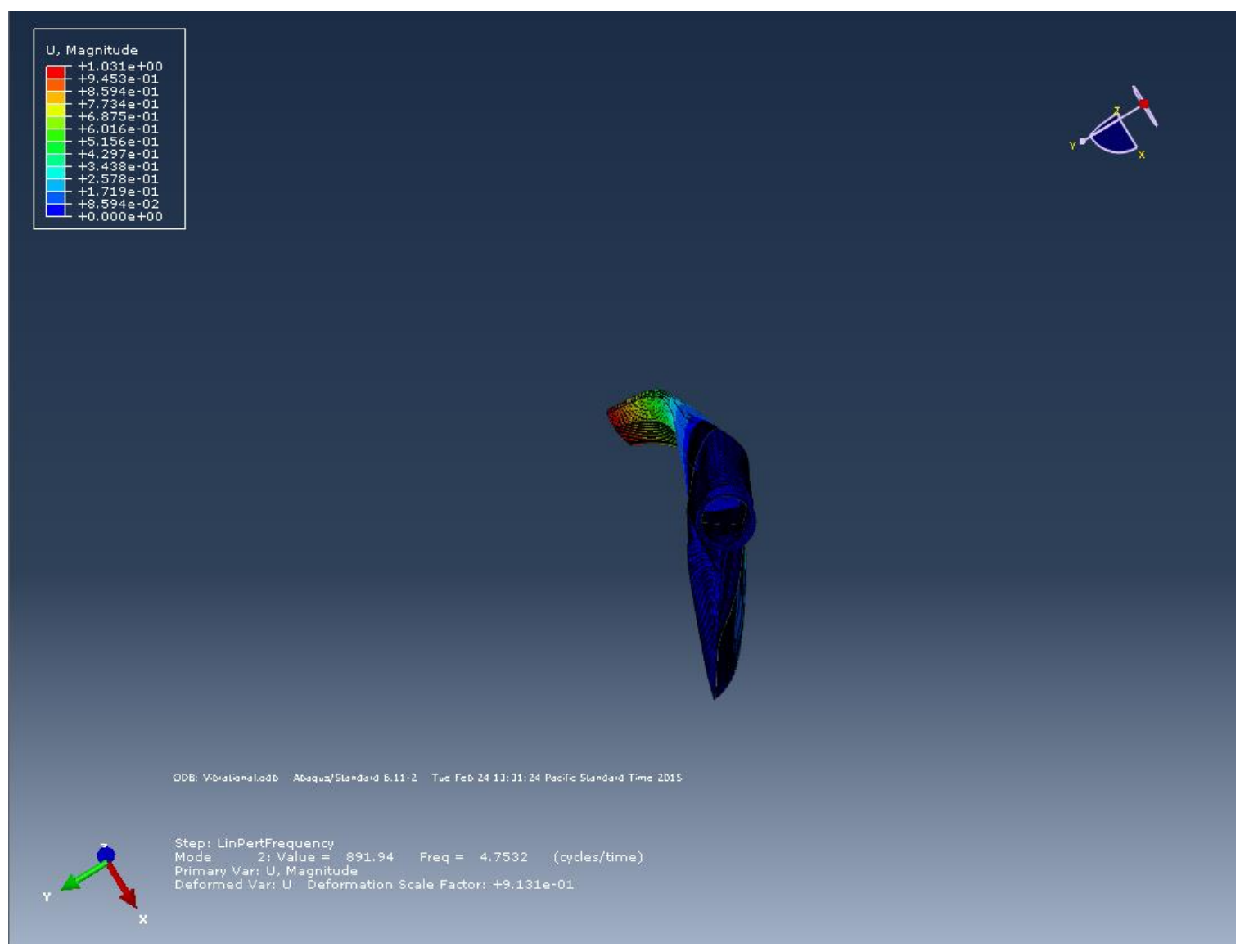

Figure 73 First edgewise bending moment shown at a frequency of $4.75 \mathrm{~Hz}$. 


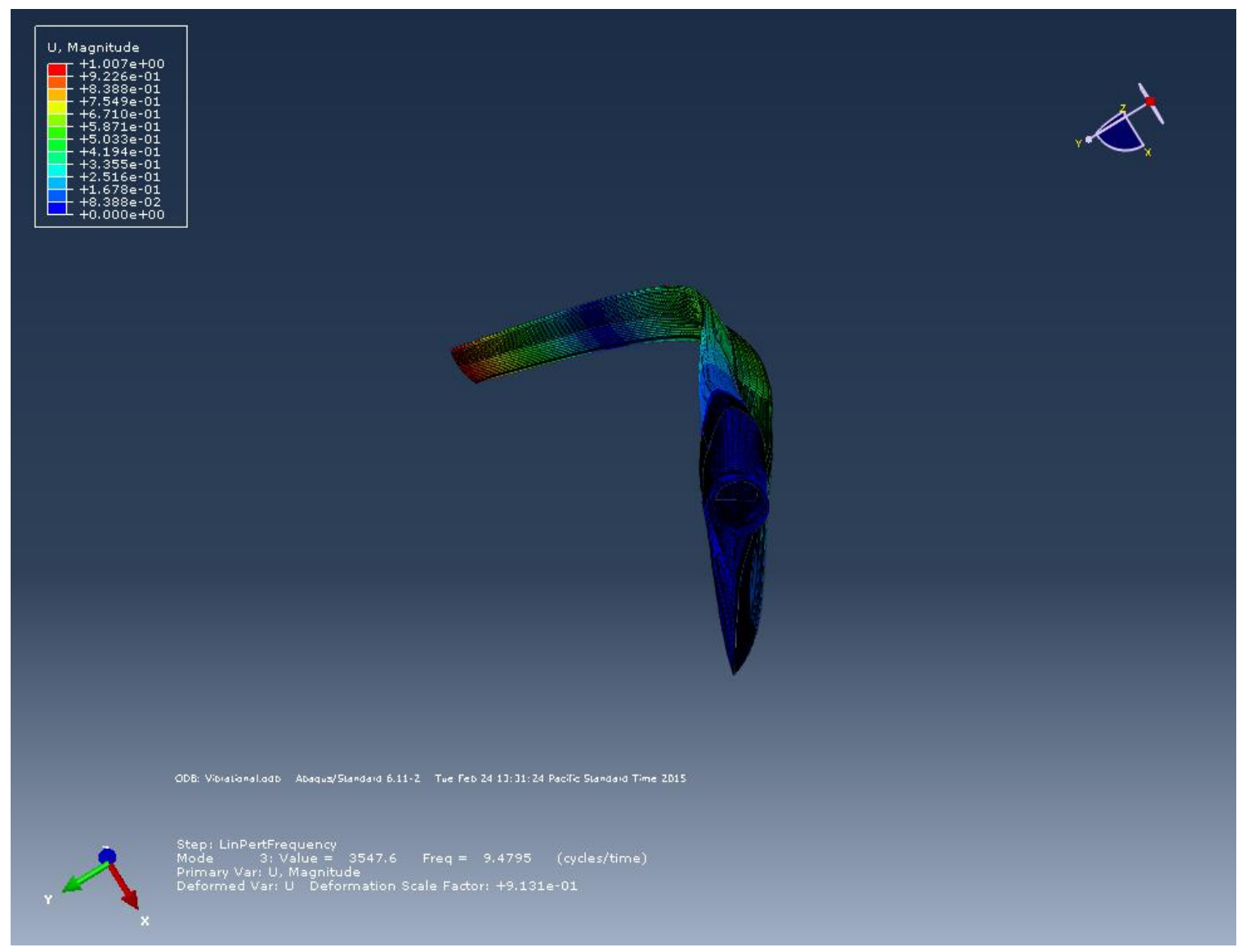

Figure 74 2nd flapwise bending moment shown at a frequency of $9.47 \mathrm{~Hz}$.

\subsubsection{Verification of Results}

It is imperative that the designer be able to verify the results of any computational models with classical design methods. Therefore, hand calculations were performed in relation to the maximum stress locations of the blade being modeled with FEA. In order to determine the amount of carbon plies required at the spar cap, the section of blade under the highest stresses due to the thrust induced bending moment at the circular blade root, line loads were developed and compared to given material data. It was found that only 2 plies of unidirectional M9.1 carbon were required to handle the maximum bending moment with a safety factor of 1.54 . This is evident by the fact that the Hashin 
damage initiation criterion is extremely low for both tension and compressive due to the fact that a total of 12 plies are used for the spar cap design.

Classical lamination theory (CLT) was also employed via MATLAB codes and standard strength of materials equations to check the validity of the Hashin damage initiation criterion as well. This method applies the material properties of the composite structure investigated with the line loading applied as in the hand calculations and the FEA modeling procedures. It was found that no plies failed during normal operation at 11 miles per hour of wind speed. CLT failure indexes were calculated according to both the ultimate stress and the ultimate strain of the carbon fiber plies with the maximum failure index of either observed to be 0.000186 denoting an extremely strong laminate. These CLT results correspond well with the very low Hashin damage initiation criterion values determined during the FE analysis further validating the FEA model. For a full listing of CLT results see Appendix B. 


\subsection{Conclusion and Future Work}

This project spanned the entirety of the process involved with designing and analyzing a small horizontal-axis wind turbine rotor blade for use at the Cal Poly Wind Power Research Center. Each step in this process was documented such that further rotor blade design and analysis projects may use this project as a guide to facilitate their efforts. The rotor blade design process starts with the basic collection of the wind conditions at the turbine site required to determine what can be done to increase the amount of wind energy captured by the turbine. In this case the most feasible way to increase the amount of wind energy captured by the turbine is to increase the swept area of the rotor which means increasing the blade length. With that information in mind, the proper airfoil selections are made by researching available airfoil types that best coincide with the design parameters established by the wind conditions and the rated output of the generator being utilized. Airfoil performance parameters such as lift and drag coefficients are determined from the use of both an aeronautical analysis program as well as empirically collected data from reliable sources to ensure their accuracy. Given these key airfoil characteristics the overall rotor blade shape was aerodynamically optimized to capture as much of the wind energy passing through the rotor swept area as possible to convert into mechanical torque for the permanent magnet induction generator to then convert to electrical power. Aerodynamic forces imparted onto the rotor blade are calculated at this point and used to design the composite spar, which acted as the load bearing component of the rotor blade, as well as other structural components of the rotor 
blade system. With an optimal blade shape established, a geometrically realistic CAD model was created utilizing the CAD program Solidworks which included all the necessary components of the blade to be used in the FEA procedure for the rotor blade structural analysis. The FEA software program ABAQUS was utilized to perform the FE analysis of the blade structure due to the ease in which ABAQUS defines and accurately models the composite structure of the spar and blade skin. These FEA results were then compared against proven mechanics of materials solutions relative to the composite section being investigated to ensure the validity of the FEA model and refined if necessary.

\subsection{Conclusion}

The beginning sections of this report involved calculating the blade length required for the turbine to operate at peak efficiency with an 8 mile per hour incoming wind speed, with a power coefficient of $40 \%$, at approximately sea level, in order to produce the maximum 3 kilowatts of generator output power. This led to the calculation of a total required blade length of 9.23 meters which is considerably larger than the previously used 1.8 meter blades.

These new, longer blades incorporated the NREL S-Series airfoils which are designed for small HAWT blades and generator usage which matched the CPWPRC specifications very well. The S822 and S823 airfoil types are chosen for the outer and root portions of the new blade, respectively, since they are designed to operate at their peak efficiency when incorporated with a rotor radius and peak generator output similar to the CPWPRC. In this way the rotor blades 
are designed to deliver the appropriate amount of lift force required for the generator to operate at peak efficiency during low wind speed conditions.

A key design factor, which has a tremendous influence on the aerodynamic performance of any HAWT blade, is the tip speed ratio which is defined as the tangential velocity of the blade tip divided by incoming wind speed. It has been shown that for a three bladed HAWT a tip speed ratio of around 7 is ideal, with insignificant increases to performance at higher tip speed ratios, and does not generate overly major centrifugal and aerodynamic stresses. Also, the solidity of the blade decreases significantly as the tip speed ratio increases thereby decreasing the blade's intrinsic weight which is a major factor in regards to the fatigue stresses and lifespan of the blade.

With this design tip speed ratio of 7 the blade shape, chord and twist angle, is optimized according to well defined and the proven airfoil planform design theories derived by momentum and blade element theories. This information is then used to generate a CAD model which then realistically reflects the final geometry of the rotor blade and is incorporated into the finite element analysis of the blade structure. Key information regarding the aerodynamic loading on the rotor blade during normal operation is also determined at this stage and used to apply realistic loading scenarios to the FEA model.

Finite element analysis is an extremely useful tool for any number of analysis methods including structural, vibrational, and thermal analyses which are invaluable to any mechanical designer. Therefore, a HAWT rotor blade design 
benefits greatly from the use of FEA by determining the stress and strain throughout the blade structure to ensure the blade does not fail due to normal usage. The FEA modeling process included importing the blade geometry, defining the appropriate composite material layup design of the structure, applying accurate loading and constraint scenarios to verify the blade's integrity and to investigate stress and displacement results of the model. With the stress and strain results gained from the FEA process the designer may then compare these values with the known ultimate stress and strain values associated with the composite materials and determine whether composite layup schedule redesigns are required.

This project was successful in regards to establishing a reliable method of designing and analyzing HAWT rotor blades as well providing a new rotor blade design to be incorporated with the CPWPRC. By going through the processes utilized in this project, a HAWT rotor blade designer may design and analyze a new rotor blade for any number of applications.

\subsection{Future Work}

There is much more research and work to be done in regards to the design and analysis of a horizontal-axis wind turbine. However, given the findings throughout this project, concepts for future research projects become evident. For instance, an investigation into alternate airfoil types could provide valuable insight into the aerodynamic capabilities of small scale HAWT's, modeling and empirically testing some of the many composite material types available could help enhance the FEA model by more accurately describing the effect of stress 
and strain on the structural materials used, and the orientation, layup schedule , and strategic application of alternate composite materials applied to components of the blade structure could reduce the amount of material required while strengthening the rotor system as well.

Airfoil types may be interchanged, more than two types of airfoil per blade, and their effect on rotor blade performance may be designed and structurally analyzed by simply substituting in the necessary geometrical and performance data where required. Composite materials have been utilized in the wind energy industry in order to design lighter, stronger blades for many years with more research constantly being performed. More complex composite materials, like tri-axial [10] or woven lamina, required similarly more complex models in order to predict their behavior and provide innovative solutions to rotor blade problems.

There are a multitude of additional research and development projects possible with each being able to contribute to the overall success of the CPWPRC and provide valuable knowledge that then can be put into practice in the wind energy industry. 


\section{Bibliography}

[1] J. Manwell, A. L. Rogers and J. G. McGowan, Wind Energy Explained Theory, Design and Application, 2nd ed., Chichester, West Sussex: John Wiley \& Sons, Ltd., 2009.

[2] E. Hau, Wind Turbines Fundamentals, Technologies, Application, Economics, 3rd ed., Munich: Spring-Verlag Berlin Heidelberg, 2013.

[3] R. v. Rooij, Terminology, Reference Systems and Conventions, Delft: R. van Rooij, 2001.

[4] K. S. Dahl and P. Fuglsang, Design of the Wind Turbine Airfoi Family RISO-A-XX, Roskilde: Riso National Laboratory, 1998.

[5] P. Fuglsang and C. Bak, Development of the Riso Wind Turbine Airfoils, Roskilde: Riso National Laboratory, 2004.

[6] J. L. Tangler and D. M. Somers, NREL Airfoil Families for HAWTs, Golden, Colorado, 1995.

[7] M. S. Selig and B. D. McGranahan, "Wind Tunnel Aerodynamic Tests of Six Airfoils for Use on Small Wind Turbines," University of Illinois at Urbana-Champaign, Urbana, 2004.

[8] D. M. Somers, "The S822 and S823 Airfoils," Pennsylvania State College, 2005.

[9] M. S. Selig and B. D. McGranahan, "Wind Tunnel Aerodynamic Tests of Six Airfoils for Use on Small Wind Turbines," University of Illinois at Urbana-Champaign, 2001.

[10] D. Berry and T. Ashwill, "Design of 9-Meter Carbon-Fiberglass Prototype Blades: CX-100 and TX-100," Sandia National Laboratories, Albuquerque, 2007.

[11] B. Edwards, "Composite Manufacturing of Small Wind Turbine Blades," California Polytechnic State University San Luis Obispo, San Luis Obispo, 2009.

[12] D. o. Energy and M. S. University, "DOE / MSU Composite Material Fatigue Database," DOE / MSU, 2010.

[13] T. D. Ashwill and J. A. Paquette, "Composite Materials for Innovative Wind Turbine Blades," Sandia National Laboratories, Albuquerque.

[14] N. R. E. Laboratory, "NWTC Information Portal," 6 July 2012. [Online]. Available: https://wind.nrel.gov/airfoils/. [Accessed September 2015]. 
[15] R. J. Crossley and P. J. Schubel, "Wind Turbine Blade Design," Energies, Nottingham, 2012. 


\section{Appendices}

\section{Appendix A: Final Blade Design Parameters}

Table 15 Initial blade design parameters required to analyze the blade aerodynamic performance and loading.

\begin{tabular}{|l|c|}
\hline Number of Blades (B) & 3 \\
\hline Tip Speed Ratio, Design (-) & 7 \\
\hline Wind Speed, Design (m/s) & 3.576 \\
\hline Power, Design (Watts) & 3000 \\
\hline Number of Blade Sections (N) & 20 \\
\hline Air Density, Sea Level (kg/m $\left.{ }^{3}\right)$ & 1.225 \\
\hline Swept Rotor Area (m $\left.{ }^{2}\right)$ & 268 \\
\hline Power Coefficient, Design (-) & 0.40 \\
\hline Rotor Radius (m) & 9.23 \\
\hline
\end{tabular}


Table 16 Optimized blade geometry for the entire new rotor blade model.

\begin{tabular}{|c|c|c|c|c|c|c|}
\hline Span Section & Section Description & Distance From Axis (m) & Pitch Angle (deg) & Twist Angle (deg) & Chord (m) & Thickness Maximum (m) \\
\hline 20 & S822 & 9.230 & -6.58 & 0.00 & 0.301 & 0.048 \\
\hline 19 & S822 & 8.769 & -6.30 & 0.28 & 0.316 & 0.051 \\
\hline 18 & S822 & 8.307 & -5.99 & 0.59 & 0.333 & 0.053 \\
\hline 17 & S822 & 7.846 & -5.64 & 0.94 & 0.352 & 0.056 \\
\hline 16 & S822 & 7.384 & -5.25 & 1.33 & 0.373 & 0.060 \\
\hline 15 & S822 & 6.923 & -4.81 & 1.77 & 0.396 & 0.063 \\
\hline 14 & S822 & 6.461 & -4.31 & 2.27 & 0.423 & 0.068 \\
\hline 13 & S822 & 6.000 & -3.74 & 2.84 & 0.454 & 0.073 \\
\hline 12 & S822 & 5.538 & -3.07 & 3.51 & 0.489 & 0.078 \\
\hline 11 & S822 & 5.077 & -2.29 & 4.29 & 0.529 & 0.085 \\
\hline 10 & S822 & 4.615 & -1.37 & 5.21 & 0.577 & 0.092 \\
\hline 9 & S822 & 4.154 & -0.26 & 6.32 & 0.633 & 0.101 \\
\hline 8 & S822 & 3.692 & 1.10 & 7.68 & 0.700 & 0.112 \\
\hline 7 & S822 & 3.230 & 2.80 & 9.38 & 0.781 & 0.125 \\
\hline 6 & S823 & 2.769 & 4.98 & 11.56 & 0.842 & 0.179 \\
\hline 5 & S823 & 2.307 & 7.83 & 14.41 & 0.955 & 0.203 \\
\hline 4 & S823 & 1.846 & 11.69 & 18.27 & 1.086 & 0.230 \\
\hline 3 & S823 & 1.384 & 17.07 & 23.65 & 1.217 & 0.258 \\
\hline 2 & S823 & 0.923 & 24.67 & 31.25 & 1.275 & 0.270 \\
\hline 1 & Hub & 0.461 & - & - & - & - \\
\hline 0 & Axis $\left(X_{B}\right)$ & 0.0 & - & - & - & - \\
\hline
\end{tabular}


Table 17 Aerodynamic loading calculated via BET.

\begin{tabular}{|c|c|c|c|c|c|c|}
\hline $\begin{array}{l}\text { Blade } \\
\text { Section }\end{array}$ & $\begin{array}{c}\text { Distance from } \\
\text { Axis (m) }\end{array}$ & $\begin{array}{c}\text { Twist Angle } \\
\text { (deg) }\end{array}$ & $\begin{array}{l}\text { Flapwise } \\
\text { Force (N) }\end{array}$ & $\begin{array}{l}\text { Lead-Lag } \\
\text { Force (N) }\end{array}$ & $\begin{array}{c}\text { Flapwise } \\
\text { Moment }\left(\mathrm{N}^{*} \mathrm{~m}\right)\end{array}$ & $\begin{array}{l}\text { Lead-Lag } \\
\text { Moment } \\
\left(\mathrm{N}^{*} \mathrm{~m}\right)\end{array}$ \\
\hline 20 & 9.230 & 0.00 & - & - & - & - \\
\hline 19 & 8.769 & 0.28 & 348.81 & 28.22 & - & 388.19 \\
\hline 18 & 8.307 & 0.59 & 408.59 & 28.71 & 161 & 483.38 \\
\hline 17 & 7.846 & 0.94 & 417.11 & 29.20 & 511 & 504.39 \\
\hline 16 & 7.384 & 1.33 & 415.93 & 29.92 & 1053 & 494.14 \\
\hline 15 & 6.923 & 1.77 & 394.60 & 30.39 & 1787 & 472.08 \\
\hline 14 & 6.461 & 2.27 & 369.48 & 30.84 & 2703 & 444.17 \\
\hline 13 & 6.000 & 2.84 & 341.71 & 31.27 & 3790 & 409.63 \\
\hline 12 & 5.538 & 3.51 & 315.57 & 31.71 & 5034 & 379.25 \\
\hline 11 & 5.077 & 4.29 & 289.32 & 32.13 & 6424 & 346.30 \\
\hline 10 & 4.615 & 5.21 & 263.02 & 32.54 & 7948 & 311.79 \\
\hline 9 & 4.154 & 6.32 & 236.70 & 32.92 & 9593 & 276.11 \\
\hline 8 & 3.692 & 7.68 & 210.35 & 33.24 & 11347 & 239.40 \\
\hline 7 & 3.230 & 9.38 & 183.97 & 33.47 & 13199 & 201.32 \\
\hline 6 & 2.769 & 11.56 & 157.51 & 32.17 & 15135 & 163.19 \\
\hline 5 & 2.307 & 14.41 & 131.05 & 33.45 & 17144 & 123.74 \\
\hline 4 & 1.846 & 18.27 & 104.53 & 32.85 & 19213 & 84.03 \\
\hline 3 & 1.384 & 23.65 & 77.94 & 31.34 & 21331 & 45.72 \\
\hline 2 & 0.923 & 31.25 & 51.30 & 27.84 & 23485 & 13.85 \\
\hline 1 & 0.461 & - & 0.00 & 0.00 & 25662 & 0.00 \\
\hline
\end{tabular}


Table 18 Normalized airfoil coordinates for the NREL S822 and S823 airfoil types.

\begin{tabular}{|r|r|r|r|}
\hline \multicolumn{2}{|r|}{ NREL's S822 Airfoil } & \multicolumn{2}{|c|}{ NREL's S823 Airfoil } \\
\hline x/c y/c & & x/c $y / c$ & \\
\hline 1 & 0 & 1 & 0 \\
\hline 0.996089 & 0.000642 & 0.996182 & 0.001021 \\
\hline 0.985048 & 0.003157 & 0.985647 & 0.004487 \\
\hline 0.968133 & 0.007602 & 0.969834 & 0.009935 \\
\hline 0.946046 & 0.013324 & 0.949208 & 0.016186 \\
\hline 0.918825 & 0.020084 & 0.923311 & 0.02286 \\
\hline 0.887037 & 0.028045 & 0.892433 & 0.030245 \\
\hline 0.851444 & 0.037037 & 0.857144 & 0.038305 \\
\hline 0.812782 & 0.046731 & 0.818037 & 0.046896 \\
\hline 0.771742 & 0.056677 & 0.775723 & 0.05581 \\
\hline 0.728946 & 0.066315 & 0.73081 & 0.064793 \\
\hline 0.684771 & 0.074819 & 0.68389 & 0.073566 \\
\hline 0.638946 & 0.081988 & 0.635537 & 0.081835 \\
\hline 0.591971 & 0.087923 & 0.586291 & 0.089312 \\
\hline 0.544321 & 0.092477 & 0.536666 & 0.095725 \\
\hline 0.496467 & 0.095295 & 0.487145 & 0.100825 \\
\hline 0.44832 & 0.096342 & 0.438182 & 0.104394 \\
\hline 0.400324 & 0.095949 & 0.390202 & 0.106236 \\
\hline 0.353012 & 0.094259 & 0.343554 & 0.106115 \\
\hline 0.306932 & 0.091363 & 0.298349 & 0.104071 \\
\hline 0.262594 & 0.087322 & 0.25503 & 0.100219 \\
\hline 0.220471 & 0.082211 & 0.213826 & 0.094667 \\
\hline 0.181021 & 0.076101 & 0.17515 & 0.087661 \\
\hline 0.144635 & 0.069084 & 0.139404 & 0.079378 \\
\hline 0.111706 & 0.061261 & 0.106993 & 0.069983 \\
\hline 0.082528 & 0.052754 & 0.078238 & 0.059647 \\
\hline 0.057423 & 0.043713 & 0.053489 & 0.048562 \\
\hline 0.036592 & 0.034302 & 0.032973 & 0.036935 \\
\hline 0.02031 & 0.024706 & 0.017013 & 0.025059 \\
\hline 0.015142 & 0.005871 & 0.013252 \\
\hline 0.006074 & 0.001538 & 0.006021 \\
\hline
\end{tabular}

\begin{tabular}{|c|c|c|c|}
\hline 0.000651 & 0.003396 & 0.000533 & 0.003322 \\
\hline 0.000138 & 0.001358 & 0.000235 & 0.00216 \\
\hline 0.000023 & -0.00054 & 0.000026 & 0.000734 \\
\hline 0.000294 & -0.00194 & 0.000174 & -0.00193 \\
\hline 0.000443 & -0.00241 & 0.0008 & -0.00484 \\
\hline 0.001282 & -0.00439 & 0.002374 & -0.00939 \\
\hline 0.005329 & -0.01012 & 0.010193 & -0.02397 \\
\hline 0.015376 & -0.01868 & 0.021425 & -0.0414 \\
\hline 0.030216 & -0.02717 & 0.03433 & -0.05938 \\
\hline 0.049559 & -0.0352 & 0.049121 & -0.07669 \\
\hline 0.073374 & -0.04256 & 0.065425 & -0.09171 \\
\hline 0.101374 & -0.04906 & 0.084347 & -0.10251 \\
\hline 0.133441 & -0.05458 & 0.108058 & -0.10978 \\
\hline 0.169219 & -0.05903 & 0.136074 & -0.11443 \\
\hline 0.208482 & -0.06236 & 0.168058 & -0.11652 \\
\hline 0.250797 & -0.06455 & 0.203782 & -0.11604 \\
\hline 0.295834 & -0.06559 & 0.243045 & -0.11306 \\
\hline 0.343087 & -0.0655 & 0.285642 & -0.10769 \\
\hline 0.392138 & -0.06434 & 0.331343 & -0.10014 \\
\hline 0.44242 & -0.06214 & 0.379872 & -0.09068 \\
\hline 0.493444 & -0.05897 & 0.430894 & -0.07971 \\
\hline 0.544594 & -0.05483 & 0.483993 & -0.06767 \\
\hline 0.595407 & -0.0496 & 0.538656 & -0.05509 \\
\hline 0.645795 & -0.04346 & 0.594258 & -0.04251 \\
\hline 0.695149 & -0.03687 & 0.650057 & -0.03052 \\
\hline 0.742856 & -0.03007 & 0.70519 & -0.01965 \\
\hline 0.788279 & -0.02303 & 0.758682 & -0.01038 \\
\hline 0.831428 & -0.01608 & 0.809471 & -0.00307 \\
\hline 0.871626 & -0.01 & 0.856439 & 0.002045 \\
\hline 0.907952 & -0.00522 & 0.89846 & 0.004922 \\
\hline 0.93944 & -0.00195 & 0.934449 & 0.005687 \\
\hline 0.96515 & -0.00014 & 0.963294 & 0.004594 \\
\hline 0.984246 & 0.000448 & 0.9839 & 0.00254 \\
\hline 0.996022 & 0.000259 & 0.996032 & 0.000732 \\
\hline 1 & 0 & 1 & 0 \\
\hline
\end{tabular}




\section{Appendix B: Classical Lamination Theory MATLAB Results and Hand Calculations}

Table 19 Classical lamination theory MATLAB strain results for the top and bottom of each ply in the spar cap during normal operation at a wind speed of $11 \mathrm{mph}$.

\begin{tabular}{|c|c|c|c|c|c|}
\hline Ply Angle & $\sigma_{1}(p s i)$ & $\sigma_{2}(p s i)$ & $T_{12}$ (psi) & Overall Failure Index & Fiber Failure Index \\
\hline 0 & $2.35 \mathrm{E}-06$ & $-1.7 \mathrm{E}-06$ & $5.85 \mathrm{E}-08$ & 0.000186 & 0.000186 \\
\hline 0 & $2.35 \mathrm{E}-06$ & $-1.7 \mathrm{E}-06$ & $5.85 \mathrm{E}-08$ & 0.000186 & 0.000186 \\
\hline 0 & $2.35 \mathrm{E}-06$ & $-1.7 E-06$ & $5.85 \mathrm{E}-08$ & 0.000186 & 0.000186 \\
\hline 0 & $2.35 \mathrm{E}-06$ & $-1.7 \mathrm{E}-06$ & $5.85 \mathrm{E}-08$ & 0.000186 & 0.000186 \\
\hline 45 & 3.7E-07 & 3.11E-07 & $-4 E-06$ & 0.00017 & $2.93 \mathrm{E}-05$ \\
\hline 45 & $3.7 \mathrm{E}-07$ & $3.11 \mathrm{E}-07$ & $-4 \mathrm{E}-06$ & 0.00017 & $2.93 \mathrm{E}-05$ \\
\hline-45 & $3.11 \mathrm{E}-07$ & 3.7E-07 & 4.03E-06 & 0.00017 & $2.46 \mathrm{E}-05$ \\
\hline-45 & $3.11 \mathrm{E}-07$ & 3.7E-07 & 4.03E-06 & 0.00017 & $2.46 \mathrm{E}-05$ \\
\hline-45 & $3.11 \mathrm{E}-07$ & $3.7 \mathrm{E}-07$ & 4.03E-06 & 0.00017 & $2.46 \mathrm{E}-05$ \\
\hline-45 & $3.11 \mathrm{E}-07$ & 3.7E-07 & 4.03E-06 & 0.00017 & $2.46 \mathrm{E}-05$ \\
\hline 45 & 3.7E-07 & $3.11 \mathrm{E}-07$ & $-4 \mathrm{E}-06$ & 0.00017 & 2.93E-05 \\
\hline 45 & $3.7 \mathrm{E}-07$ & $3.11 \mathrm{E}-07$ & $-4 E-06$ & 0.00017 & $2.93 \mathrm{E}-05$ \\
\hline 0 & $2.35 \mathrm{E}-06$ & $-1.7 \mathrm{E}-06$ & 5.85E-08 & 0.000186 & 0.000186 \\
\hline 0 & $2.35 \mathrm{E}-06$ & $-1.7 E-06$ & $5.85 \mathrm{E}-08$ & 0.000186 & 0.000186 \\
\hline 0 & $2.35 \mathrm{E}-06$ & $-1.7 \mathrm{E}-06$ & 5.85E-08 & 0.000186 & 0.000186 \\
\hline 0 & $2.35 \mathrm{E}-06$ & $-1.7 \mathrm{E}-06$ & 5.85E-08 & 0.000186 & 0.000186 \\
\hline
\end{tabular}


Table 20 Classical lamination theory MATLAB stress results for the top and bottom of each ply in the spar cap during normal operation at a wind speed of $11 \mathrm{mph}$.

\begin{tabular}{|c|c|c|c|c|c|}
\hline Ply Angle & $\sigma_{1}(p s i)$ & $\sigma_{2}(p s i)$ & $T_{12}$ (psi) & Overall Failure Index & Fiber Failure Index \\
\hline 0 & $6.03 E+04$ & $-1.58 \mathrm{E}+03$ & $4.88 \mathrm{E}+01$ & $1.86 \mathrm{E}-04$ & $1.86 \mathrm{E}-04$ \\
\hline 0 & $6.03 E+04$ & $-1.58 \mathrm{E}+03$ & $4.88 \mathrm{E}+01$ & $1.86 \mathrm{E}-04$ & $1.86 \mathrm{E}-04$ \\
\hline 0 & $6.03 E+04$ & $-1.58 \mathrm{E}+03$ & $4.88 \mathrm{E}+01$ & $1.86 \mathrm{E}-04$ & $1.86 \mathrm{E}-04$ \\
\hline 0 & $6.03 E+04$ & $-1.58 \mathrm{E}+03$ & $4.88 \mathrm{E}+01$ & $1.86 \mathrm{E}-04$ & $1.86 \mathrm{E}-04$ \\
\hline 45 & $9.82 \mathrm{E}+03$ & $7.63 E+02$ & $-3.36 \mathrm{E}+03$ & $1.70 \mathrm{E}-04$ & 2.93E-05 \\
\hline 45 & $9.82 E+03$ & $7.63 E+02$ & $-3.36 \mathrm{E}+03$ & $1.70 \mathrm{E}-04$ & 2.93E-05 \\
\hline-45 & $8.33 E+03$ & $8.32 E+02$ & $3.36 \mathrm{E}+03$ & $1.70 \mathrm{E}-04$ & $2.46 \mathrm{E}-05$ \\
\hline-45 & $8.33 \mathrm{E}+03$ & $8.32 \mathrm{E}+02$ & $3.36 \mathrm{E}+03$ & $1.70 \mathrm{E}-04$ & $2.46 \mathrm{E}-05$ \\
\hline-45 & $8.33 E+03$ & $8.32 \mathrm{E}+02$ & $3.36 \mathrm{E}+03$ & $1.70 \mathrm{E}-04$ & $2.46 \mathrm{E}-05$ \\
\hline-45 & $8.33 E+03$ & $8.32 \mathrm{E}+02$ & $3.36 \mathrm{E}+03$ & $1.70 \mathrm{E}-04$ & $2.46 \mathrm{E}-05$ \\
\hline 45 & $9.82 \mathrm{E}+03$ & $7.63 E+02$ & $-3.36 E+03$ & $1.70 \mathrm{E}-04$ & 2.93E-05 \\
\hline 45 & $9.82 \mathrm{E}+03$ & $7.63 E+02$ & $-3.36 \mathrm{E}+03$ & $1.70 \mathrm{E}-04$ & 2.93E-05 \\
\hline 0 & $6.03 E+04$ & $-1.58 \mathrm{E}+03$ & $4.88 \mathrm{E}+01$ & $1.86 \mathrm{E}-04$ & $1.86 \mathrm{E}-04$ \\
\hline 0 & $6.03 E+04$ & $-1.58 \mathrm{E}+03$ & $4.88 \mathrm{E}+01$ & $1.86 \mathrm{E}-04$ & $1.86 \mathrm{E}-04$ \\
\hline 0 & $6.03 E+04$ & $-1.58 \mathrm{E}+03$ & $4.88 \mathrm{E}+01$ & $1.86 \mathrm{E}-04$ & $1.86 \mathrm{E}-04$ \\
\hline 0 & $6.03 E+04$ & $-1.58 \mathrm{E}+03$ & $4.88 \mathrm{E}+01$ & $1.86 \mathrm{E}-04$ & $1.86 \mathrm{E}-04$ \\
\hline
\end{tabular}


Cal Poly HAWT

Thesis Hand

Dylan

Calculations

Perry 4/G/15

- Root tube subject to the highest bending moment of

(1) any cross -section along the blade.

- Root tube constructed of M9.1 carbon fiber prepreg:

$E_{1}=115[\mathrm{GPa}] ; t_{\text {Ply }}=0.523 \mathrm{~mm} ; 500 \mathrm{~g} / \mathrm{m}^{2}$

$\varepsilon_{1 t}^{u}=0.0158[-]$

- Line load formulations for root tube a rectangular spar:
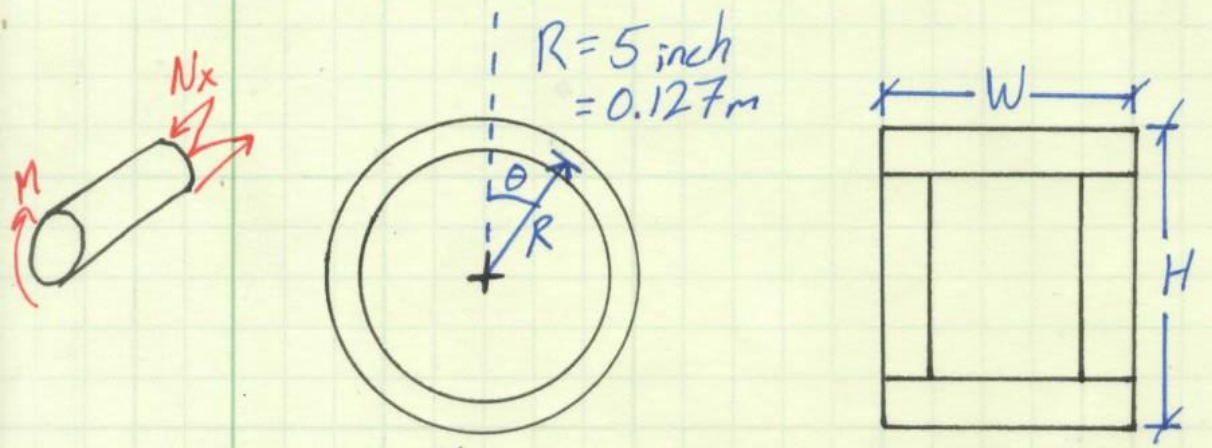

$$
\begin{aligned}
& W=10 \mathrm{in}=0.254 \mathrm{~m} \\
& H=0.252 \mathrm{~m}
\end{aligned}
$$

$$
\begin{aligned}
& N_{x}=\frac{M_{y}}{\pi R^{3}} \\
& N_{y y}=\frac{V \sin \theta}{\pi R}
\end{aligned}
$$$$
N_{x}=\frac{ \pm M}{W H} \equiv \text { Bending } * \text { Largest line lours }
$$

$$
\left.\begin{array}{l}
N_{x y}=\frac{T}{2 \omega H} \equiv \text { Torque Shear } \\
N_{x y}=\frac{P}{2 H} \equiv \text { Vertical Shear }
\end{array}\right\} * \text { Negligible }
$$

- Loading data for incoming wind speed of $5 \mathrm{~m} / \mathrm{s}$ :

$$
\begin{aligned}
& M_{\max }=50,149[\mathrm{~N} \cdot \mathrm{m}] ; \quad V=5578[\mathrm{~N}] \\
& \Rightarrow N_{x}=\frac{(50,149 \mathrm{Nm})(0.127 \mathrm{~m})}{\pi(0.127 \mathrm{~m})^{3}}\left[\frac{\mathrm{N}}{\mathrm{m}}\right]=989,703\left[\frac{\mathrm{N}}{\mathrm{m}}\right] \text { for root tube. }
\end{aligned}
$$

- Allowable line load per ply of M9.I using an 80\% property basis:

$$
\begin{aligned}
N_{p_{y}} & =E_{1}(0.80) \xi_{t}^{u} t_{p h} \\
& =\left(115 E 9 P_{a}\right)(0.80)(0.0158)(0.523 E-3 m) \\
N_{p_{y}} & =760,233\left[\mathrm{~N} / \mathrm{m} \cdot p_{y}\right]
\end{aligned}
$$
- Number of plies required: $n=\frac{N_{x}}{N_{p h}}=\frac{989,703 \frac{\mathrm{N}}{\mathrm{m}}}{760,233 \mathrm{~N} / \mathrm{mpd}}=1.3$ for rout tube
$n=2$ plies required $\therefore S F=1.54$ 
Thesis, Hand

Dylan

Calculations

Perry 4/le/15

- Line loads for rectangular spar at blade section 2, or the

(2) first aerodynamically - driven blade section:

- Using largest moment from root tube for added safety.

$$
N_{x}=\frac{ \pm 50,149 \mathrm{~N} \cdot \mathrm{m}}{(0.254 \mathrm{~m})(0.252 \mathrm{~m})}\left[\frac{\mathrm{N}}{\mathrm{m}}\right]=783,480\left[\frac{\mathrm{N}}{\mathrm{m}}\right]
$$

$-N_{P l y}=760,233[\pi / m \cdot p l y]$ remains valid for allowable line loads

- Number of plies required for spar cap to withstand maximum bending:

$$
\begin{aligned}
& n=\frac{N_{x}}{N_{\text {ply }}}=\frac{783,480 \mathrm{~N} / \mathrm{m}}{760,233 \mathrm{~N} / \mathrm{n} \text {. ply }}=1.03 \\
\therefore & n=2 \text { plies required for spar cap SF =1.94 }
\end{aligned}
$$

- Rectangular spar calculations may be performed at any point along the black with no cross-sectroned moment being larger than that found at the $2^{\text {nd }}$ blade section. 